2014

\title{
IMPACT OF PLUG-IN ELECTRIC VEHICLES AND WIND GENERATORS ON HARMONIC DISTORTION OF ELECTRIC DISTRIBUTION SYSTEMS
}

Ritam Misra

Michigan Technological University

Follow this and additional works at: https://digitalcommons.mtu.edu/etds

Part of the Electrical and Computer Engineering Commons

Copyright 2014 Ritam Misra

Recommended Citation

Misra, Ritam, "IMPACT OF PLUG-IN ELECTRIC VEHICLES AND WIND GENERATORS ON HARMONIC DISTORTION OF ELECTRIC DISTRIBUTION SYSTEMS", Master's Thesis, Michigan Technological University, 2014.

https://doi.org/10.37099/mtu.dc.etds/775

Follow this and additional works at: https://digitalcommons.mtu.edu/etds

Part of the Electrical and Computer Engineering Commons 


\title{
IMPACT OF PLUG-IN ELECTRIC VEHICLES AND WIND GENERATORS ON HARMONIC DISTORTION OF ELECTRIC DISTRIBUTION SYSTEMS
}

\author{
By \\ Ritam Misra \\ A THESIS \\ Submitted in partial fulfillment of the requirements for the degree of \\ MASTER OF SCIENCE \\ In Electrical Engineering \\ MICHIGAN TECHNOLOGICAL UNIVERSITY \\ 2014
}

(C) 2014 Ritam Misra 
This thesis has been approved in partial fulfillment of the requirements for the Degree of MASTER OF SCIENCE in Electrical Engineering.

\section{Department of Electrical and Computer Engineering}

Dissertation Advisor: Dr. Sumit Paudyal

Committee Member: Dr. Mahdi Shahbakhti

Committee Member: Dr. Lucia Gauchia Babe

Department Chair: Dr. Daniel R. Fuhrmann 


\section{Contents}

List of Figures..........................................................................................................................vi

List of Tables ............................................................................................................................. viii

Acknowledgements ......................................................................................................................

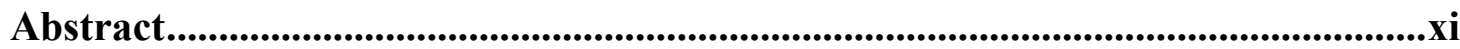

1 Introduction ..........................................................................................................................

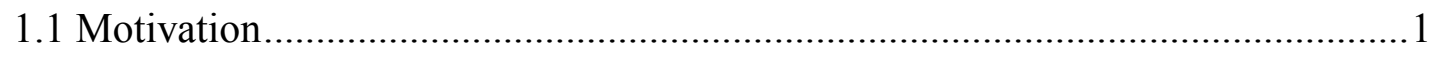

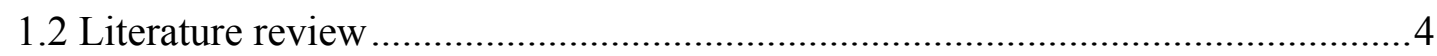

1.2.1 Optimal Sitting and Sizing of DGs ............................................................

1.2.2 Optimal Operation of Distribution System in Presence of PEVs and DGs ..6

1.2.3 Coordinated Energy Scheduling in a Distribution System in Presence of

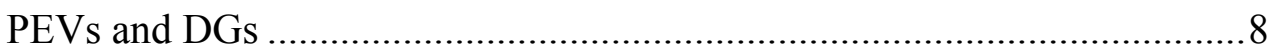

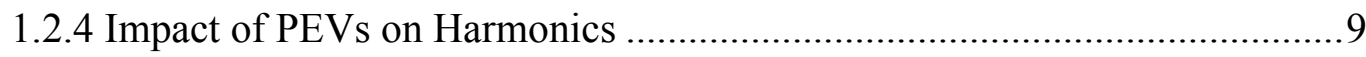

1.2.5 Smart Load Management (SLM) of PEVs...................................................10

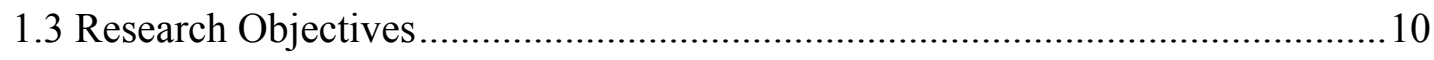

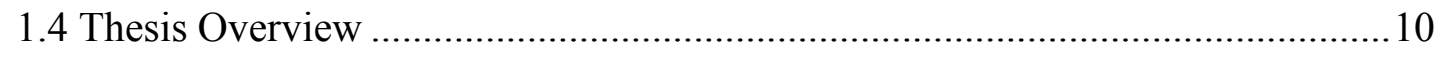

2 Background ........................................................................................................................12

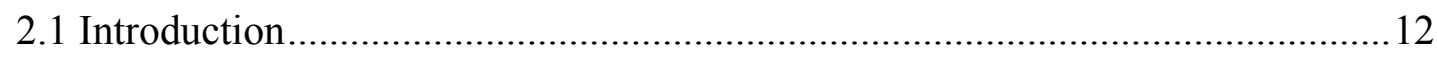

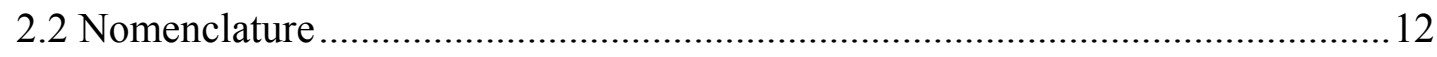

2.3 Distribution Systems ................................................................................... 13

2.4 Harmonic Power Flow ………………………................................................ 15 


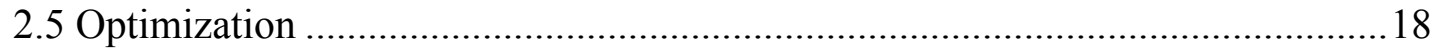

2.6 Optimization Solution Techniques ………………….....................................2

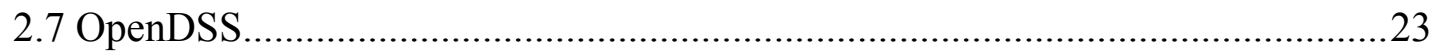

2.7.1 Harmonic Modeling in OpenDSS ............................................................24

2.7.2 Components Modeling in OpenDSS.......................................................27

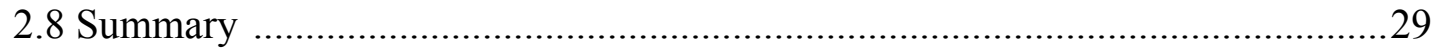

\section{Impact of Plug-in Electric Vehicles (PEVs) and Wind Generators (WGs) on}

Total Harmonic Distortion (THD) ................................................................................30

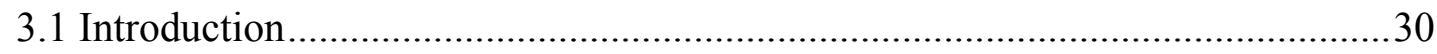

3.2 IEEE 34 Node Test Feeder ...................................................................................30

3.3 PEV Model with Harmonics...............................................................................31

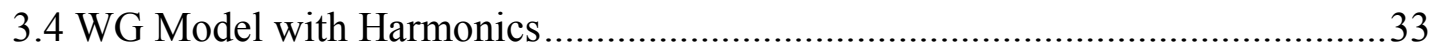

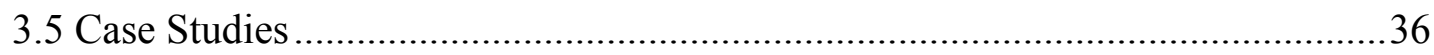

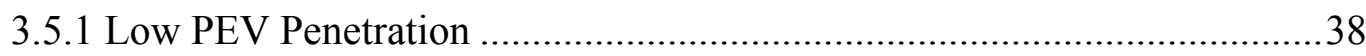

3.5.2 Moderate PEV Penetration ....................................................................... 40

3.5.3 High PEV Penetration.................................................................................

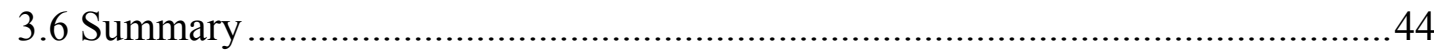

4 Mitigating THDs with WGs .......................................................................................45

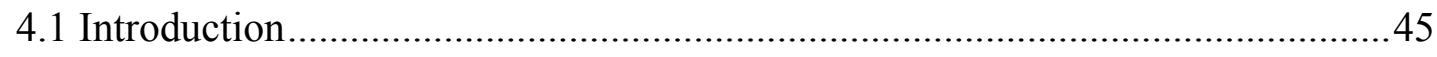

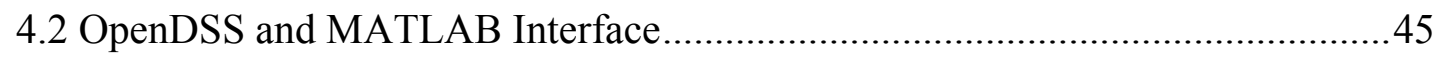

4.3 Proposed Genetic Algorithm (GA) for Optimization ............................................47

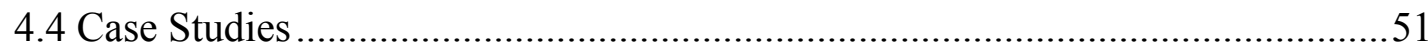


4.4.1 Low PEV Penetration ..........................................................................5 51

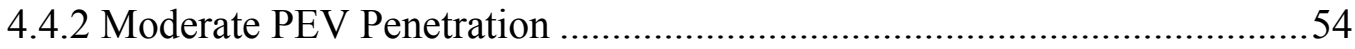

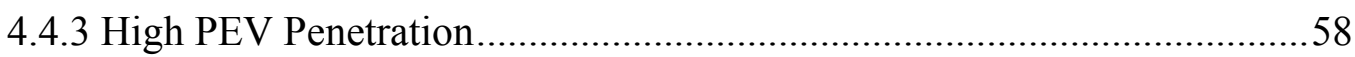

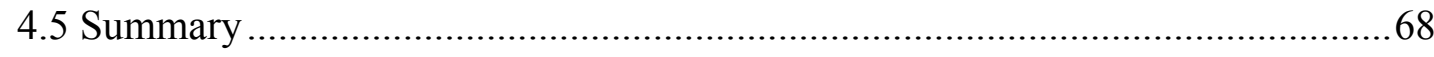

5 Conclusions and Future Work.........................................................................69

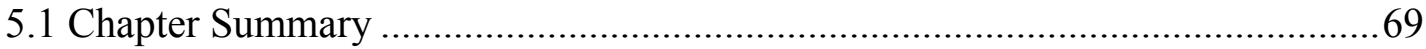

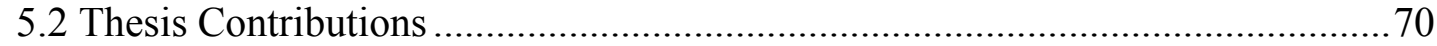

5.3 Limitations and Future Work.................................................................... 71

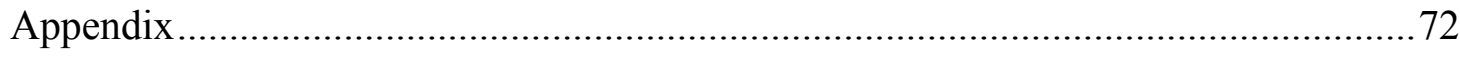

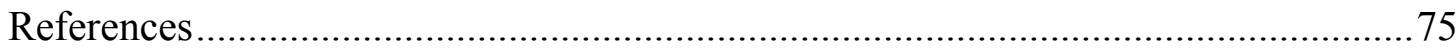




\section{List of Figures}

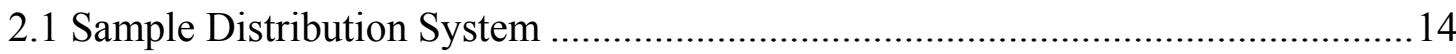

2.2 The Network after Integration of WGs and PEVs .................................................17

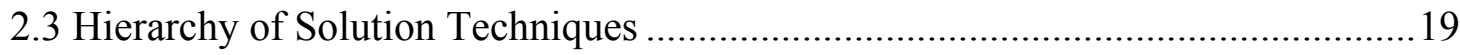

2.4 Sample Flowchart of Evolutionary Algorithm ...................................................22

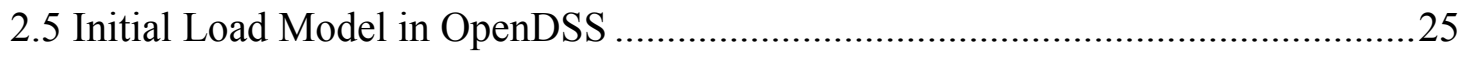

2.6 Updated Harmonic Load Model in OpenDSS .....................................................26

3.1 IEEE 34 Node Test Feeder System...................................................................

3.2 IEEE 34 Node Test Feeder System after the Addition of One WG..........................37

3.3 IEEE 34 Node Test Feeder System after the Addition of Three WGs .....................37

4.1 Com Interface between OpenDSS and MATLAB ..................................................46

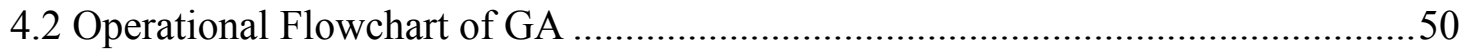

4.3 Minimization of Voltage THDs for Low PEV Penetration using GA....................52

4.4 Minimization of Current THDs for Low PEV Penetration using GA ……….........54

4.5 Minimization of Voltage THDs for Moderate PEV Penetration using GA.............56

4.6 Minimization of Current THDs for Moderate PEV Penetration using GA .............57

4.7 Minimization of Voltage THDs for High PEV Penetration using GA ....................59

4.8 Minimization of Current THDs for High PEV Penetration using GA.....................61

4.9 Change of Voltage THD in Line 844-846 for High PEV Penetration.......................62

4.10 Change of Voltage THD in Line 828-830 for High PEV Penetration...................63

4.11 Change of Voltage THD in Line 808-806 for High PEV Penetration...................63

4.12 Change of Voltage THD in Line 834-860 for High PEV Penetration....................64

4.13 Change of Current THD in Line 844-846 for High PEV Penetration ...................64 
4.14 Change of Current THD in Line 828-830 for High PEV Penetration ..................65

4.15 Change of Current THD in Line 808-806 for High PEV Penetration ..................65

4.16 Change of Current THD in Line 834-860 for High PEV Penetration ..................66

4.17 Optimal WG Values for Minimized Voltage THDs at High PEV Penetration ....67

4.18 Optimal WG Values for Minimized Current THDs at High PEV Penetration.....67 


\section{List of Tables}

3.1 Battery Capacity of Recently Released PEVs ........................................................ 32

3.2 Line Current Harmonic Content of PEV Charger....................................................33

3.3 Current Content in Harmonic Injections of WG ........................................................ 35

3.4 Phase to Phase Voltage THDs for Low PEV Penetration..........................................38

3.5 Current THDs for Low PEV Penetration....................................................................39

3.6 Phase to Phase Voltage THDs for Moderate PEV Penetration..................................40

3.7 Current THDs for Moderate PEV Penetration............................................................41

3.8 Phase to Phase Voltage THDs for High PEV Penetration.........................................42

3.9 Current THDs for High PEV Penetration ...............................................................4

4.1 THD of Phase to Phase Voltages for Low PEV Penetration ....................................51

4.2 Optimal WG Size for Voltage THDs in Low PEV Penetration...............................52

4.3 THD of Line Currents for Low PEV Penetration ..................................................53

4.4 Optimal WG Size for Current THDs in Low PEV Penetration ................................53

4.5 THD of Phase to Phase Voltages for Moderate PEV Penetration ............................55

4.6 Optimal WG Size for Voltage THDs in Moderate PEV Penetration........................55

4.7 THD of Line Currents for Moderate PEV Penetration ..............................................56

4.8 Optimal WG Size for Current THDs in Moderate PEV Penetration .......................57

4.9 THD of Phase to Phase Voltages for High PEV Penetration....................................58

4.10 Optimal WG Size for Voltage THDs in High PEV Penetration ............................58

4.11 THD of Line Currents for High PEV Penetration ..................................................60

4.12 Optimal WG Size for Current THDs in High PEV Penetration .............................60

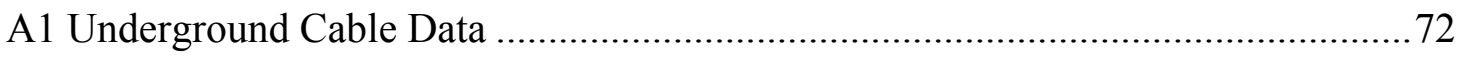

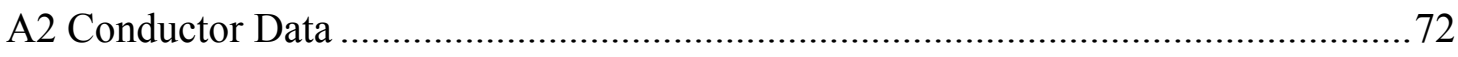




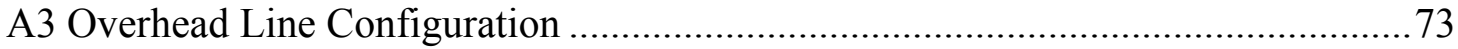

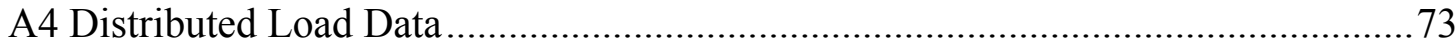

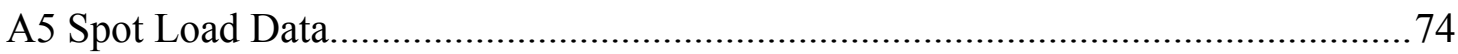

A6 All Aluminum Cable .................................................................................... 74 


\section{Acknowledgements}

I would like to thank my advisor, Dr. Sumit Paudyal, in the first place for giving me the opportunity to work under him. His meticulous guidance and encouragement have helped me immensely throughout the course of the project to overcome the obstacles. He also showed me the way for running my simulations, hands on work, and to see it though until the very end. He has been available for each and every occasion when help was sought.

I would also like to thank my friends out here. They have supported me each and every occasion and helped me through the process.

In the end I would like to express my gratitude for my parents, without their support this work wouldn't have been possible. I am forever indebted to them and this work is dedicated to my mom and dad. 


\section{Abstract}

Harmonic distortion on voltages and currents increases with the increased penetration of Plug-in Electric Vehicle (PEV) loads in distribution systems. Wind Generators (WGs), which are source of harmonic currents, have some common harmonic profiles with PEVs. Thus, WGs can be utilized in careful ways to subside the effect of PEVs on harmonic distortion. This work studies the impact of PEVs on harmonic distortions and integration of WGs to reduce it. A decoupled harmonic three-phase unbalanced distribution system model is developed in OpenDSS, where PEVs and WGs are represented by harmonic current loads and sources respectively. The developed model is first used to solve harmonic power flow on IEEE 34-bus distribution system with low, moderate, and high penetration of PEVs, and its impact on current/voltage Total Harmonic Distortions (THDs) is studied. This study shows that the voltage and current THDs could be increased upto $9.5 \%$ and $50 \%$ respectively, in case of distribution systems with high PEV penetration and these THD values are significantly larger than the limits prescribed by the IEEE standards. Next, carefully sized WGs are selected at different locations in the 34-bus distribution system to demonstrate reduction in the current/voltage THDs.

In this work, a framework is also developed to find optimal size of WGs to reduce THDs below prescribed operational limits in distribution circuits with PEV loads. The optimization framework is implemented in MATLAB using Genetic Algorithm, which is interfaced with the harmonic power flow model developed in OpenDSS. The developed framework is used to find optimal size of WGs on the 34-bus distribution system with low, moderate, and high penetration of PEVs, with an objective to reduce voltage/current THD deviations throughout the distribution circuits. With the optimal size of WGs in distribution systems with PEV loads, the current and voltage THDs are reduced below 5\% and 7\% respectively, which are within the limits prescribed by IEEE. 


\section{Chapter 1}

\section{Introduction}

\subsection{Motivation}

Plug-in Electric Vehicles (PEVs) and wind energy have emerged as two recent entities which have the potential of being included in modern day electric distribution system at a large scale. With the increasing exhaustion of fossil energy, depletion of global energy reserves is a major worldwide concern at economic, environmental and industrial levels. Potentially, the greenhouse gas emissions are changing the climate which would be a major threat to human society. PEVs and wind power has capability to reduce the emissions as well as depletion of energy reserve. However, accommodating PEVs and wind power in the network will have adverse impacts in the distribution network because of the increased load from PEV charging and intermittency of wind power $[1,2]$. The placement and size of PEV loads or wind generator (WG) impacts the voltage profile as the load profile changes in the network. Also, the presence of PEV can cause power loss and power quality degradation.

PEVs integrated into the grid poses challenge from power system operation point of view. As most of the Electric Vehicles (EV) is charged completely or partially by electricity, it is required to be connected with the distribution grid for considerable time duration. This may require remodeling of the modern grid system as a large number of PEVs will introduce a new set of uncertainty into power system operation, which might be proven harmful for the grid [3]. As the studies have shown, that without any kind of mitigation, the charging of PEVs leads the electricity grid with additional loads which might result an increment of aggregated load in peak hours, and hence impacts the overall reliability of the grid [4]. 
It is natural that energy demand increases every year. Also for the growing concern of the climate changes and energy security issues, increment of the usage of PEVs in the near future is unavoidable. In a recent study, it has been indicated that the number of gridable vehicles will reach roughly 2 million by the end of 2020 in U.S.A. By 2030 there would be 14 million PEVs on the road of U.S.A, which is about $5 \%$ of the light duty vehicle fleet $[5,6]$. However, the penetration of PEV in the grid will not be uniform across the country. Some of the utilities in west coast are expecting PEV penetration of around 5\% in their service territories by the end of 2020. By that time large scale deployment of residential and public load chargers will be required. Similarly in other countries like Germany have plans to have one million PEV by 2020 [7, 8]. Also, Japan is planning to have 50\% market share of PEV by 2020 [9-11].

Wind energy is a green renewable energy which is cleaner than most of the traditional power sources. To solve the current problem of world's depleting reserve and shortage of fossil energy reserves, deployment of wind energy resources is very important [12]. Both of PEVs and wind energy are considered to reduce the use of fossil fuels, reduce green-house gas emission, carbon footprints around the world. The intermittency of wind power is one of the biggest challenges in the practical application of wind power. In one of the most ambitious projects to ensure energy security, governments around the world are taking steps to incorporate wind energy into the modern day power grid [13]. By 2020, the state of California alone has set a target of reaching 33\% renewable penetration $[14,15]$. Similarly one of the studies made by the Global Wind Energy Council in 2006 showed that world's total installed wind power capacity will reach almost 3.0 billion $\mathrm{kW}$ by 2050 , and generated electrical energy will reach 5 trillion $\mathrm{kWh}$ in 2030, and 8 trillion $\mathrm{kWh}$ in 2050 [12]. To mitigate fluctuations, aggregation of the output of multiple wind turbines or wind farm is usually practiced. In some cases, the operator needs to procure more reserves to supply the demand in case of wind intermittency. The extra power could cost vary from $\$ 0.45-\$ 8.85 / \mathrm{MWh}$. Thus, 
scheduling highly fluctuating wind energy is not an easy task for the operator $[4,16$, 17].

The integration of PEVs into the grid is also a challenging problem for Demand Side Management (DSM). Utilities face problems when PEVs charge from the grid due to the size of its battery chargers which can represent sizable loads. One example is that after arriving home from work, a large number of PEV users will to try to charge their vehicles within a short range of time, thus resulting in increased peak demand [13]. The batteries of the PEVs take significant amount of time to charge, the charging duration varies with different manufacturers such as Nissan, Mitsubishi, GM, Tesla Motors, Chevrolet, etc. The timing of PEV charging are mostly uncoordinated and random which negatively impact the power grid. Severe voltage fluctuation, suboptimal generation dispatch, increment of the Total Harmonic Distortion (THD), degraded system efficiency, irregular economic dispatch are some of the problems that could be caused by increased PEV penetration. Also, the likelihood of blackout becomes higher as the demand to generation scenario could be impacted as most of the PEVs draw significant amount of power from the grid [18-20]. To overcome this, the need of high speed bidirectional communication is becoming imminent. With the advent of smart grid networking system, an effort is going to modernize power grid to cope with the ever increasing energy demand. Real-time monitoring, control of transmission, distribution and end-user consumers will be much easier with an evolving smart grid framework [21, 22]. To manage intelligent or smart coordinated charging of the PEVs, communication systems and proper usage of available energy resources will be of utmost importance [23].

In recent studies, it has been also shown that the PEVs can be used as energy storage devices. It has been shown in [3] that PEVs are not used for $96 \%$ of a day. The Vehicle to Grid (V2G) technology helps to partially solve the problem of depletion of energy reserves. It is a recent application of energy storage technology, which will eventually allow a bidirectional power flow between vehicles batteries and the power 
grid. The PEVs, which have a successful collaboration with the grid, are often termed as Gridable Vehicles (GV). For GV technology, the State-Of-Charge (SOC) of the vehicle's battery is controllable. With a proper grid framework, through V2G technology these unused PEVs can inject power back to the grid during the peak load hours [2]. PEVs can also be used to mitigate the intermittency of the Distributed Generation (DG) as PEV acts as a dispatchable energy sources. However, economic dispatch models of PEVs and its solution methods should be thoroughly studied before these methods can be directly applied to solve the aforementioned problems [3].

The aforementioned observations have motivated this research to conduct the assessment of WGs and PEVs on the Total Harmonic Distortion (THD) of voltages and currents in distribution circuits.

\subsection{Literature Review}

This section briefly discusses the literature survey carried out to assess the impact of PEV loads in distribution system, the optimal planning of renewable DGs in distribution system, and the advantages that PEVs and DGs pose to the distribution system operations.

\subsubsection{Optimal Sitting and Sizing of DGs}

As the penetration of DGs are increasing in the modern grid, the placement and proper sizing of DGs are one of the most important factors from planning perspective. Relay system configurations, voltage profiles, network losses can be affected due to improper sitting and sizing of DGs. The problems become more complicated with PEV loads. Random charging and discharging schedule of the PEVs may play a key role in the planning of the grid. In present studies deterministic approach is mainly used to find the optimal sitting and sizing of DGs [24]. In [25], to determine the optimal location of the DG, analytical methods are used in radial as well as meshed systems with objective function of network loss minimization. Then, from the bus admittance matrix, generation information, and load distribution, optimal site of DGs 
are determined. For loss reduction and voltage profile improvement in distribution system, fuzzy goal programming technique has been used to determine the optimal placement of the DGs in [26]. In some other works, Newton-Raphson load-flow method has been used to develop an iterative technique which will determine the optimal placement and sizing of the DGs [27]. In [28], three indices such as losses, voltage profile and short-circuit levels have been included to optimally determine the locations and size of the DGs in a large mesh-connected distribution. The issue with deterministic approach is that it uses Mixed-Integer Non-Linear Programming (MINLP) method to derive mathematical models which has multiple variables and constraints. In [29], an analytical method with minimization of the total power losses as objective has been considered to determine the optimal placement and sizing of the DGs. This method is based on the equivalent current injection technique. A multiobjective programming and decision theory based approach has been taken in [30] with the optimized use of DGs to solve voltage quality and THD related problems. Similar studies have been reported in [31, 32] where the authors have considered Particle Swarm Optimization (PSO) technique for optimal sitting and sizing of DGs to improve voltage profile and reduce THDs. The distribution network should be utilized in an optimal way to integrate the DGs. Voltage and thermal constraints are considered in [33], while developing an optimal power flow technique that maximizes the DG capacity across the network. In [34], to determine the optimal location and size of the DGs a Genetic Algorithm (GA) based approach is taken in single distributed generation, as well as in multi distributed generation separately, where the objective is loss minimization. Electricity deregulation and its impact on the optimal DG placement are studied in [35]. Optimal sitting and sizing of DG's is also achievable by using Chance Constrained Programming (CCP) framework which uses a Monte Carlo simulation embedded genetic algorithm. This model developed with minimization of DGs investment cost, operating cost, maintenance cost, network loss constraint, capacity adequacy cost as objective function [24]. 
From these aforementioned studies, it can be understood that placement and sizing of the DGs have a large impact while performing an optimal planning of the power grid. But, these studies haven't considered the problem related to current and/or voltage harmonics which necessitates a work that will deal with the issue of harmonics in the optimal planning and operational problems.

\subsubsection{Optimal Operation of Distribution System in presence of PEVs and DGs}

In [11], optimal operation of PEVs in the presence of high wind penetration is studied, where the energy cost for the PEV owners can be reduced in both spot and regulation market. This study has considered an aggregated battery storage model in load frequency control simulations to demonstrate the application of PEV as regulation power provider. As the battery of the PEV acts as a source of energy, it can provide ancillary service management such as supply of primary and secondary control and voltage regulation. Also, the PEVs can mitigate the high variation in the power generation caused by wind fluctuation in a PEV wind integrated grid. In [36], a primary control method of PEV to control the frequency deviation significantly is reported. Also, as shown in $[37,38]$ a secondary control of demand balance can be achieved through PEVs. Based on the voltage at the connection point, PEV charger can control charge/discharge profiles. With the advent of advanced power electronic converter installed within the charger of $\mathrm{PEV}$, it will be able to provide reactive power support. With the high wind power penetration in some countries these secondary controls of PEVs could be very helpful $[39,40]$.

In the Western Danish power system, the total share of annual power production is more than $27 \%$ [41]. By 2025, wind power is expected to be $50 \%$ of total power generation. The optimal operation of PEVs can significantly decrease the power intermittency due to wind across Europe. In Nordic power market, the hourly spot market price is available one day ahead and the consumers will make the changes based on the optimal charging and discharging patterns of the PEVs to minimize 
energy costs [42]. In Denmark, during real-time operations, the system operator uses regulation market as a tool to balance the power generation with the load. By providing regulation power, the PEV owners can get some benefits from the regulation market [43].

To mitigate the impact of PEV charging from the electric grid, one of the potential ways is to combine PEV charging with renewable DGs and local storage facilities into a single system. Several utility companies across the globe are currently working on this to make it commercially feasible. However, there are still several unknown issues that can adversely impact the architectural combination and control methodology. In [44], a GA based approach has been taken to design an optimally size standalone i. e., non-grid connected hybrid wind/PV power system model. In [45], a method has been developed to optimally size the combination of a battery bank and PV array into a wind/PV hybrid system. An optimum control method is required in order to settle the dispatch strategy to determine the optimized system unit cost [46]. Although, here the uncertainty still lays in the design of grid-interfaced DG and the storage systems. There are also several constraints and objective functions which has not been clearly explained to meet the PEV charging requirements. In [8], an optimal architecture of the grid has been designed using the constraint of lowest system lifecycle cost. Cost, efficiency and reliability are taken as important attributes of the PEV charging system. The system has been designed in a way, that it has the independence of drawing power from the grid. Also at the same time, different limits on the power drawn from the grid have been used as a constraint in the algorithm. Such systems are, self-sufficient with substantial renewable DG and energy storage without any kind of grid interface.

Some of the studies which deal with the optimal operation of distribution network in presence of PEVs and DGs have mainly seen the problem from the operation point of view. However, in this work a similar study have been done from the power system perspective, where it deals with the harmonics that are being introduced into grid due to the presence of PEVs and DGs. 


\subsubsection{Coordinated Energy Scheduling in a Distribution System in presence of PEVs and DGs}

PEVs can support the grid by improving voltage control and congestion management. However, uncoordinated PEV charging in a grid, which have WGs, may cause several local grid problem including additional extra power losses, voltage swings, power quality disturbances. A study is conducted in [47] to understand the coordinated charging and discharging behavior. Several other studies have been made for coordinated energy dispatch of microgrid where the PEV works as load and wind power as a source for generation. In [48], a modeling package has been proposed by the authors, which can simulate impact of PEV integration into a wind-thermal network. The emission level of this wind-PEV grid network is also very less compared to the system with number of PEVs. In [49], a novel unit commitment model is proposed to determine the interactive behavior between the PEVs and WGs. The model analyzes the demand response characteristics and proposed different PEV charging scenarios. It shows that the total system cost can be reduced significantly at an optimal dispatch level of the PEV loads. Also in the wind-PEV complementation models, consideration of the carbon emission models of the conventional and carbon capture power plants are effective as it can reduce the carbon emission as well the use of fuels [50]. This has demonstrated an improvement of wind power energy supply efficiency of the PEVs and also the optimal control of energy dispatch in power networks. However, it should be noted that most of these models don't consider the variability of the PEV charging behaviors and the deviation between actual and forecasted wind power outputs. The distribution of the SOC with respect to individual vehicles has not been considered as well. The wind power volatility scenarios are important for the coordinated scheduling of wind-PEV network. So on the basis of coordinated wind-PEV energy dispatching and control of PEV charging and discharging behaviors, energy dispatching approaches has been reported in [51]. 


\subsubsection{Impact of PEVs on Harmonics}

As discussed above, unexpected number of PEV charging during the peak demand hours impact the overall residential load curve, increase system losses and overloading of lines and increase harmonics introduction into the system. In [52] two PEV charging regime is taken to analyze such detrimental effects. In the uncoordinated random charging scenario, maximum bus voltage deviation is observed. However in the case of scheduled coordinated charging, total power losses and THD for voltage is much less. Also it has been shown that, when the PEV penetration is about $20 \%$, the THD distortion is not so significant that utilities can ignore it [52]. In [53], it is demonstrated that, due to the nonlinear nature of PEV loads the resulting current harmonics can cause abnormal operation such as increased losses, reduced efficiency, temperature rise, premature insulation and windings failure, etc. In overall, this can significantly have an adverse impact on reliability, security and efficiency of the grid. Despite the higher ratings of the PEVs and their rapid charging capabilities, the power demand will increase during the peak charging hours. So, even in newly developed smart grids, the power operations, component life cycle would be affected adversely [52-55]. These studies have been carried out to find the impact on harmonics due to the integration of PEVs. However the authors haven't considered any kind of DGs in the network. So, this thesis tries to address the issue of optimal operation of DGs and PEVs together for the reduction of THDs in the system.

\subsubsection{Smart Load Management (SLM) of PEVs}

Due to nature of irregularity in PEV charging, it poses a significant threat to DSM. From the utilities perspective, the PEV battery chargers represent sizeable nonlinearity in the system and difficult to predict. So there is a need for monitoring and control of the network which will also help the modern Distribution Management Systems (DMS). The DMS will directly coordinate with the PEV chargers through the evolving smart grid communication infrastructure. The process of SLM will also be helpful to coordinate the charging multiple PEVs, while maintaining system stresses, grid 
reliability, security, etc. In this SLM approach, human input such as time of the PEV charging, location of the PEVs are required. Based on the system constraints, SLM will may consider loss minimization, voltage regulation, and load variation over 24 hours [13].

\subsection{Research Objectives}

This thesis focuses on the mitigation of current and voltage THDs in distribution network due to the PEVs and WGs. The main contributions of this thesis are:

- To develop a three-phase unbalanced distribution system model required for harmonic power flow studies. The model is used to study the impact of PEVs on voltage and current THDs in distribution system with varying degree of penetration. The same model is used to demonstrate that careful planning of WGs can help to reduce the harmonic distortions caused by the PEVs.

- To develop an optimization framework based on GA that utilizes previous model as constraints and WGs as decision variables. The model is then used to find optimal size of WGs that will reduce the voltage or current THDs in the distribution circuit with varying penetration level of the PEVs.

\subsection{Thesis Overview}

The remainder of the thesis is organized as follows:

Chapter 2 discusses background topics and tools related to this research. Also, a brief background to the basic distribution system circuits and harmonic power flow has been provided. It also discusses basics of optimization, GA which are directly relevant to the work presented in this thesis.

Chapter 3 presents basics of IEEE 34 node test system. The models of PEVs and WGs in terms of harmonics are presented. Initial set of case studies have been presented where the penetration of the PEV is varied from $30 \%, 50 \%$ and $100 \%$. More case 
studies considering random placement of WGs in the 34 node test system to demonstrate WGs benefit on reducing THDs are also included in Chapter 3.

Chapter 4 discusses the interface between MATLAB and OpenDSS and the modeling work. Next, a GA based approach has been presented where WGs have demonstrated to reduce the voltage and current THDs in the presence of varying level of PEV penetration i. e., $30 \%, 50 \%$ and $100 \%$.

Chapter 5 presents the main results and conclusions. Also, some directions for future have been briefly discussed. 


\section{Chapter 2}

\section{Background}

\subsection{Introduction}

This chapter discusses a background review of the main concepts and tools related to this research work. Nomenclature of all parameters, variables, indices and function is given in Section 2.2. In Section 2.3 an overview of the distribution system is provided. The mathematically model required for harmonic power flow studies is provided in Section 2.4. A brief overview of optimization techniques related to the present work is discussed in Section 2.5 and 2.6. A detailed description of OpenDSS tool and the modeling of the distribution system in OpenDSS are presented in Section 2.7.

\subsection{Nomenclature}

$\alpha$ Set of series elements whose receiving end is connected to node $\mathrm{n}, \alpha \subseteq l$.

$\beta$ Set of series elements whose receiving end is connected to node $\mathrm{n}, \beta \subseteq l$.

$\Delta S$ Percentage voltage change for each LTC tap.

$\theta$ Load power factor angle, rad.

$A, B, C, D$ Three phase $\mathrm{ABCD}$ parameter matrices, p.u.

$C(h)$ Ratio of $\mathrm{h}^{\text {th }}$ harmonic current component to its fundamental current.

$h$ Set of harmonics, $h \in\{1,3,5, \ldots \ldots, 13\}$.

$h_{1}$ Set of harmonics, $h_{1} \in\{1\}$ and $h_{1} \subseteq h$.

$h_{2}$ Set of harmonics, $h_{2} \in\{1,5,7,11,13\}$ and $h_{2} \subseteq h$.

I Phase current vector. 
$I_{w}$ Current from wind generators.

$I_{e v}$ Current from electric vehicles.

$I_{O}$ Load phase current at a specified power and nominal voltage, p.u.

$l$ Set of series elements.

$L$ Set of wye-connected loads at each node.

$n$ Set of nodes.

$p$ Set of phases, $p \in\{a, b, c\}$.

$r$ Receiving-end of series elements.

$s$ Sending-end of series elements.

$t$ Controllable set of tap changers, $t \subseteq l$.

tapTap position.

$V$ Phase current vector.

\subsection{Distribution Systems}

In electric distribution system, everything begins with the distribution substation. It might be fed by one or more than one sub-transmission lines. Without the presence of sub-transmission system, the distribution substation is fed directly by high voltage transmission line. Normally the distribution substation is connected to multiple feeders. Only in case of radial distribution system, there is only one path for the power to flow from substation to the user end. The various components of a standard distribution are shown in Figure 2.1.

Feeders are three-phase wires which might be overhead conductors or underground cables, generated from the source through which the power is being transmitted to the 
loads and eventually to the end users. These can have lateral branches which could be three-phase, two-phase, or single-phase. Switches and regulators are used to reconfigure the feeders. From the distribution substation, step-down transformer is required to bring down the voltage to distribution level. Normally, in U.S.A the distribution source voltage is $132 \mathrm{kV}$ and the distribution voltage levels are $34.5 \mathrm{kV}$, $23.9 \mathrm{kV}, 14.4 \mathrm{kV}, 13.2 \mathrm{kV}, 12.47 \mathrm{kV}, 4.16 \mathrm{kV}$, etc. [56]. The transformers can have two or more phases. The three-phase transformers can have various connections like delta-wye grounded, wye grounded-wye grounded, etc.

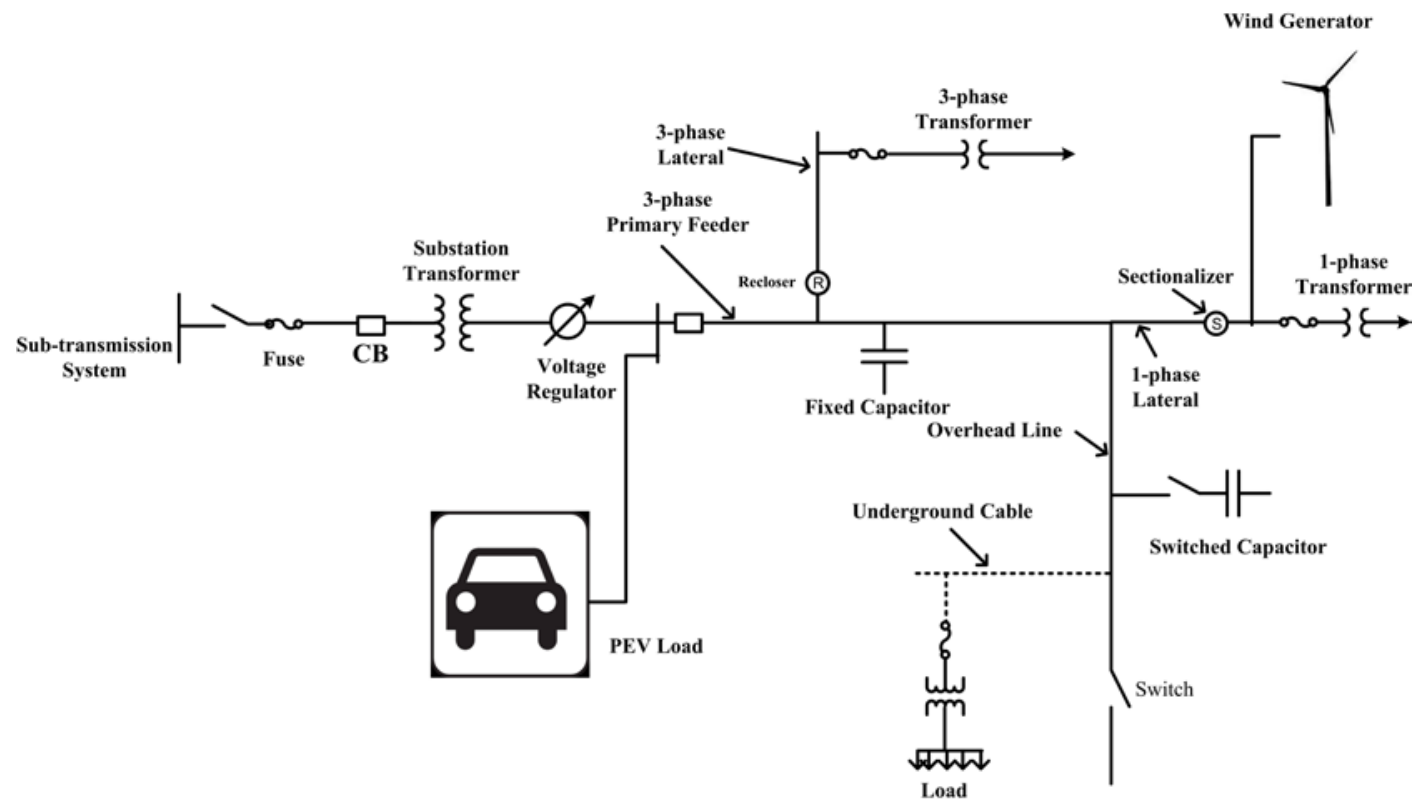

Figure 2.1: Sample Distribution System. Figure adapted from figures in Kresting [56] and Gonen [57].

Voltage regulators are used in distribution system to regulate voltage drop between substation and users. The substation voltage changes as load changes, but the voltage regulator keeps the voltage variation within a certain range in order to meet the standards. Load Tap Changing (LTC) transformers are used to vary these voltages. In 
the low voltage windings, the LTC changes the tap as the load varies. The substation transformers normally have fixed tap on the high voltage side of the transformer.

Protection schemes are an inevitable aspect of distribution system. Different circuit breaker relay protection schemes are generally employed to protect the system in high and low voltage buses to protect the system from faults. Meters are used in a substation to record line to line, phase to phase voltages and currents in a substation design. Digital meters are used in the output of the transformer or feeder as a part of the advanced metering system to record the values of voltages and current in specified time intervals $[56,57]$.

\subsection{Harmonic Power Flow}

The mathematical model for harmonic power flow studies is discussed next. The series parameters are conductors/cables, transformers. LTCs are modeled using the ABCD parameters. The conductors and cables are modeled using $\pi$-equivalent circuits. These are designed to include all the types i. e., single-phase, two-phase, three-wire threephase, and four-wire three-phase connections.

The model of three-phase transformers depends on the connection type (wye or delta). In the distribution system, voltage regulating transformers are equipped with LTCs. Shunt components like loads are modeled for individual phases separately to represent the unbalanced three-phase loads since single phase loads are very common in distribution feeders. For loads, constant current loads are considered. For each of the series element, a set of equations based on the ABCD parameters have been used. These relates to three-phase voltages and current of the sending end and receiving end for each harmonics. These are as follows:

$$
\left[\begin{array}{c}
V_{l, S}^{h} \\
I_{l, s}^{h}
\end{array}\right]=\left[\begin{array}{ll}
A^{h} & B^{h} \\
C^{h} & D^{h}
\end{array}\right]\left[\begin{array}{l}
V_{l, r}^{h} \\
I_{l, r}^{h}
\end{array}\right]
$$


The ABCD parameters of all the elements except the LTCs are constant. In case of LTCs these parameters depend upon the tap position during the time of operation. The following sets of equations are used to represent the A and D matrices for each LTC:

$$
\begin{gathered}
A_{t}^{h}=\left[\begin{array}{ccc}
1+\Delta S_{t} \operatorname{tap}_{a, t} & 0 & 0 \\
0 & 1+\Delta S_{t} \operatorname{tap}_{b, t} & 0 \\
0 & 0 & 1+\Delta S_{t} \operatorname{tap}_{c, t}
\end{array}\right] \\
D_{t}^{h}=A_{t}^{-h}
\end{gathered}
$$

These tap variablestap $a, t, \operatorname{tap}_{b, t}, \operatorname{tap}_{c, t}$ take only integer values.

In this study, only the constant power loads have been considered. The next equation is used to represent the wye-connected loads on a per-phase basis.

$$
\left|I_{p, L}^{h}\right|\left(\angle V_{p, L}^{h}-\angle I_{p, L}^{h}\right)=\left|I_{0 p, L}^{h}\right| \angle \theta_{p, L}^{h}
$$

For the delta-connected loads and capacitor banks, line-to-line voltages and currents are required. In (2.5) line variables are replaced by line-to-line variables. The equations for currents and voltages which can properly relate line-to-line variables to line variables are as following:

$$
\begin{aligned}
& {\left[\begin{array}{l}
V_{a, b}^{h} \\
V_{b, c}^{h} \\
V_{c, a}^{h}
\end{array}\right]=\left[\begin{array}{ccc}
1 & -1 & 0 \\
0 & 1 & -1 \\
-1 & 0 & 1
\end{array}\right]\left[\begin{array}{c}
V_{a}^{h} \\
V_{b}^{h} \\
V_{c}^{h}
\end{array}\right]} \\
& {\left[\begin{array}{l}
I_{a}^{h} \\
I_{b}^{h} \\
I_{c}^{h}
\end{array}\right]=\left[\begin{array}{ccc}
1 & -1 & 0 \\
0 & 1 & -1 \\
-1 & 0 & 1
\end{array}\right]\left[\begin{array}{l}
I_{a, c}^{h} \\
I_{b, a}^{h} \\
I_{c, a}^{h}
\end{array}\right]}
\end{aligned}
$$

To represent the current balance in each phase and node, after the integration of wind and PEV as shown in Figure 2.2, the following equation is used [58]:

$$
I_{w_{p, n}}^{h}+\sum_{\alpha} I_{p, l, r}^{h}=\sum_{\beta} I_{p, l, s}^{h}+\sum_{L} I_{p, l}^{h_{1}}+I_{e v_{p, n}}^{h_{2}}
$$




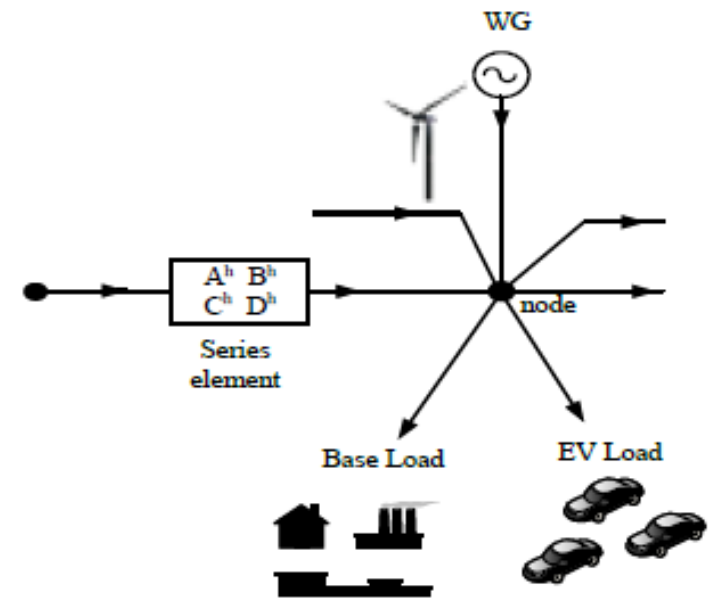

Figure 2.2: The Network after Integration of WGs and PEVs.

For the harmonic power flow calculation a decoupled approach is considered. The proposed Decoupled Harmonic Power Flow (DHPF) is justified due to the acceptable accuracy of the technique. Most of the industrial distribution systems consist of a large number of linear and non-linear loads. If the harmonic couplings are considered, then it may cause convergence and memory storage problems but the results will be improved. At harmonic frequencies, the system is modeled in the presence of the passive elements and harmonic current sources. The related admittance matrix is modified with the accordance to the harmonic frequency. Due to harmonic current injections into the system, the non-linear loads are modeled as current sources. Modeling of the fundamental and the $h^{\text {th }}$ harmonic current of nonlinear load connected at node $\mathrm{n}$ is given by the following equations:

$$
\begin{gathered}
I_{n}^{1}=\left[\left(P_{n}+j Q_{n}\right) / V_{n}^{1}\right]^{*} \\
I_{n}^{h}=C(h) I_{n}^{1}
\end{gathered}
$$

The total harmonic distortion of voltage $\left(T H D_{v}\right)$ and current $\left(T H D_{i}\right)$ are defined as, $[21,58]$

$$
T H D_{v}=\left[\left(\sum_{h=2}^{13}\left|V_{n}^{h}\right|^{2}\right)^{1 / 2} /\left|V_{n}^{1}\right|\right] \times 100 \%
$$




$$
T H D_{i}=\left[\left(\sum_{h=2}^{13}\left|I_{n}^{h}\right|^{2}\right)^{1 / 2} /\left|I_{n}^{1}\right|\right] \times 100
$$

In the equations (2.10) and (2.11), upto $13^{\text {th }}$ harmonics are considered, as the harmonic injection by WGs and PEVs are negligible beyond $13^{\text {th }}$ harmonics.

\subsection{Optimization}

Optimization can be defined as the process of obtaining a set of solutions for a certain set of variables, which forms user defined objective function. The solution can be obtained under the condition of some user defined constraints. In several engineering processes, it is very common to find a minimized or maximized solution for a certain function under the subject of decision variables. Through the optimization, it is easy to understand the conditions for yielding the minimized or maximized solution of the process. The set of values that can minimize or maximize the objective function is called an optimal solution. The optimization is generally defined as the minimized solution of the objective function, since it is same as maximization of the negative of the same function. The optimization problems normally arrive at either local and/or global optimum solutions depending upon the nature of the problem, solution techniques, constraints and the initial guess.

The mathematics behind the optimization problem is comprised of a objective function which is to minimized or maximized. These objective functions are set to a number of different constraints which is as follows:

Minimize:

$f(x)$

Set of variables: $\quad x=\left(\begin{array}{c}x_{1} \\ x_{2} \\ x_{3} \\ \cdot \\ \cdot \\ \cdot \\ x_{n}\end{array}\right)$ 
Subjected to:

$$
\begin{aligned}
& g_{m}(x)=0 ; \quad m=1,2, \ldots \ldots ., l \\
& h_{k}(x) \leq 0 ; \quad k=1,2, \ldots \ldots \ldots, p
\end{aligned}
$$

Here, $f(x)$ is user defined objective function and $x$ is the solution set which user is trying to obtain through optimization problem. $n$ is the number of variables. $g_{m}(x)$ and $h_{k}(x)$ are called equality and inequality constraints respectively. Based on the objective function and constraints, the problem can be linear or non-linear of nature. The constraints and the number of variables are not needed to be related. These types of problems are defined as constrained optimization problem.

The nature of the optimization problems is basically divided in two large areas: Linear Programming (LP) and Non-Linear Programming (NLP) as shown in Figure 2.3. The LP is defined on the basis of linear objective function and the linear equality and inequality constraints.

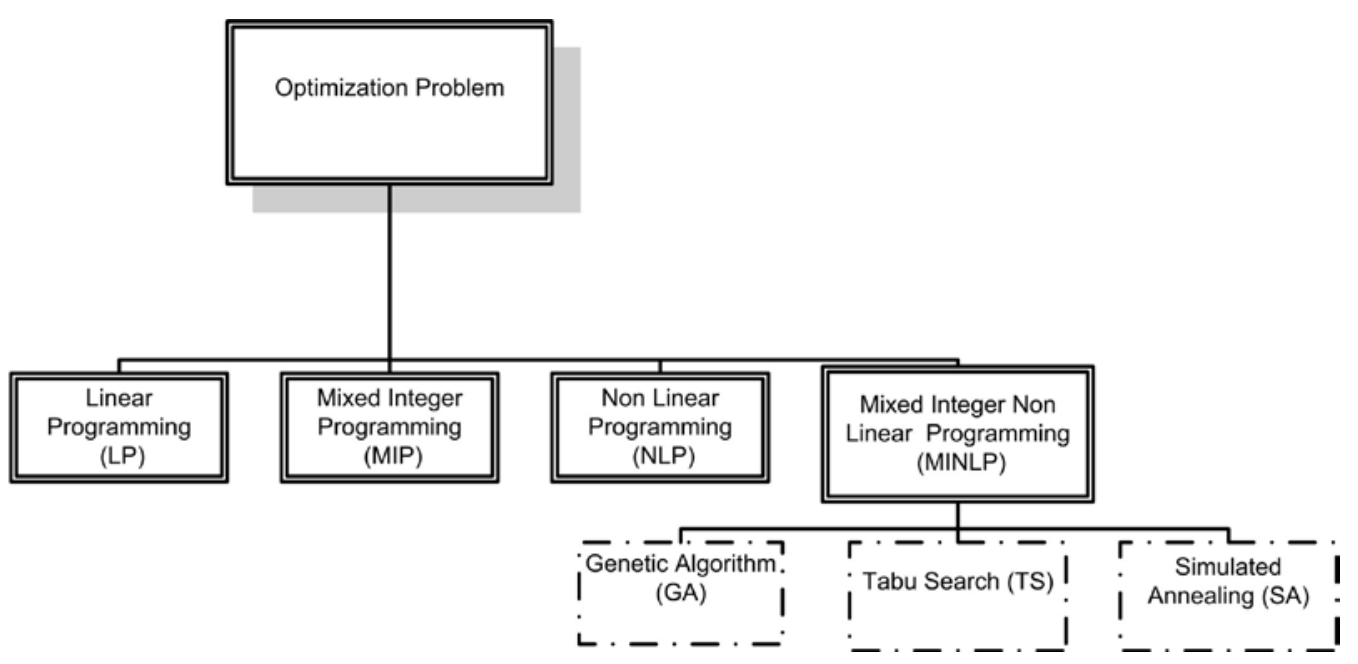

Figure 2.3: Hierarchy of Solution Techniques.

In the LP problems, the optimal solution is at one of the vertices of polyhedrons and the inequalities define the polyhedron solutions. Normally through the simplex method and interior-point method the LP solutions can be solved. In case of the simplex method, the polyhedron is built through a systematic process. The vertices are 
generated and tested in a systematic way. An arbitrary vertex is taken as the candidate solution, and the candidate solution is moved iteratively from one vertex to another. It is done in order to achieve the maximum improvement of the objective function [59]. For the interior-point method the candidate solution goes through the interior of the polyhedron to reach a vertex which is maximum improvement of the objective function [60].

In the optimization problem equation (2.12)-(2.15), if all the equations are linear and if the set of variables consist of at least one integer variable, then the nature of the problem is categorized as Mixed Integer Linear Programming (MILP) problem. For MILP problem the solution process becomes more complex as it has integer variables [59]. The cutting plane technique, Branch and Bound (B\&B) method is normally used to solve these types of problems. For the cutting plane technique constraints are being added to the MILP problem to reach vertex which has feasible space for integers. For the $\mathrm{B} \& \mathrm{~B}$ method large set of useless candidates are discarded with an intelligent enumeration of candidate solutions by using the lower and upper bounds of the constraints in the problem. Also if any variable in the NLP problem is an integer then it is called the MINLP $[60,61]$.

\subsection{Optimization Solution Techniques}

As shown in Figure 2.3, MINLP problem can be solved in different ways. GA is an evolutionary algorithm technique to obtain a set of optimized solution of a given problem. This modern heuristic search technique can be used for modeling, forecasting and simulation. GA starts with a population of candidates which searches several places of a solution space in a simultaneous and adaptive nature. The GA is the most used method to solve combinatorial optimization problems. The combinatorial optimization requires the use of enumeration technique like dynamic programming, $\mathrm{B} \& \mathrm{~B}$ which usually requires a large number of initial solutions. 
In case of heuristic optimization methods there are some methods which use local search and others use a non-convex optimization approach. Some of the common methods which go beyond the local search are Simulated Annealing (SA), Tabu Search (TS), and Particle Swarm Optimization (PSO). Short-time adaptive memory is used in TS which excludes the possibility of cycling. It searches in the neighborhood with local optima avoidance. In case of SA the approach of the search uses a probability function that allows the move to a worse solution in a decreasing probability. The SA and GA both use a memoryless search technique. The SA and GA methods do have the proof of convergence [60,61]. The main problem with SA procedure is that it has a slower asymptotic convergence rate with respect to the temperature which determines the cooling schedule. For TS methods the experiencebased fine-tuning of a large collection of parameters determines its efficiency. It uses a systematic search in the neighborhood. Both SA and TS take multiple solutions to the next iteration.

The initial population of the GA is encoded as a binary string of fixed length. This is a direct analogy of chromosomes. The initial population is generated randomly and after that it is being used in an iterative process throughout the algorithm. After each iteration, a new generation is formed and if these solutions are better than the initial population in terms of the objective function and constraints, then these replaces the initial population until and unless an optimal solution is reached. The procedure has three stages: selection, crossover, mutation. The process has been depicted through a flowchart in Figure 2.4. Following the sequence in flowchart, with the evaluation of each string, a fitness value is being assigned after the initial population is created. Through the objective function, the fitness of a string is defined with respect to other present members of the population. The encoded chromosomes are the input in the fitness function. The fitness function considers the constraints defined by the user and also incorporates different subojectives. Selection normally sets up the convergence characteristics of GA problems. With higher pressure of selection the degree of 
choosing the best individual is always high [62]. The convergence rate of GA is also directly proportional with the selection pressure. With the selection pressure, it will determine whether the optimization will take longer time to converge. Different types of selection schemes such as tournament selection, truncation selection, proportional selection, linear ranking selection are available in the GA. By selecting bits randomly from the pool offspring(s) are generated.

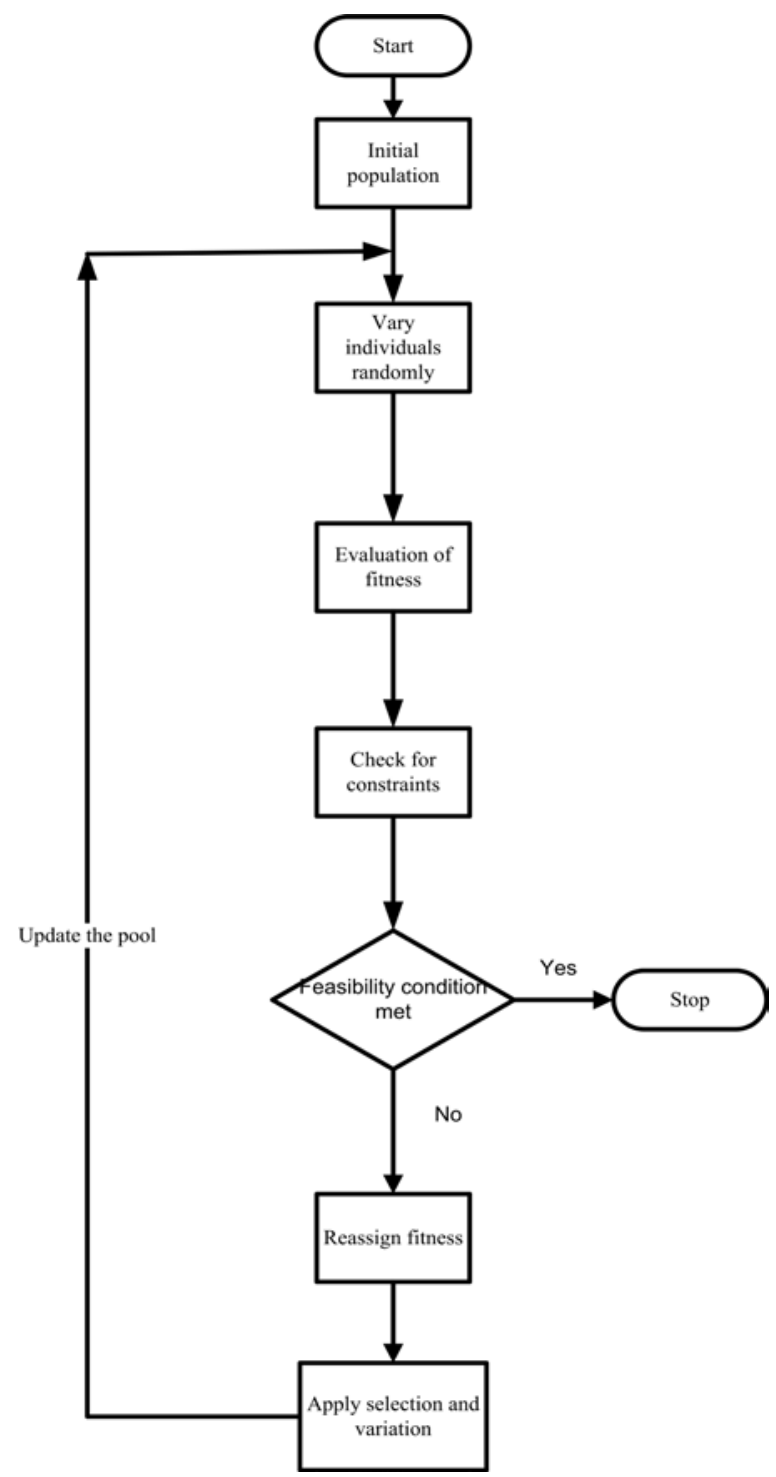

Figure 2.4: Sample Flowchart of Evolutionary Algorithm. Figure adapted from figures in K. Y. Lee et.al. [63]. 
In crossover the bits of offspring(s) are exchanged between themselves. The crossing of the bits can be in one point or in multiple points. Usually, GA employs all types of crossover.

In mutation, the binary bits of the offspring(s) are flipped. A mutation constant is normally set up at the beginning of this process. Normally this constant value gets compared with a random number and if the mutation constant is smaller than the random number then the bits are flipped [63].

\subsection{OpenDSS}

The Open Distribution System Simulator (OpenDSS) is a comprehensive electrical system simulator tool developed by the Electric Power Research Institute (EPRI) for studies of utility distribution systems. This software refers to the open source implementation of Distribution System Simulator (DSS). OpenDSS has an in-process Component Object Model (COM) server which acts as an interface with a variety of existing software. It can be implemented as a stand-alone executable program driven by various programming tools.

In OpenDSS most of the codes are written in a text based script. Also, as the OpenDSS is solely made to design distribution systems, it gives the developer more windows of accuracy and reliability for designing distribution systems. In OpenDSS, it has command and syntax for each distribution system components which can be given in any order. The compiler takes every line or parameter individually and then develops the model of interconnected distribution systems. A new command is used to add a new circuit element. This command can confirm the registered class and then determines the type of elements to add.

In this program most of the steady-state i. e., frequency domain analyses can be done for utility distribution system for planning and analysis purposes. With the advent of smart grid technology and deregulation in market, several complexities would arise 
which the OpenDSS can address. The OpenDSS has features to support different studies in distribution generation needs, energy efficiency analysis on power delivery, harmonic analysis, smart grid applications, etc. Also the modeling feature of OpenDSS can be applicable for annual load and generation simulations, probabilistic planning studies, protection system simulation, storage modeling, distribution state estimation, geomagnetically-induced currents and general multi-phase AC circuit analysis.

The circuit in the OpenDSS can be solved by different built-in solution models like daily power flow, harmonics, dynamics, montecarlo fault study etc. As these solvers are given in OpenDSS, the user just need to design the system in OpenDSS and call right solver to obtain the results. With the presence of COM interface, the user can execute different solution techniques in an external program and can transfer data of the system to utilize those in the program. It can be entirely driven by official tool through VBA or other programs like Python, MATLAB, R which can handle COM. It also increases the chance of better analysis of the system as well as excellent graphics for displaying results. Also the user can develop DLLs, so that the DSS can perform the analysis of all aspects of distribution system from a user built interface [64].

\subsubsection{Harmonic Modeling in OpenDSS}

For harmonic studies, the load model in OpenDSS is originally designed as the norton equivalent. The current source in the model, as shown in Figure 2.5 is set to the value of the fundamental current $I_{\text {fund }}$ times the multiplier of the spectrum object, which is associated with the load for the desired frequency. In the load equivalent admittance, $G+j B$, the B part is adjusted with the frequencies. This type of model is sufficient for the cases where the load object is being retained for the harmonic analysis. 


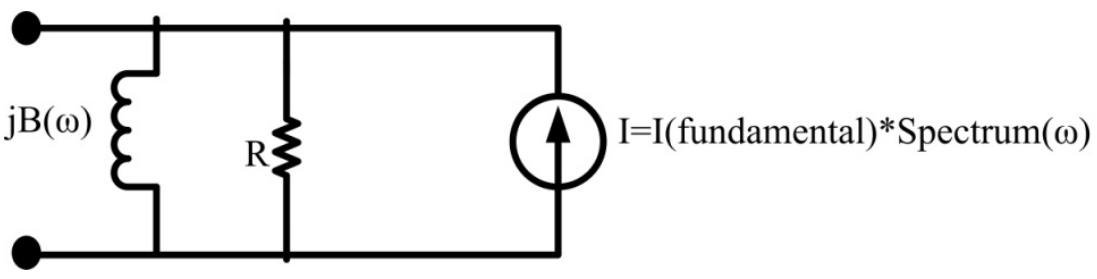

Figure 2.5: Initial Load Model in OpenDSS.

In the aforementioned models at the time of power flow solution, the load objects would automatically get converted and the system would be solved for all the frequencies present at the spectrum objects. Since at frequencies, where the system is near resonance the driving-point impedance looking into the system is very high. Thus, a significant portion of the harmonic current gives a rise in the harmonic content which also is the cause of significant damping of the resonance. Also, if the shunt admittances are added in the model, then the values of voltages will appear higher in near resonant conditions.

To avoid these issues, the model is modified in such a way that the user can define what percentage of load is to be modeled as a series R-L and the remainder would be automatically considered as the parallel R-L as shown in Figure 2.6. This has a significant impact on controlling the amount of damping in harmonic solutions. Generally, the resistance in distribution system has little to do with the effect of flow of harmonic currents when the system is not in resonance. However, the damping of harmonic resonance by resistance of loads, lines and transformers can make a significant impact on the level of harmonic current and voltage distortions predicted by the models. Substation transformers and larger transformers which supply the industrial consumers have a relatively high $\mathrm{X} / \mathrm{R}$ ratio of 10 or greater at fundamental power frequency. Although distribution service transformers which serve the residential loads can have a much lower value of $\mathrm{X} / \mathrm{R}$. 


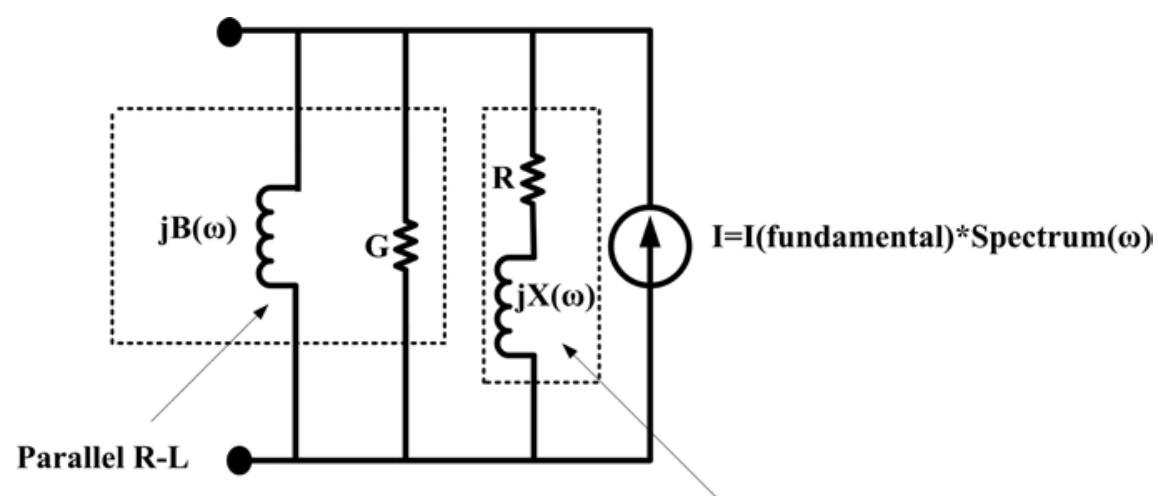

Series R-L

Figure 2.6: Updated Harmonic Load Model in OpenDSS.

In OpenDSS, without any modifications of the winding resistance $\mathrm{R}$, the equivalent $\mathrm{X} / \mathrm{R}$ will increase in proportion to the harmonic. The apparent resistance of transformers increases with frequency at a rate proportional to the design. The chief component of this increase comes from the stray eddy current losses which is quite significant in transformers that have conductors with large cross sectional areas. Also, in windings, design with conductors in parallel can have circulating currents that yield and cause effective increase in $\mathrm{R}$.

OpenDSS works with a solution method for fundamental frequency power flow since it performs the analysis in the frequency domain and does not work in the electromagnetic transients or time domain studies. Solving power flows occur in OpenDSS for various modes like snapshot in time, daily and yearly mode. The modeling of distribution systems can be done in OpenDSS for selected time periods at various intervals. Also harmonic flow analysis is one of the most important aspects of OpenDSS. There is a separate mode i. e., "harmonics mode" for doing harmonic studies in OpenDSS for all kind of distribution networks.

Harmonics are mainly periodical waveforms or signal whose frequency is a multiple of the frequency of the reference waveform or signal. Harmonics occur due to the periodic distortion of the voltage and current waveforms. This happens due to nonlinear devices typically loads. Harmonic analysis of a system in OpenDSS is one 
of its built-in functions. It implements the linear admittance solution. The linear system models are solved at each frequency of interest for voltages and currents. The system admittance matrix is built from each component of the model. The method is based on the nodal admittance matrix harmonic solution model.

In OpenDSS the harmonic analysis is done in two steps. First the power flow is carried out in the model and the solution must converge before starting the next step. Next, the harmonic sources are activated with proper magnitude and phase angle. The "solve mode $=$ harmonics" solves the system for each frequency defined in any circuit elements [64-66].

\subsubsection{Component Modeling in OpenDSS}

\section{Transformer}

The transformers are modeled as a three-phase step-down transformer for this work. A substation transformer connected in delta-wye is used to bring down the voltage of 69 $\mathrm{kV}$ to $24.9 \mathrm{kV}$. Another transformer is used between node 832 and node 888 to reduce the voltage level of $24.9 \mathrm{kV}$ to $4.16 \mathrm{kV}$ [64].

\section{Regulator}

The regulator control objects are designed in OpenDSS to emulate the LTC control or voltage regulator. It is normally attached to only one of the windings in the transformer to adjust the tap in that winding but could be used for control of the taps in other windings. It also has a line drop compensator model which requires resistance, reactance, CT ratings and PT ratio as input parameters [64].

\section{Overhead and Underground Line Modeling}

In OpenDSS, both the overhead and underground lines are required. In case of the underground cable All Aluminum (AA) concentric cable of $15 \mathrm{kV}$ has been used. Also 
tape shielded AA cable of $15 \mathrm{kV}$ has been used. In case of overhead conductors apart from AA Copper Conductor (CU) and Aluminum-Conductor Steel-Reinforced (ACSR) cable have been used [64].

\section{Line Code}

The line code objects of the OpenDSS are general library objects. This also contains the impedance characteristics for the lines and cables. Through the series impedance matrix and nodal capacitive admittance matrix, the impedance of a line is described. These matrices can be specified directly or with the use of symmetrical component data it can be generated. The line code also performs a kron reduction. It can reduce the last conductor which is also the neutral conductor in the impedance matrix. If the impedance is not specified as a matrix rather as a symmetrical component, this function does not work as the reduction is already assumed in the symmetrical component [64].

\section{Load}

In OpenDSS the load is modeled as current injection for this case. In case of wyeconnected load the primitive Y matrix contains only the impedance which is between the load and the ground. The load is defined as $\mathrm{kW}$, kvar and kVA. The base load can be specified by either two of the mentioned three parameters. There are eight load models specified in OpenDSS.

1. Normal load-flow load- Constant P and constant Q

2. Constant Impedance Load

3. Constant $\mathrm{P}$ and quadratic $\mathrm{Q}$

4. Linear $\mathrm{P}$ and quadratic $\mathrm{Q}$

5. Rectifier Load- Constant $P$ and constant current 
6. Constant P; Q fixed at nominal value

7. Constant P; Q fixed impedance at nominal value

Both spot and distributed loads have designed for the model. Also, a spectrum component can be defined which determines the harmonic current magnitude and angle of that load. Normally when spectrum is not defined the load takes a default value [64].

\section{Generator}

The generator works as the power conversion element same as the load in OpenDSS. The rating of generator is defined by its $\mathrm{kW}$ and $\mathrm{kVA}$. The generator works as negative load at the time of power flow studies. At the time of harmonic study the generator gets converted to a voltage source. A duty cycle loadshape can be separately defined for the generator. At the time of modeling wind generators, a separate normalized loadshape have been defined [64].

\subsection{Summary}

In this chapter a review of distribution system components has been presented. The software that has been used to design the distribution system is discussed. Mathematical modeling of harmonic power-flow is discussed briefly. A review on optimization and different optimization techniques have been presented as well. 


\section{Chapter 3}

\section{Impact of Plug-in Electric Vehicles (PEVs) and Wind Generators (WGs) on Total Harmonic Distortion (THD)}

\subsection{Introduction}

This chapter presents the impacts on harmonics of a distribution system when PEVs and WGs are integrated into the system. In Section 3.2, parameters related to IEEE 34 node test feeder system are discussed briefly. In Section 3.3 and 3.4, the harmonic modeling of PEVs and WGs have been analyzed. In Section 3.5, different case studies with or without the presence of WGs and PEVs have been presented to show the impacts of PEVs and WGs on the harmonics of the system.

\subsection{IEEE 34 Node Test Feeder}

To demonstrate the propose research objectives, IEEE 34 node test feeder system have been considered. Figure 3.1 shows the one line diagram of the IEEE 34 node test feeder system. In Figure 3.1, the numbers of crossbars on the feeders represent the number of phases in the IEEE 34-node test feeder. Following are the information about the test feeder:

- The test feeder has a nominal voltage of $24.9 \mathrm{kV}$.

- The substation is rated at $2500 \mathrm{kVA}$.

- The network has very long distribution lines.

- Multiple laterals are branching out from the main feeder which is single-phase and three-phase. This is representative of a rural network system which is able to incorporate distributed generation.

- Test feeder has two voltage regulators to keep the voltage under prescribed limit. The regulators are connected at node 814 and 852 , respectively. 
- A substation transformer connected in delta-wye is used to step down the voltage of $69 \mathrm{kV}$ to $24.9 \mathrm{kV}$. Another transformer is used between node 832 and node 888 to step down the voltage level from $24.9 \mathrm{kV}$ to $4.16 \mathrm{kV}$.

- The system has both spot and distributed loads.

- Shunt capacitors have been used at node 844 and 848 to improve the power factor by compensating reactive power [67].

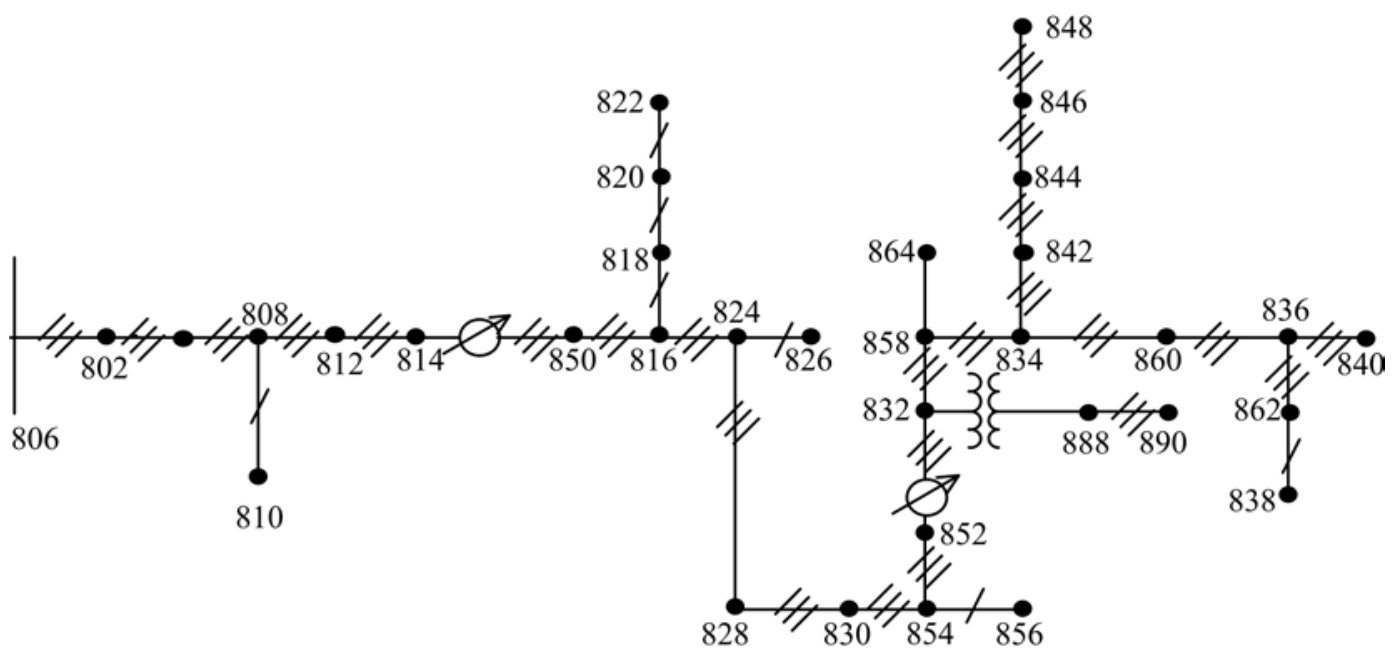

Figure 3.1: IEEE 34 Node Test Feeder System.

More information and other data of IEEE 34 node test feeder system are provided in the Appendix.

\subsection{PEV Model with Harmonics}

The impact of integrating PEVs in the grid is becoming a matter of concern. With the extensive presence of PEVs in residential and distribution loads, the smart grid provides a unique opportunity on energy storage systems. Normally the PEV battery has a capacity range of few $\mathrm{kWh}$ to over $50 \mathrm{kWh}$ [68-71]. In Table 3.1 a comparison of recent PEVs battery capacity have shown. 
Table 3.1: Battery Capacity of Recently Released PEVs [53].

\begin{tabular}{|c|c|}
\hline PEV Models & Battery Capacity (kWh) \\
\hline Mitsubishi iMiev & 16 \\
Tesla Roadster & 54 \\
GM Chevrolet Volt & 16 \\
Nissan Leaf & 24 \\
\hline
\end{tabular}

Most of the PEVs have multiple charger models allowing slow to rapid charging because of the time constraint similar to filling the tank of a fuel based car. Lithiumion batteries are mostly used because of their lightweight, energy dense and rapid charging capability. To recharge these batteries with a suitable battery charger, it will take approximately 10 minutes with $95 \%$ of full charge. For example, in Australia the recently released Mitsubishi iMiev PEV gets charged from home from 240V/15A power supply. However, for rapid charging it is required to install a special rapid power battery charger. In case of the iMiev a quick charging facility using a special socket is offered. It will get charged from a rapid charge unit such as those installed in charging stations [53].

For this work, the PEV loads have been calculated based on the IEEE 34 bus system base loads. The rated power of PEV is taken as $8.8 \mathrm{~kW}$ for the studies. It is more reasonable to assume that level-2 charging infrastructure is helpful for residential areas as level-1 charging is mostly slow. Also level-3 charging is the fastest but it is more expensive. So, it is safer to assume usage of 220V/40A [72].

It can be assumed that the percentage of residential load $\left(N_{R L}\right)$ in the residential mix is $30 \%$ as reported in [73], the average monthly electricity consumption is $1500 \mathrm{kWh}$, so, for a residential customer the average hourly electricity load will be $2.0833 \mathrm{~kW}$. If the total load at a particular node is $x \mathrm{~kW}$ then the number of the residential load will be computed using the following equation [2]: 


$$
N_{R L}=0.3 \times \frac{x}{2.0833}
$$

According to aforementioned calculation the load of the PEV $\left(P E V_{L O A D}\right)$ will be:

$$
P E V_{L O A D}=N_{R L} \times \text { Percentage of PEV Penetration } \times \text { Rated PEV Power }
$$

The typical harmonic current content of PEV's which have been obtained from $[21,74]$ has been shown in Table 3.2 .

Table 3.2: Line Current Harmonic Content of PEV Charger [21, 74].

\begin{tabular}{|c|c|c|}
\hline $\begin{array}{c}\text { Harmonic } \\
\text { order }\end{array}$ & $\begin{array}{c}\text { Magnitude } \\
\mathbf{( \% )}\end{array}$ & Angle (deg.) \\
\hline 1 & 100 & -26 \\
\hline 5 & 25 & -94 \\
\hline 7 & 17 & -67 \\
\hline 11 & 9 & -67 \\
\hline 13 & 5 & -46 \\
\hline
\end{tabular}

\subsection{WG Model with Harmonics}

In wind farms harmonics are generated due to the power electronic components present in the wind power generation system. In case of the WG, the harmonics generated includes the inherent harmonic produced by generator system and the harmonic generated through the excitation system. The inherent harmonic component produces the air-gap space harmonic magnetic potential. Also sinusoidal pulse width modulation (SPWM) inverters are used in wind turbines to provide the AC excitation. The output voltage of the SPWM inverter has a large number of harmonics which gets 
amplified by the motor air-gap magnetic field in the stator ultimately posing an adverse impact in the system [12].

Using the usual cube law equation, the mechanical output power of the wind turbine is calculated as;

$$
P_{m}=0.5 \rho C_{\rho} A U_{w}^{3} W
$$

Here, $C_{\rho}$ is the power coefficient. It is expressed as a function of tip speed ratio $\lambda$ and blade angle. $\rho$ is air density, $A$ is the wind turbine rotor swept area and $U_{w}$ is the wind speed.

The tip speed ratio $\lambda$ is;

$$
\lambda=\frac{r \omega_{m}}{U_{w}}
$$

Here $r$ is the rotor speed, and $\omega_{m}$ is shaft's mechanical angular speed.

The power coefficient ratio is;

$$
C_{p}=\frac{1}{2}(\lambda-5.6) e^{-0.17 \lambda}
$$

The optimum power of variable speed wind turbine with pitch control is obtained by applying appropriate conditions. The maximum power and optimum generator speed are respectively;

$$
\begin{gathered}
P_{m \max }=k_{p} U_{m}^{3} \\
\omega_{m \text { opt }}=k_{m} U_{m}
\end{gathered}
$$

Here $k_{p}$ and $k_{m}$ are wind turbine constants determined from wind turbine characteristics [75].

Wind turbine doesn't have a proper start/stop schedule, which generates harmonic current. Also, new harmonics are generated when the low order harmonics are 
connected with existing low order harmonics of power system. In unbalanced power system, due to the presence of negative sequence components, low order harmonics are being generated. The step-up transformer of wind farm has a magnetizing current waveform which results in the odd harmonics. The core saturation, nonlinear magnetization curve, design considerations also contribute in harmonic generation [12].

There are various types of power electronic components present in a wind power generation system. The electronic converters in wind turbine bear power transmission, load switching, etc. At the time of their operation, these will cause waveform distortion in the grid voltage and current which leads to major harmonic contribution. At the time of WGs operation, the converter feeds a large amount of current into the network. Although the self-generated harmonics are low in WGs, the introduction of these electronic components brings a number of changes in the waveform patterns [2]. The current injections of wind farm in p.u. based on 100 MVA is given in Table 3.3 [76].

Table 3.3: Current Content in Harmonic Injections of WG [76].

\begin{tabular}{|c|c|}
\hline Harmonic & Magnitude (p.u.) \\
\hline 2 & 0.000183 \\
\hline 3 & 0.000147 \\
\hline 4 & 0.00011 \\
\hline 5 & 0.00077 \\
\hline 6 & $7.33 \mathrm{E}-05$ \\
\hline 7 & 0.00033 \\
\hline 8 & $3.67 \mathrm{E}-05$ \\
\hline 11 & 0.000293 \\
\hline 13 & $7.33 \mathrm{E}-05$ \\
\hline 25 & $3.67 \mathrm{E}-05$ \\
\hline
\end{tabular}




\begin{tabular}{|c|c|}
\hline 45 & $3.67 \mathrm{E}-05$ \\
\hline 47 & 0.00011 \\
\hline
\end{tabular}

\subsection{Case Studies}

For this work, an uncoordinated PEV-WG charging system is studied. Three different levels of PEV penetration schemes have been presented. For the first part, the low penetration scheme is studied, where the penetration level of the PEV in the grid is $30 \%$. In the next two parts moderate and high penetration has been studied, where the PEV penetration is $50 \%$ and $100 \%$, respectively. In each penetration level three different type cases are considered. The results from the each case study have been compared to evaluate its usefulness.

The first case is the base case where only base loads and the PEV loads are present. The system loads of the IEEE 34 node test system is designed in the base frequency $i$. e., $60 \mathrm{~Hz}$. PEVs are designed as the non-linear loads with no reactive power. For the second case, one wind generator of $2 \mathrm{MW}$ is added in node 848 with the presence of PEV and system loads as shown in Figure 3.2. For the last case study, two more WGs of $2 \mathrm{MW}$ have been added in node 834 and node 890 in addition with the previous WG present in node 848 as shown in Figure 3.3. To measure the harmonic voltages and currents, four monitors have been placed in the different areas of the test system. In OpenDSS the monitors record the voltages and current harmonics, which can be placed in any component of the system. For this work monitor M1 is placed in the line which is connecting node 844 and 846. Similarly monitors M2, M3, M4 have been placed in the lines $828-830,808-806$ and $834-860$ respectively, as shown in Figure 3.2 and 3.3 , respectively. 


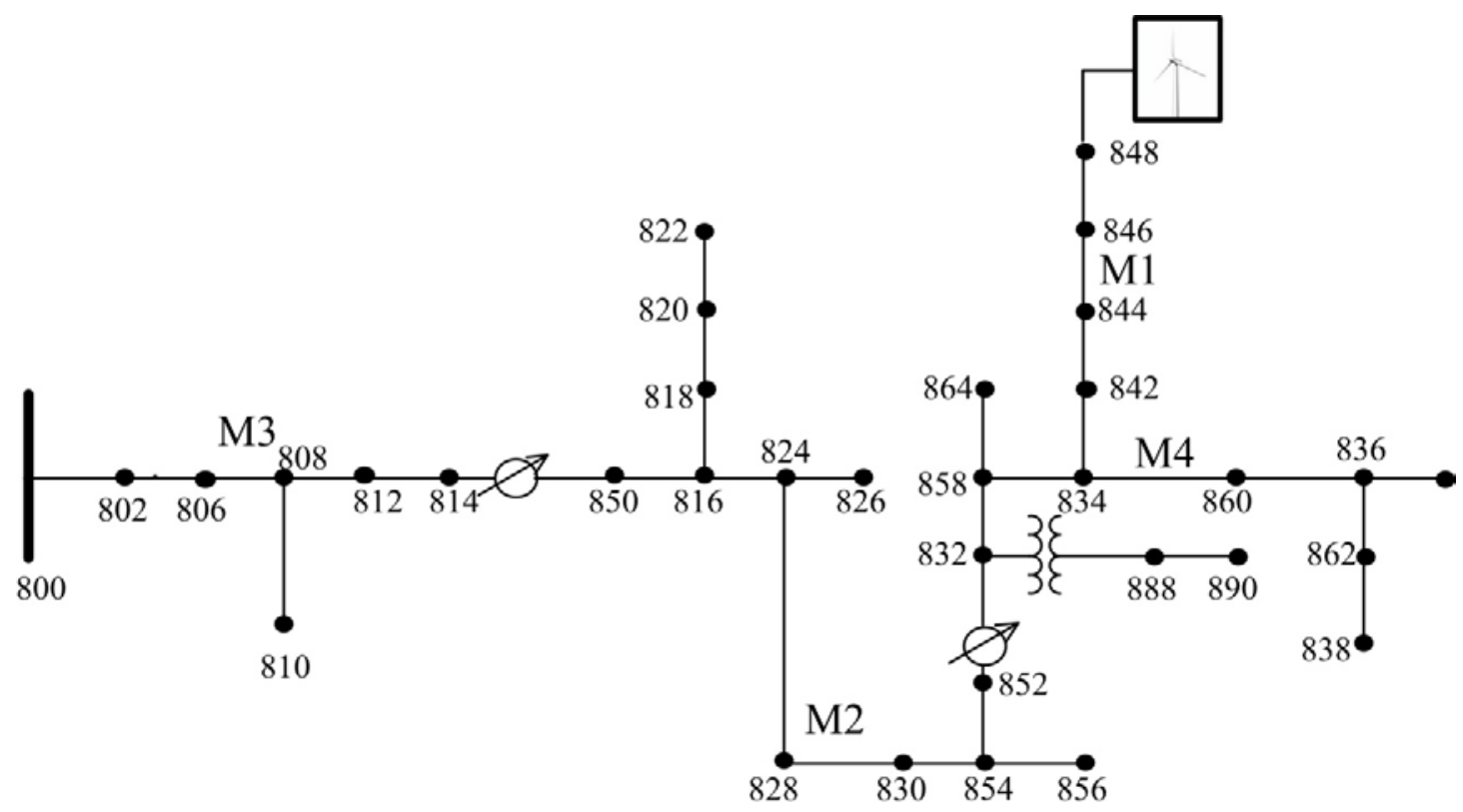

Figure 3.2: IEEE 34 Node Test Feeder System after the Addition of One WG.

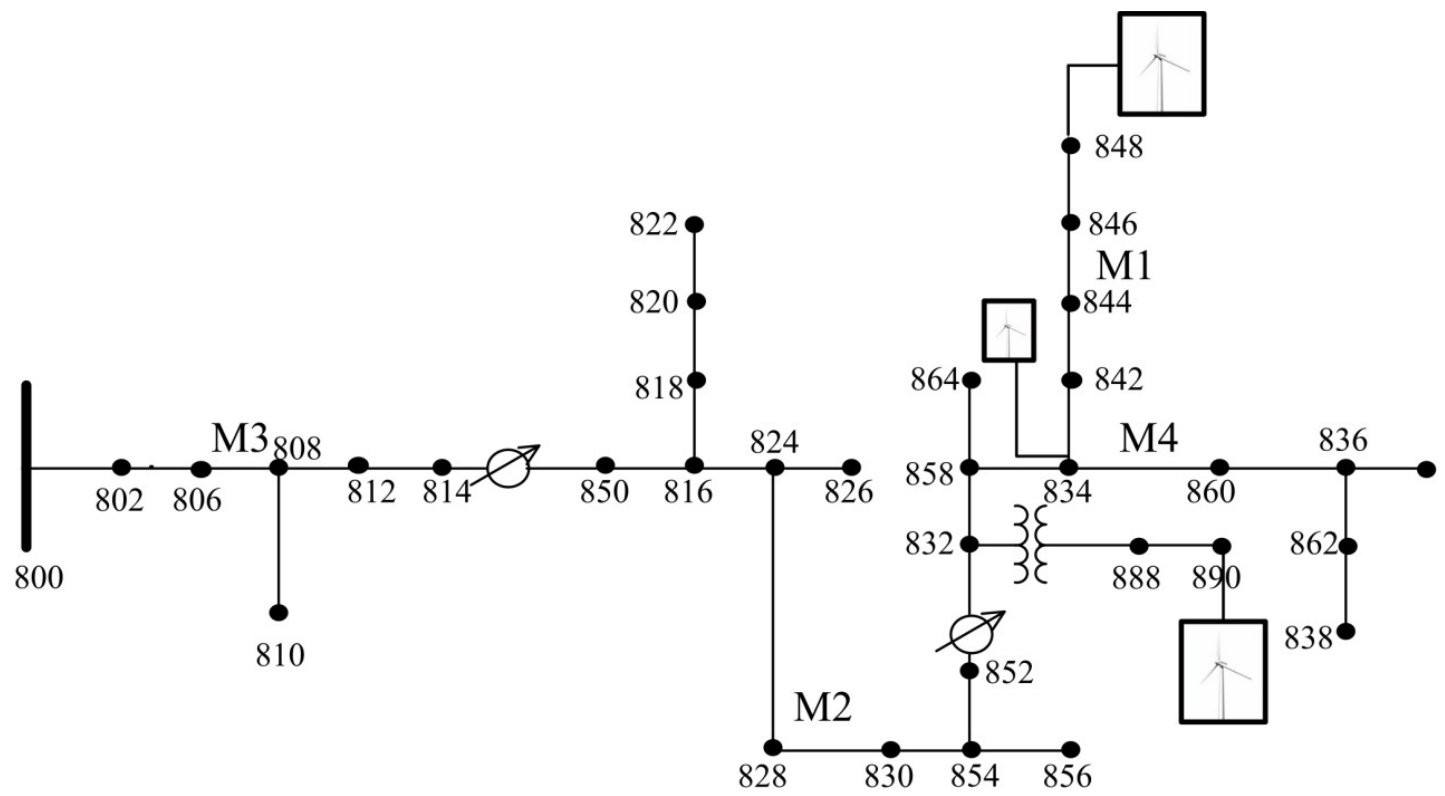

Figure 3.3: IEEE 34 Node Test Feeder System after the Addition of Three WGs. 


\subsubsection{Low PEV Penetration}

For the first case study, the low penetration of PEV i. e., $30 \%$ has been considered. The voltage and current THDs for this is shown in Table 3.4 and 3.5 respectively. In Case 1 and Case 4, only the base and PEV loads have been considered. In Case 2 and Case 5, one WG has been integrated in node 848 as shown in Figure 3.2. In Case 3 and Case 6, two more wind turbines have been added in node 834 and 890 as shown in Figure 3.3. The load of the PEV has been calculated by using the same procedure given in Section 2.4.

It can be seen from the THD value that even without WGs, the voltage THDs is subsequently low i. e., less than $5 \%$ and it is also under the limits prescribed by IEEE [77]. So, it can be understood that the lower PEV penetration does not make a significant impact on the voltage THDs. On the other hand, current THD values are subsequently high for feeder sections those are away from the substation source. However, with the introduction of consecutive WGs, it can be seen that current THD value has been gradually reduced in the range of $2 \%$ to $3 \%$.

Table 3.4: Phase to Phase Voltage THDs for Low PEV Penetration.

\begin{tabular}{|c|c|c|c|c|}
\hline $\begin{array}{c}\text { Case } \\
\text { Studies }\end{array}$ & Branch & THD $\boldsymbol{V}_{\boldsymbol{a} \boldsymbol{b}}(\%)$ & THD $\boldsymbol{V}_{\boldsymbol{b} \boldsymbol{c}}(\%)$ & $\mathbf{T H D} \boldsymbol{V}_{\boldsymbol{c} \boldsymbol{a}}(\%)$ \\
\hline \multirow{3}{*}{$\begin{array}{c}\text { Case } 1 \\
(\text { PEV) }\end{array}$} & $844-846$ & 4.62 & 4.64 & 4.14 \\
\cline { 2 - 5 } & $828-830$ & 2.73 & 2.77 & 2.52 \\
\cline { 2 - 5 } & $808-806$ & 0.09 & 0.09 & 0.08 \\
\cline { 2 - 5 } & $834-860$ & 4.58 & 4.60 & 4.11 \\
\hline \multirow{2}{*}{$\begin{array}{c}\text { Case 2 } \\
(\mathrm{PEV}+\end{array}$} & $844-846$ & 3.81 & 4.06 & 3.74 \\
\cline { 2 - 5 } $1 \mathrm{WG})$ & $828-830$ & 2.60 & 2.71 & 2.53 \\
\cline { 2 - 5 } & $808-806$ & 0.11 & 0.11 & 0.10 \\
\hline
\end{tabular}




\begin{tabular}{|c|c|c|c|c|}
\hline & $834-860$ & 3.78 & 4.03 & 3.71 \\
\hline \multirow{3}{*}{$\begin{array}{c}\text { Case } 3 \\
\text { (PEV+ }+\end{array}$} & $844-846$ & 3.99 & 4.58 & 4.13 \\
\cline { 2 - 5 } $2 \mathrm{WG})$ & $828-830$ & 2.96 & 3.39 & 3.11 \\
\cline { 2 - 5 } & $808-806$ & 0.13 & 0.14 & 0.14 \\
\cline { 2 - 5 } & $834-860$ & 3.95 & 4.54 & 4.09 \\
\hline
\end{tabular}

Table 3.5: Current THDs for Low PEV Penetration.

\begin{tabular}{|c|c|c|c|c|}
\hline $\begin{array}{c}\text { Case } \\
\text { Studies }\end{array}$ & Branch & THD $I_{a}(\%)$ & THD $I_{b}(\%)$ & THD $I_{c}(\%)$ \\
\hline \multirow{4}{*}{$\begin{array}{l}\text { Case } 4 \\
(\mathrm{PEV})\end{array}$} & $844-846$ & 25.75 & 24.20 & 23.19 \\
\hline & $828-830$ & 8.04 & 7.22 & 6.16 \\
\hline & $808-806$ & 5.5 & 6.46 & 6.31 \\
\hline & $834-860$ & 6.41 & 3.43 & 6.09 \\
\hline \multirow{4}{*}{$\begin{array}{c}\text { Case } 5 \\
(\mathrm{PEV}+1 \\
\mathrm{WG})\end{array}$} & $844-846$ & 2.81 & 2.90 & 2.59 \\
\hline & $828-830$ & 3.49 & 3.81 & 3.92 \\
\hline & $808-806$ & 4.42 & 4.29 & 4.14 \\
\hline & $834-860$ & 4.41 & 3.55 & 4.37 \\
\hline \multirow{4}{*}{$\begin{array}{c}\text { Case } 6 \\
(\mathrm{PEV}+2 \\
\mathrm{WG})\end{array}$} & $844-846$ & 2.04 & 2.05 & 1.77 \\
\hline & $828-830$ & 2.31 & 2.32 & 2.23 \\
\hline & $808-806$ & 2.14 & 2.33 & 2.35 \\
\hline & $834-860$ & 3.35 & 3.53 & 3.79 \\
\hline
\end{tabular}




\subsubsection{Moderate PEV Penetration}

In moderate PEV penetration, the PEV penetration level is 50\%. The THD of voltages and currents have been represented in Table 3.6 and 3.7 for all the six case studies from Case 7 to Case 12. As it can be seen from Table 3.6, for the Case 7, the value of voltage THD is around 6\%. Both voltage and current THD has increased with the penetration. In case of Branch 808-806, the voltage THD values are less as it is closer to the substation transformer. When the distance of the lines is increasing from substation transformer, the THDs are getting worst. But in Case 8 and Case 9 for voltage THDs and in Case 11 and Case 12 for current THDs, after the introduction of the WGs, the THD values are substantially reduced.

Table 3.6: Phase to Phase Voltage THDs for Moderate PEV Penetration.

\begin{tabular}{|c|c|c|c|c|}
\hline $\begin{array}{c}\text { Case } \\
\text { Studies }\end{array}$ & Branch & THD $V_{a b}(\%)$ & THD $V_{b c}(\%)$ & THD $V_{c a}(\%)$ \\
\hline \multirow{4}{*}{$\begin{array}{l}\text { Case } 7 \\
(\mathrm{PEV})\end{array}$} & $844-846$ & 6.66 & 6.67 & 5.85 \\
\hline & $828-830$ & 3.88 & 3.98 & 3.54 \\
\hline & $808-806$ & 0.12 & 0.13 & 0.11 \\
\hline & $834-860$ & 6.61 & 6.61 & 5.80 \\
\hline \multirow{4}{*}{$\begin{array}{c}\text { Case } 8 \\
(\mathrm{PEV}+1 \\
\mathrm{WG})\end{array}$} & $844-846$ & 4.37 & 4.65 & 4.15 \\
\hline & $828-830$ & 3.09 & 3.14 & 2.87 \\
\hline & $808-806$ & 0.13 & 0.13 & 0.12 \\
\hline & $834-860$ & 4.34 & 4.62 & 4.11 \\
\hline \multirow{3}{*}{$\begin{array}{c}\text { Case } 9 \\
(\mathrm{PEV}+2 \\
\mathrm{WG})\end{array}$} & $844-846$ & 4.45 & 5.17 & 4.57 \\
\hline & $828-830$ & 3.32 & 3.83 & 3.45 \\
\hline & $808-806$ & 0.14 & 0.16 & 0.15 \\
\hline
\end{tabular}




\begin{tabular}{|l|l|l|l|l|}
\hline & $834-860$ & 4.41 & 5.12 & 4.53 \\
\hline
\end{tabular}

Table 3.7: Current THDs for Moderate PEV Penetration.

\begin{tabular}{|c|c|c|c|c|}
\hline $\begin{array}{c}\text { Case } \\
\text { Studies }\end{array}$ & Branch & THD $I_{a}(\%)$ & THD $\boldsymbol{I}_{\boldsymbol{b}}(\%)$ & THD $I_{c}(\%)$ \\
\hline \multirow{4}{*}{$\begin{array}{l}\text { Case } 10 \\
\text { (PEV) }\end{array}$} & $844-846$ & 36.71 & 32.42 & 31.14 \\
\hline & $828-830$ & 10.06 & 8.78 & 7.18 \\
\hline & $808-806$ & 6.68 & 7.72 & 7.35 \\
\hline & $834-860$ & 9.69 & 5.07 & 8.85 \\
\hline \multirow{4}{*}{$\begin{array}{c}\text { Case } 11 \\
(\mathrm{PEV}+1 \\
\mathrm{WG})\end{array}$} & 844-846 & 3.35 & 3.57 & 3.06 \\
\hline & $828-830$ & 3.55 & 4.37 & 4.45 \\
\hline & $808-806$ & 5.59 & 5.30 & 4.75 \\
\hline & $834-860$ & 6.58 & 4.66 & 6.40 \\
\hline \multirow{4}{*}{$\begin{array}{c}\text { Case } 12 \\
(\mathrm{PEV}+2 \\
\mathrm{WG})\end{array}$} & $844-846$ & 2.14 & 2.16 & 1.75 \\
\hline & $828-830$ & 2.72 & 2.69 & 2.5 \\
\hline & $808-806$ & 2.39 & 2.66 & 2.73 \\
\hline & $834-860$ & 4.84 & 4.53 & 5.21 \\
\hline
\end{tabular}

\subsubsection{High PEV Penetration}

In this case maximum penetration level of PEVs is considered which is $100 \%$. The voltage and current THD values have been shown in Table 3.8 and Table 3.9, respectively. Similar to the previous case studies Case 13 and Case 16 considers the base and PEV loads only. Case 14 and Case 17 is representing integration of one WG 
with $100 \%$ PEV loads and its impact on voltage and current THDs. Similarly, Case 15 and 18 represent integration of three WGs.

As the PEV penetration level is $100 \%$, it is expected that the PEV load will inject more harmonics into the system. In case 18, the values of the current THDs are almost around $50 \%$ from which is a clear indication that harmonics distortion gets worse. Also the voltage THDs in Case 13 have reached around 9.5\%. However, by looking at THD values throughout the system, it is evident that near substation node the THD are less. Also, the THD value increases as we move away from the substation transformer.

In Case 14 with the introduction of one WG the voltage THDs has been reduced to $5 \%$ and in Case 17 the current THD have been reduced in the range of $4 \%$ to $10 \%$. So it can be seen that with proper sizing and location of WGs, the THDs can be reduced significantly.

Table 3.8: Phase to Phase Voltage THDs for High PEV Penetration.

\begin{tabular}{|c|c|c|c|c|}
\hline $\begin{array}{c}\text { Case } \\
\text { Studies }\end{array}$ & Branch & THD $V_{a b}(\%)$ & THD $V_{b c}(\%)$ & THD $V_{c a}(\%)$ \\
\hline \multirow{4}{*}{$\begin{array}{c}\text { Case } 13 \\
(\mathrm{PEV})\end{array}$} & $844-846$ & 9.61 & 9.54 & 7.82 \\
\hline & $828-830$ & 5.38 & 5.57 & 4.62 \\
\hline & $808-806$ & 0.16 & 0.17 & 0.14 \\
\hline & $834-860$ & 9.54 & 9.46 & 7.76 \\
\hline \multirow{4}{*}{$\begin{array}{c}\text { Case } 14 \\
(\mathrm{PEV}+1 \\
\mathrm{WG})\end{array}$} & $844-846$ & 5.43 & 5.84 & 4.73 \\
\hline & $828-830$ & 4.19 & 4.04 & 3.53 \\
\hline & $808-806$ & 0.18 & 0.18 & 0.15 \\
\hline & $834-860$ & 5.40 & 5.80 & 4.62 \\
\hline Case 15 & $844-846$ & 5.91 & 6.80 & 5.84 \\
\hline
\end{tabular}




\begin{tabular}{|c|c|c|c|c|}
\hline $\begin{array}{c}(\mathrm{PEV}+2 \\
\mathrm{WG})\end{array}$ & $828-830$ & 4.47 & 4.97 & 4.35 \\
\cline { 2 - 5 } & $808-806$ & 0.19 & 0.20 & 0.19 \\
\cline { 2 - 5 } & $834-860$ & 5.84 & 6.72 & 5.77 \\
\hline
\end{tabular}

Table 3.9: Current THDs for High PEV Penetration.

\begin{tabular}{|c|c|c|c|c|}
\hline $\begin{array}{c}\text { Case } \\
\text { Studies }\end{array}$ & Branch & THD $\boldsymbol{I}_{\boldsymbol{a}}(\%)$ & THD $I_{b}(\%)$ & THD $I_{c}(\%)$ \\
\hline \multirow{4}{*}{$\begin{array}{c}\text { Case } 16 \\
(\mathrm{PEV})\end{array}$} & $844-846$ & 50.26 & 38.70 & 37.75 \\
\hline & $828-830$ & 11.02 & 9.52 & 6.98 \\
\hline & $808-806$ & 6.67 & 7.913 & 7.12 \\
\hline & $834-860$ & 14.89 & 7.62 & 12.96 \\
\hline \multirow{4}{*}{$\begin{array}{c}\text { Case } 17 \\
(\mathrm{PEV}+1 \\
\mathrm{WG})\end{array}$} & $844-846$ & 4.50 & 5.03 & 4.03 \\
\hline & $828-830$ & 3.43 & 5.98 & 5.93 \\
\hline & $808-806$ & 10.91 & 9.00 & 6.46 \\
\hline & $834-860$ & 10.20 & 6.37 & 9.56 \\
\hline \multirow{4}{*}{$\begin{array}{c}\text { Case } 18 \\
(\mathrm{PEV}+2 \\
\mathrm{WG})\end{array}$} & 844-846 & 2.59 & 2.73 & 2.07 \\
\hline & $828-830$ & 3.87 & 3.78 & 3.72 \\
\hline & $808-806$ & 3.72 & 3.99 & 3.96 \\
\hline & $834-860$ & 7.39 & 5.88 & 7.33 \\
\hline
\end{tabular}

In all the aforementioned case studies, it can be seen that irrespective of the PEV penetration, the introduction of three WGs can bring down the current and voltage THD values in less than 5\%. However as the process is still arbitrary, there is an 
anomaly in the range and the process of bringing down the THD values. It can be seen in Case 15 of the voltage THDs is increased from Case 14 even with two additional WGs. This is happening as the selection of WG locations is completely random.

It can be inferred from the aforementioned case studies that the introduction of WGs certainly helps to reduce the voltage/current THD values caused by the PEVs. However, the positioning and sizing of the WGs are making some differences in the THD profile of the system. So, it would be more acceptable if the process is more regular and can bring down the THD values in a systematic way. To do it in a more acceptable and systematic way, in the next chapter a GA based approach has been presented to reduce the voltage and current THD values of the system irrespective of PEV penetration or placement of the WGs.

\subsection{Summary}

In this chapter a brief description of test system has been presented. The harmonic modeling of both PEVs and WGs are discussed. Case studies depicting increased current/voltage THDs due to PEVs are presented. Also, a prospective mitigation technique to reduce the THDs due to PEVs by WGs is presented. 


\section{Chapter 4}

\section{Mitigating THDs with WGs}

\subsection{Introduction}

This chapter discusses about the GA technique applied to mitigate the voltage and current THDs using the WGs. The procedures and tools used for this technique have also been discussed in this chapter. In Section 4.2, the property of COM interface between MATLAB and OpenDSS is briefly discussed. In Section 4.3, the details of used GA method applied for this work have been presented. In Section 4.4, different case studies on voltage/current THDs, optimal sizing of WGs with different penetration of PEVs are discussed. In the end, a comparative study has been made to explain the usefulness of this technique.

\subsection{OpenDSS and MATLAB Interface}

OpenDSS is basically used to design the distribution system where MATLAB is used for the coding and execution purposes of the GA. As it have been mentioned in Section 2.7 OpenDSS and MATLAB has a built-in COM interface. So, this is used to make a data transaction from one software to the other. In the OpenDSS, mainly the IEEE 34 node test feeder system has been designed and in the MATLAB the GA technique has been employed to mitigate the voltage and current THDs.

In OpenDSS, the various components required to build a standard distribution system has been modeled. For the modeling of this particular system as shown in Figure 4.1, transformer, overhead lines, underground cables, loads, capacitor, regulator and WGs have been designed in OpenDSS. There are two types of load i. e., base loads and PEV loads, which have been modeled in the system. Both the loads have been assigned with its individual harmonic characteristics. A normalized loadshape has defined the 
characteristics of WGs. The voltage and current limits has been defined for each phase and line.

The structure of this work is dependent on the interaction between both software. Initially MATLAB calls the OpenDSS distribution system model to assign input values for particular variables. The user can call the active circuit of the OpenDSS in between MATLAB program execution as well. Then on the users request OpenDSS solve different types of power flow to give the voltage and current data.

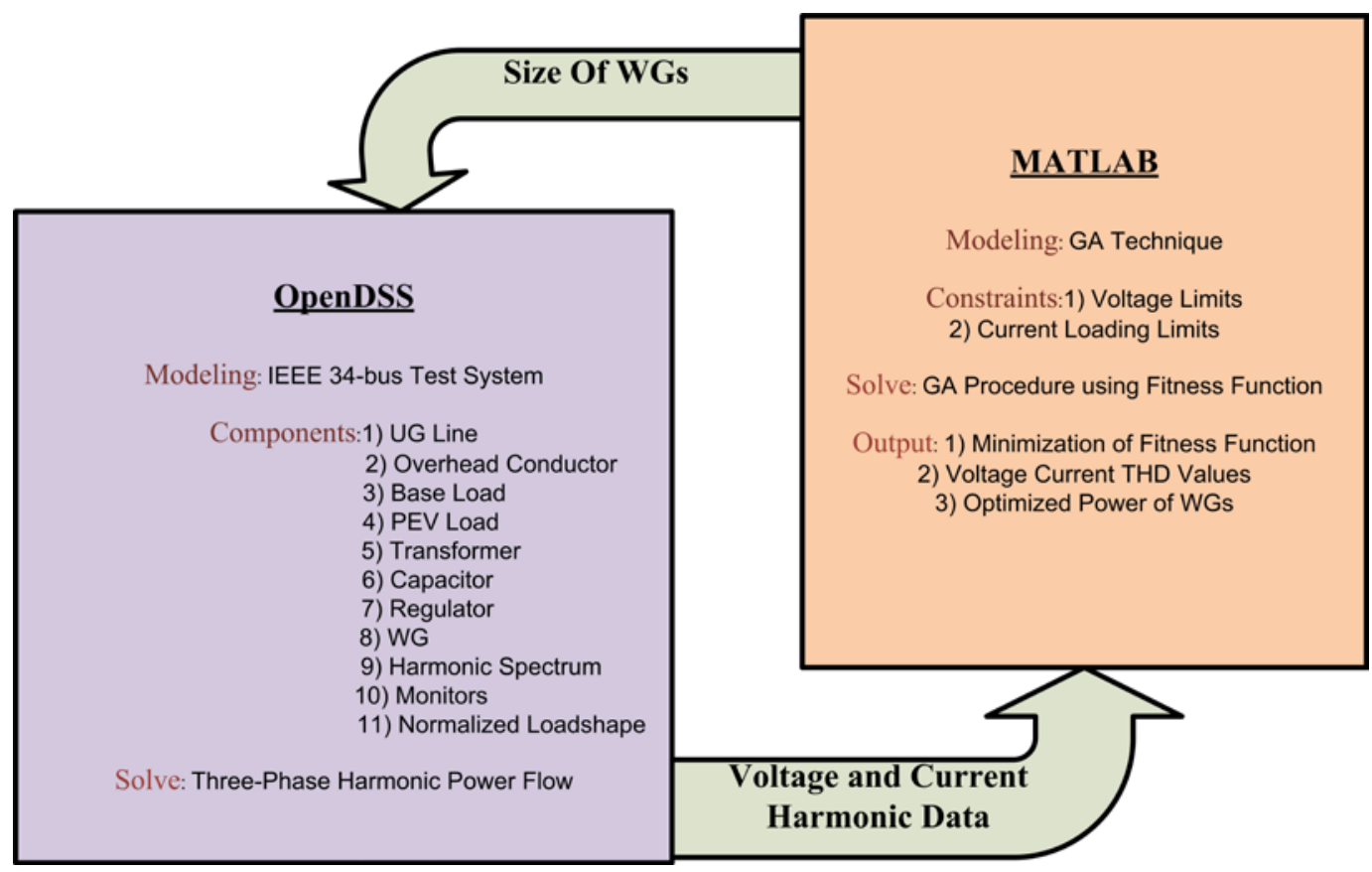

Figure 4.1 Com Interface between OpenDSS and MATLAB.

These extracted data is then used in the MATLAB code to solve optimization using GA. In the end, the optimally sized WG output power and minimization of voltage and current THDs have been obtained. 


\subsection{Proposed Genetic Algorithm (GA) for Optimization}

A GA based method similar to the one discussed in Section 2.5 and Section 2.6 has been implemented to minimize the voltage and current THD deviation. A brief overview of the generic GA based solution method has already been presented in the aforementioned sections. In Figure 4.2, the operational algorithm of the GA based technique has been shown for better understanding of the procedure. Though mainly the programming of GA has been done in MATLAB through the COM interface, OpenDSS has been called several times during this process.

The GA can be divided in four processes. These processes are following:

- Initial Population: A population pool of total 20 individual, with 34 variables in each individual is considered for each case. These individuals are the output power of the WGs, which are to be assigned in the OpenDSS through the help of COM interface. Each individual population is also considered as the feasible solution of the problem. With each individual or the WG output OpenDSS solves the three-phase harmonic flow to generate current and voltage harmonics for each individual lines and phases of the IEEE 34 node test feeder. For each iteration, these 34 variables should satisfy the pre-defined constraints: voltage limit and current loading limits. If not, then from the MATLAB, a random set of 34 values, which represents WG outputs should be send in the OpenDSS to investigate the feasibility condition. After the criteria check, each screened individual is stored in the initial population pool. Thus, the process has been iterated to develop a matrix of 20 rows and 34 columns, which is considered as the initial population pool, where row represents number of individuals and column represents number of variables. Each individual has been encoded into a binary number using 8 bits. These binary numbers are considered as chromosomes. 
- Fitness Function: The fitness function shown in (4.1) and (4.2) is used to evaluate the fitness of the initial population and offspring(s) that will subsequently be generated. Any offspring value that does not satisfy the constraints is going to yield a very high value in fitness function using penalty. Here, the fitness function is the cumulative THD deviation from the base case calculated for all the lines and phases. In both the equation $p$ and $m$ has been used to represent the phases and branches respectively.

$$
\begin{aligned}
& \text { Fitness (VoltageTHD) }=\sum_{m} \sum_{p}\left(T H D_{v_{m, p}}-1\right)^{2} \\
& \text { Fitness (Current THD) }=\sum_{m} \sum_{p}\left(T H D_{i_{m, p}}-1\right)^{2}
\end{aligned}
$$

- Generation: The GA method is implemented for 1000 generations.

- Constraints: The fitness function is evaluated in the presence of both linear and non-linear constraints. In case of linear constraints as shown in (4.3) - (4.5) the line model, KCL equation and the load modeling described in Section 2.4 has been taken.

$$
\begin{gathered}
{\left[\begin{array}{l}
V_{l, s}^{h} \\
I_{l, s}^{h}
\end{array}\right]=\left[\begin{array}{ll}
A^{h} & B^{h} \\
C^{h} & D^{h}
\end{array}\right]\left[\begin{array}{c}
V_{l, r}^{h} \\
I_{l, r}^{h}
\end{array}\right]} \\
I_{w_{p, n}}^{h}+\sum_{\alpha} I_{p, l, r}^{h}=\sum_{\beta} I_{p, l, s}^{h}+\sum_{L} I_{p, l}^{h_{1}}+I_{e v_{p, n}}^{h_{2}} \\
\left|I_{p, L}^{h}\right|\left(\angle V_{p, L}^{h}-\angle I_{p, L}^{h}\right)=\left|I_{0 p, L}^{h}\right| \angle \theta_{p, L}^{h}
\end{gathered}
$$

For non-linear constraints, shown in (4.6) and (4.7), the voltage limits and the current loading limits of IEEE 34-node test system has been taken. For voltage limits IEEE ANSI standards has been taken. However, the value of the upper and lower bound of voltages has been relaxed for the solution space of the optimization problem. The $V_{\text {min }}$ have been kept as 0.75 p.u and $V_{\text {max }}$ is kept as 1.2 p.u. In case of current limits the ampacity of the conductor of the test system has been used. Here the value of $I_{\max }$ is 119 A. 


$$
\begin{gathered}
V_{\min } \leq V_{m, p} \leq V_{\max } \\
I_{m, p} \leq I_{\max }
\end{gathered}
$$

- Selection: The selection is a random process where from the population pool, two values would be selected. It is done from the encoded binary population pool. A probabilistic approach has been taken for this selection.

- Cross-over: A two point cross-over has been done between the parent chromosomes. It is done in after the 5 th bit to 8 th bit.

- Mutation: The mutation value is kept constant as 0.07. A random number is generated and compared with this value and if the random number is equal to or less than the mutation probability, then the bits in the chromosomes are flipped.

- Offspring(s): Two sets of offspring(s) will be born from the parent(s). Each offspring is an array of 34 values, which are basically the WG outputs. The OpenDSS will again solve three-phase harmonic power flow to obtain the current and voltage harmonic value for each offspring. If the voltage and current constraints are satisfied then the fitness function will be calculated for these offspring(s).

- Comparison and Update: In this part a comparison criteria between the fitness of parent(s) and offspring(s) would be set and if the criteria is successfully met then the parent values get replaced by the offspring values. As the main focus of this GA is minimization, if the fitness of the offspring(s) is lesser than the fitness of the parent(s), then it is deemed to have better fitness and the parent(s) from the pool will get replaced by the offspring(s). 


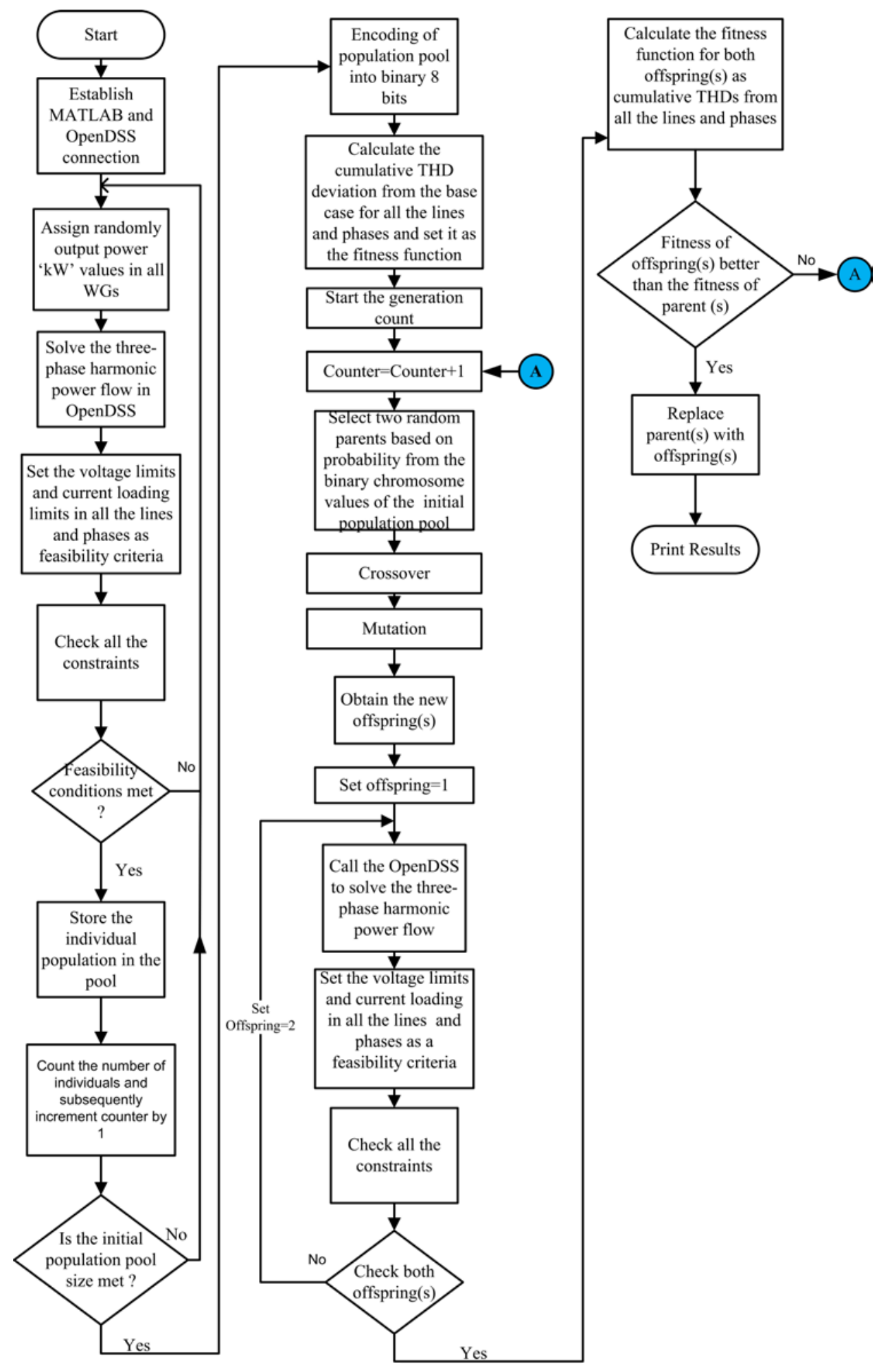

Figure 4.2: Operational Flowchart of GA. 


\subsection{Case Studies}

In this section, three different case studies have been presented with varying level of penetration. As it was discussed in the last chapter, three different penetration levels are: $30 \%$ (low), 50\% (moderate), and 100\% (high).

\subsubsection{Low PEV Penetration}

In all the nodes of the IEEE 34 node test system, a WG is connected. For this case study, in low PEV penetration which is $30 \%$, the GA has been applied to determine the optimal size of WGs at all the nodes, while reducing the THD values. The output power of the optimally sized WGs has been determined in $\mathrm{kW}$ as shown in Table 4.2. Also in Table 4.1 THD of phase to phase voltages of some selected branches has been shown. In Figure 4.3, the characteristics of the GA fitness function have been shown. The minimization of the cumulative voltage THDs is depicted in Figure 4.3. The fitness function has been defined by percentage value.

Table 4.1: THD of Phase to Phase Voltages for Low PEV Penetration.

\begin{tabular}{|c|c|c|c|}
\hline Branch & THD $\boldsymbol{V}_{\boldsymbol{a b}}(\mathbf{\%})$ & $\mathbf{T H D} \boldsymbol{V}_{\boldsymbol{b c}} \mathbf{( \% )}$ & $\mathbf{T H D} \boldsymbol{V}_{\boldsymbol{c a}}(\mathbf{\%})$ \\
\hline $844-846$ & 2.39 & 2.96 & 2.92 \\
\hline $828-830$ & 1.57 & 2.04 & 1.88 \\
\hline $808-806$ & 0.13 & 0.15 & 0.14 \\
\hline $834-860$ & 2.35 & 2.9 & 2.86 \\
\hline
\end{tabular}

From Table 4.1, it can be seen that the THDs of phase to phase voltages after the GA enabled optimization is less than $5 \%$ which is the standard limit set by the IEEE [77]. 
Table 4.2: Optimal WG Size for Voltage THDs in Low PEV Penetration.

\begin{tabular}{|c|c|c|c|c|c|c|c|c|c|}
\hline Node & $\begin{array}{c}\text { WG } \\
\mathbf{( k W )}\end{array}$ & Node & $\begin{array}{c}\text { WG } \\
\mathbf{( k W})\end{array}$ & Node & $\begin{array}{c}\text { WG } \\
\mathbf{( k W )}\end{array}$ & $\mathbf{N o d e}$ & $\begin{array}{c}\text { WG } \\
\mathbf{( k W )}\end{array}$ & Node & $\begin{array}{c}\text { WG } \\
\mathbf{( k W )}\end{array}$ \\
\hline 1 & 254.9 & 8 & 490.2 & 15 & 176.47 & 22 & 58.82 & 29 & 950.98 \\
\hline 2 & 372.55 & 9 & 1205.8 & 16 & 352.94 & 23 & 264.7 & 30 & 2323.5 \\
\hline 3 & 2450.98 & 10 & 950.98 & 17 & 88.24 & 24 & 617.65 & 31 & 1568.6 \\
\hline 4 & 303.92 & 11 & 715.69 & 18 & 1568.83 & 25 & 245.1 & 32 & 2294.1 \\
\hline 5 & 519.61 & 12 & 19.61 & 19 & 1833.33 & 26 & 2480.4 & 33 & 137.25 \\
\hline 6 & 215.69 & 13 & 1450.9 & 20 & 833.33 & 27 & 1950.9 & 34 & 2490.2 \\
\hline 7 & 1862.75 & 14 & 156.86 & 21 & 215.69 & 28 & 1382.3 & & \\
\hline
\end{tabular}

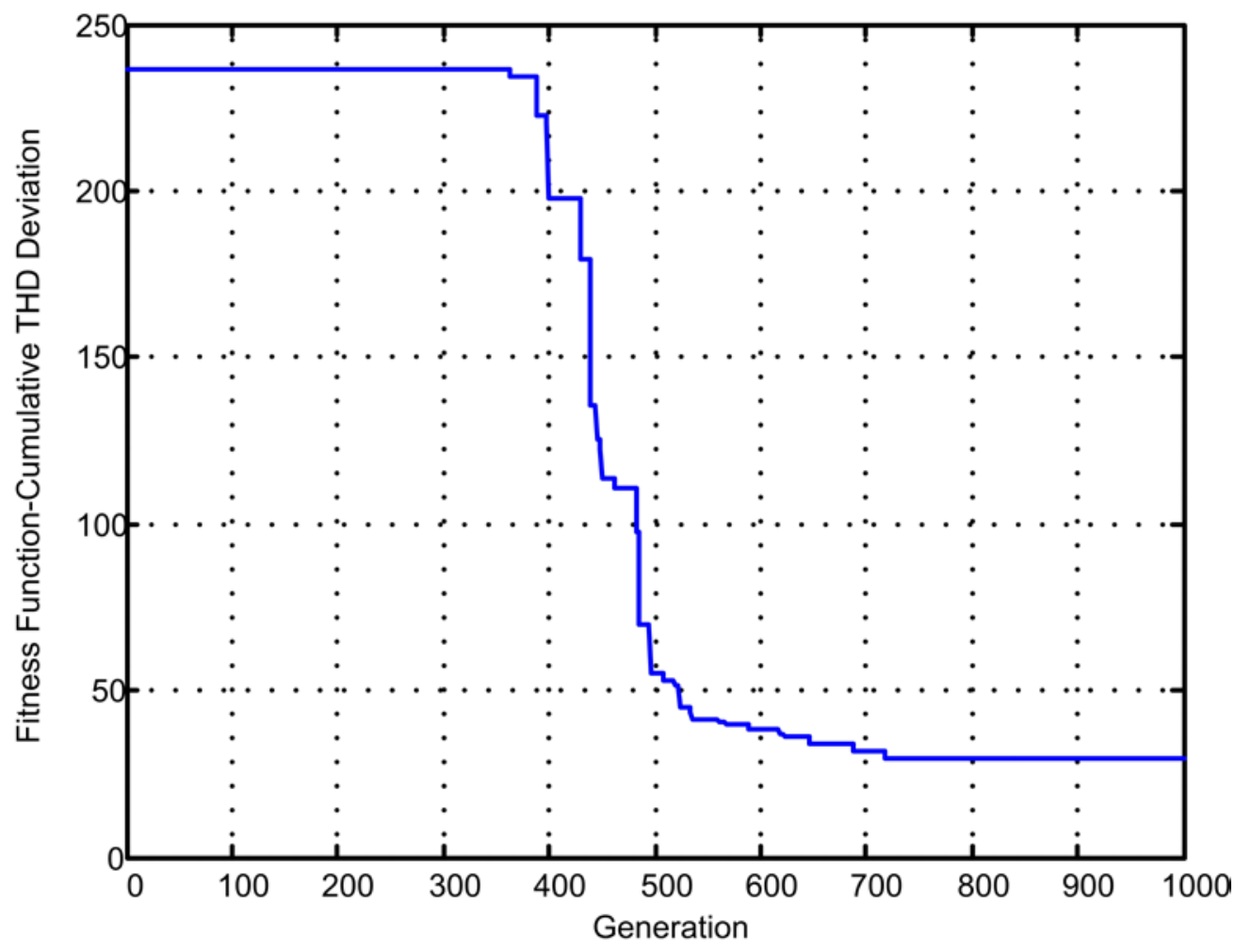

Figure 4.3: Minimization of Voltage THDs for Low PEV Penetration using GA.

A similar kind of approach has been taken for the minimization of current THDs. In Table 4.3 and Table 4.4, the line current THD values and the optimal size of the WGs 
are shown respectively. Also in Figure 4.4, the GA plot for minimizing the current THDs have been shown. The line current THD values of the selected branches in Table 4.3, are also below IEEE standard limit of 7\% [77].

Table 4.3: THD of Line Currents for Low PEV Penetration.

\begin{tabular}{|c|c|c|c|}
\hline Branch & THD $\boldsymbol{I}_{\boldsymbol{a}} \mathbf{( \% )}$ & ${\text { THD } \boldsymbol{I}_{\boldsymbol{b}} \mathbf{( \% )}}^{\mathbf{T}} \mathbf{\text { THD } \boldsymbol { I } _ { \boldsymbol { c } } \mathbf { ( \% ) }}$ \\
\hline $844-846$ & 3.33 & 3.42 & 3.91 \\
\hline $828-830$ & 1.08 & 1.07 & 1.22 \\
\hline $808-806$ & 0.37 & 0.34 & 0.42 \\
\hline $834-860$ & 2.83 & 2.42 & 2.96 \\
\hline
\end{tabular}

Table 4.4: Optimal WG Size for Current THDs in Low PEV Penetration.

\begin{tabular}{|c|c|c|c|c|c|c|c|c|c|}
\hline Node & $\begin{array}{c}\mathbf{W G} \\
\mathbf{( k W )}\end{array}$ & Node & $\begin{array}{c}\mathbf{W G} \\
\mathbf{( k W )}\end{array}$ & Node & $\begin{array}{c}\text { WG } \\
\mathbf{( k W )}\end{array}$ & Node & $\begin{array}{c}\text { WG } \\
\mathbf{( k W )}\end{array}$ & Node & $\begin{array}{c}\text { WG } \\
\mathbf{( k W )}\end{array}$ \\
\hline 1 & 655.69 & 8 & 436.08 & 15 & 800 & 22 & 781.18 & 29 & 781.18 \\
\hline 2 & 800 & 9 & 787.45 & 16 & 737.25 & 23 & 724.71 & 30 & 730.98 \\
\hline 3 & 420.39 & 10 & 410.98 & 17 & 765.49 & 24 & 727.84 & 31 & 178.82 \\
\hline 4 & 643.14 & 11 & 740.39 & 18 & 633.73 & 25 & 687.06 & 32 & 169.41 \\
\hline 5 & 78.43 & 12 & 730.98 & 19 & 746.67 & 26 & 3.14 & 33 & 90.98 \\
\hline 6 & 718.43 & 13 & 665.1 & 20 & 715.29 & 27 & 407.84 & 34 & 18.82 \\
\hline 7 & 768.63 & 14 & 737.25 & 21 & 567.84 & 28 & 743.53 & & \\
\hline
\end{tabular}




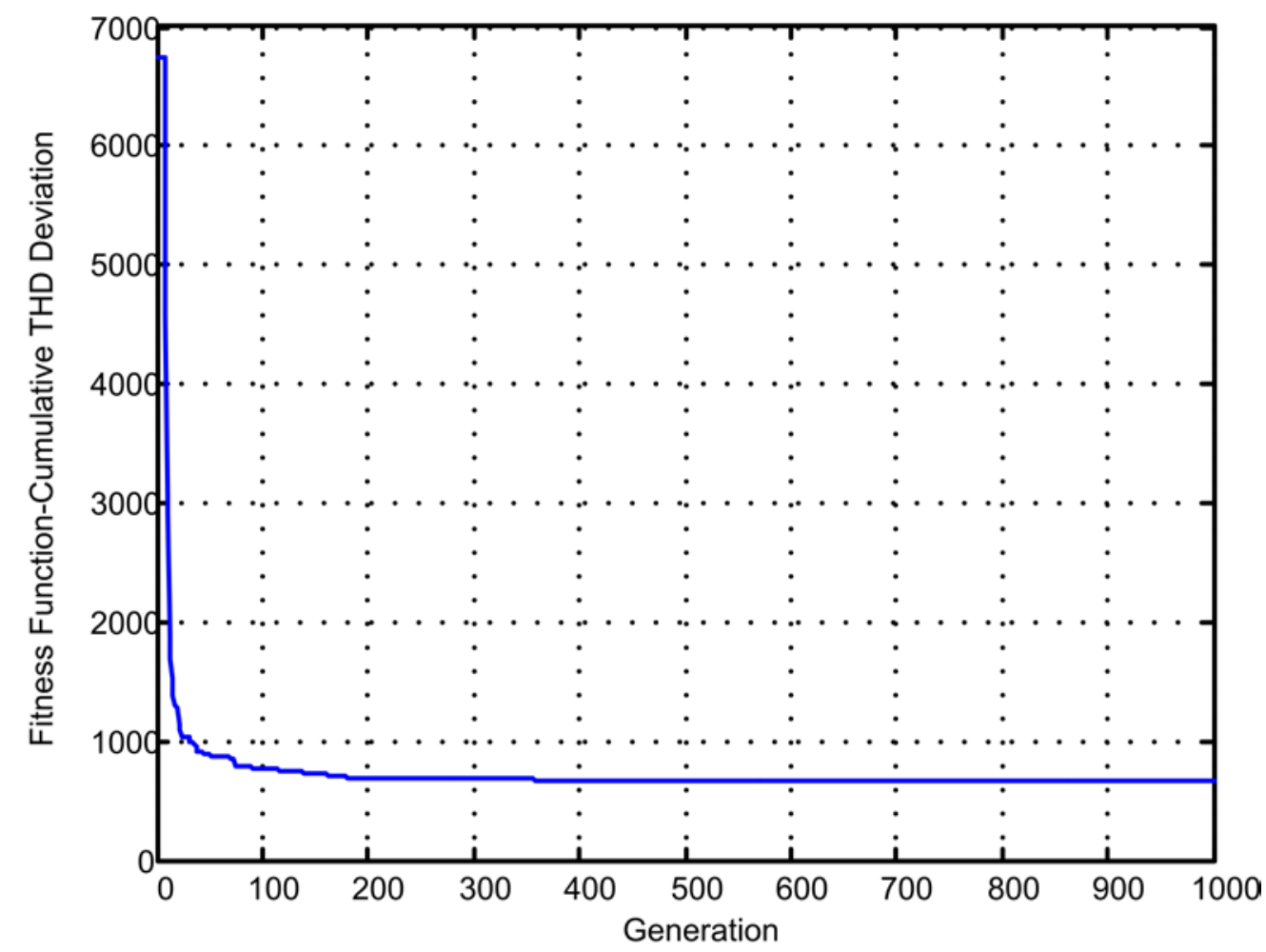

Figure 4.4: Minimization of Current THDs for Low PEV Penetration using GA.

\subsubsection{Moderate PEV Penetration}

In the second set of case study moderate PEV penetration, i. e. 50\% has been considered. The phase to phase voltage THD is in Table 4.5 for the selected lines. Similarly, in Table 4.6, the optimal size of WGs obtained after the implementation of GA has been shown. It can be seen that as the penetration level is increased, the GA has been able to limit the phase to phase voltage THD level within aforementioned limit of 5\% [77]. The performance of GA to minimize the cumulative THD is shown in Figure 4.5. 
Table 4.5: THD of Phase to Phase Voltages for Moderate PEV Penetration.

\begin{tabular}{|c|c|c|c|}
\hline Branch & THD $\boldsymbol{V}_{\boldsymbol{a} \boldsymbol{b}} \mathbf{( \% )}$ & ${\text { THD } \boldsymbol{V}_{\boldsymbol{b c}} \mathbf{( \% )}}^{\mathbf{T H D} \boldsymbol{V}_{\boldsymbol{c a}}(\mathbf{\%})}$ \\
\hline $844-846$ & 2.59 & 3.65 & 3.46 \\
\hline $828-830$ & 1.57 & 2.36 & 2.03 \\
\hline $808-806$ & 0.18 & 0.22 & 0.2 \\
\hline $834-860$ & 2.54 & 3.56 & 3.37 \\
\hline
\end{tabular}

Table 4.6: Optimal WG Size for Voltage THDs in Moderate PEV Penetration.

\begin{tabular}{|c|c|c|c|c|c|c|c|c|c|}
\hline Node & $\begin{array}{c}\text { WG } \\
\mathbf{( k W )}\end{array}$ & Node & $\begin{array}{c}\text { WG } \\
\mathbf{( k W )}\end{array}$ & Node & $\begin{array}{c}\text { WG } \\
\mathbf{( k W )}\end{array}$ & Node & $\begin{array}{c}\text { WG } \\
\mathbf{( k W )}\end{array}$ & Node & $\begin{array}{c}\text { WG } \\
\mathbf{( k W )}\end{array}$ \\
\hline 1 & 147.06 & 8 & 441.18 & 15 & 39.22 & 22 & 235.3 & 29 & 2049.02 \\
\hline 2 & 196.08 & 9 & 1490.2 & 16 & 529.41 & 23 & 333.33 & 30 & 2284.31 \\
\hline 3 & 352.94 & 10 & 1098.4 & 17 & 39.22 & 24 & 49.02 & 31 & 1039.22 \\
\hline 4 & 2225.5 & 11 & 205.88 & 18 & 2235.3 & 25 & 323.53 & 32 & 1774.51 \\
\hline 5 & 9.8 & 12 & 88.24 & 19 & 19.61 & 26 & 2313.73 & 33 & 509.8 \\
\hline 6 & 2323.53 & 13 & 1323.5 & 20 & 431.37 & 27 & 2303.92 & 34 & 2500 \\
\hline 7 & 284.31 & 14 & 294.1 & 21 & 774.57 & 28 & 1588.82 & & \\
\hline
\end{tabular}




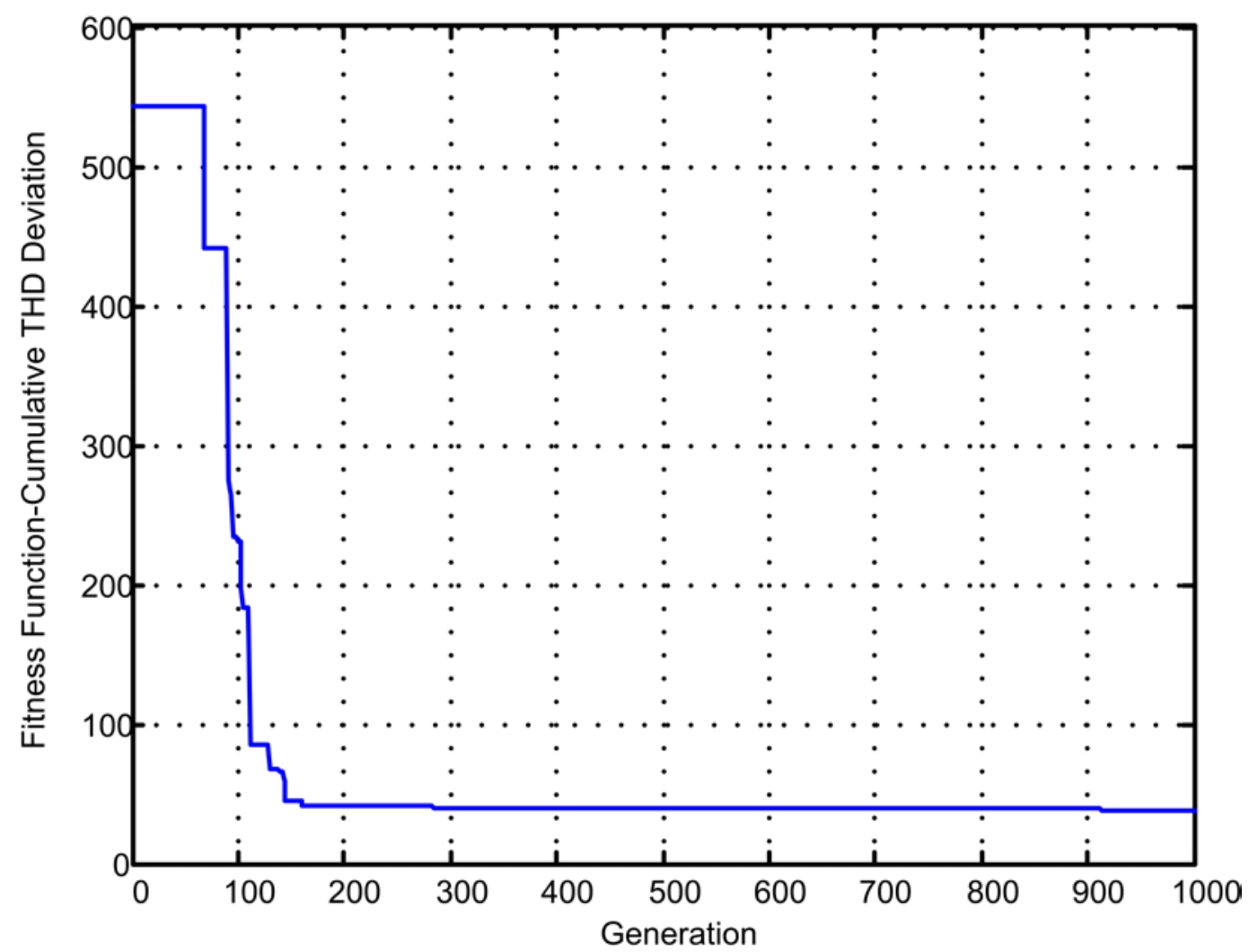

Figure 4.5: Minimization of Voltage THDs for Moderate PEV Penetration using GA. The results for current THD minimization are shown in Table 4.7 and 4.8. In Figure 4.6, the GA plot for minimizing the current THDs is shown. In case of the current THDs, all the values are under the desired limit of 7\% [77].

Table 4.7: THD of Line Currents for Moderate PEV Penetration.

\begin{tabular}{|c|c|c|c|}
\hline Branch & ${\text { THD } \boldsymbol{I}_{\boldsymbol{a}} \mathbf{( \% )}}^{\mathbf{T}}{\text { THD } \boldsymbol{I}_{\boldsymbol{b}} \mathbf{( \% )}}^{\text {THD } \boldsymbol{I}_{\boldsymbol{c}} \mathbf{( \% )}}$ \\
\hline $844-846$ & 3.47 & 3.62 & 4.3 \\
\hline $828-830$ & 0.87 & 0.88 & 1.05 \\
\hline $808-806$ & 0.5 & 0.47 & 0.57 \\
\hline $834-860$ & 3.36 & 2.81 & 3.73 \\
\hline
\end{tabular}


Table 4.8: Optimal WG Size for Current THDs in Moderate PEV Penetration.

\begin{tabular}{|c|c|c|c|c|c|c|c|c|c|}
\hline Node & $\begin{array}{c}\mathbf{W G} \\
\mathbf{( k W})\end{array}$ & Node & $\begin{array}{c}\text { WG } \\
\mathbf{( k W})\end{array}$ & Node & $\begin{array}{c}\mathbf{W G} \\
\mathbf{( k W )}\end{array}$ & $\mathbf{N o d e}$ & $\begin{array}{c}\text { WG } \\
\mathbf{( k W )}\end{array}$ & Node & $\begin{array}{c}\text { WG } \\
\mathbf{( k W )}\end{array}$ \\
\hline 1 & 627.45 & 8 & 250.98 & 15 & 800 & 22 & 756.08 & 29 & 194.51 \\
\hline 2 & 796.86 & 9 & 485.04 & 16 & 800 & 23 & 752.94 & 30 & 370.2 \\
\hline 3 & 269.8 & 10 & 31.37 & 17 & 793.73 & 24 & 539.61 & 31 & 272.94 \\
\hline 4 & 260.39 & 11 & 589.8 & 18 & 3.14 & 25 & 778.04 & 32 & 272.94 \\
\hline 5 & 31.37 & 12 & 771.76 & 19 & 448.63 & 26 & 3.14 & 33 & 285.49 \\
\hline 6 & 429.8 & 13 & 84.71 & 20 & 800 & 27 & 373.33 & 34 & 3.14 \\
\hline 7 & 762.35 & 14 & 762.35 & 21 & 285.49 & 28 & 3.14 & & \\
\hline
\end{tabular}

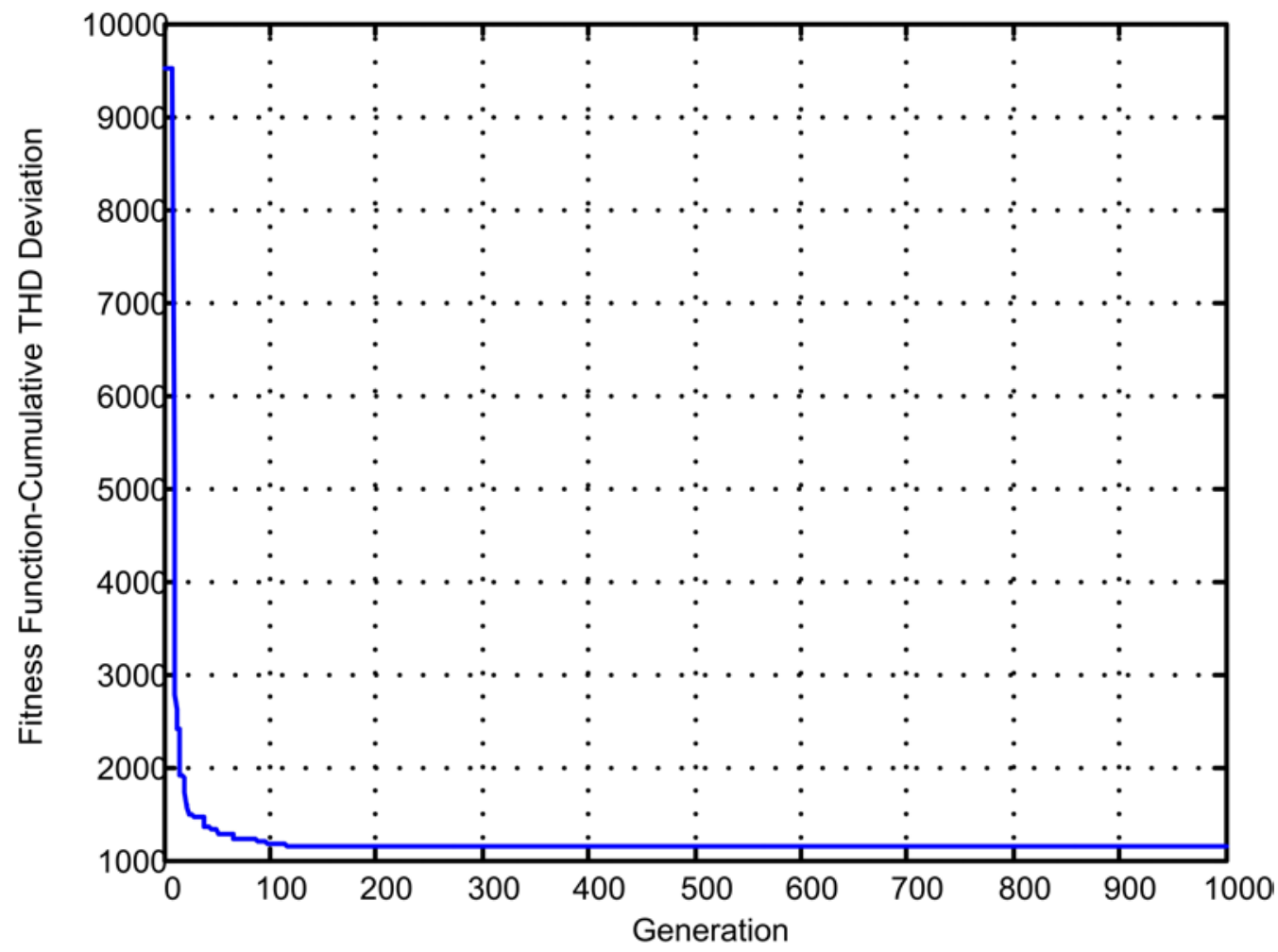

Figure 4.6: Minimization of Current THDs for Moderate PEV Penetration using GA. 


\subsubsection{High PEV Penetration}

In the last study, high penetration level of PEVs has been considered which is $100 \%$. The increase of the harmonics for unmitigated cases has been shown in Chapter 3, Section 3.5.3 in Case 13 and Case 16. Through the implementation of GA, voltage harmonics have been suppressed below 5\% in all branches. Table 4.9 and Table 4.10 , represent THD of phase to phase voltages and optimal size of WGs. Figure 4.7, shows the performance of GA method. It can be seen that initial cumulative voltage/current cumulative THD deviation is higher than the previous case, but with successive

Table 4.9: THD of Phase to Phase Voltages for High PEV Penetration.

\begin{tabular}{|c|c|c|c|}
\hline Branch & THD $\boldsymbol{V}_{\boldsymbol{a b}}(\mathbf{\%})$ & THD $\boldsymbol{V}_{\boldsymbol{b c}}(\mathbf{\%})$ & THD $\boldsymbol{V}_{\boldsymbol{c a}}(\mathbf{\%})$ \\
\hline $844-846$ & 3.72 & 4.04 & 3.73 \\
\hline $828-830$ & 1.59 & 1.43 & 1.51 \\
\hline $808-806$ & 0.24 & 0.28 & 0.26 \\
\hline $834-860$ & 3.66 & 3.97 & 3.68 \\
\hline
\end{tabular}

Table 4.10: Optimal WG Size for Voltage THDs in High PEV Penetration.

\begin{tabular}{|c|c|c|c|c|c|c|c|c|c|}
\hline $\begin{array}{c}\text { Nod } \\
\mathbf{e}\end{array}$ & $\begin{array}{c}\text { WG } \\
\mathbf{( k W})\end{array}$ & Node & $\begin{array}{c}\text { WG } \\
\mathbf{( k W})\end{array}$ & Node & $\begin{array}{c}\text { WG } \\
\mathbf{( k W})\end{array}$ & Node & $\begin{array}{c}\text { WG } \\
\mathbf{( k W )}\end{array}$ & $\begin{array}{c}\text { Nod } \\
\mathbf{e}\end{array}$ & $\begin{array}{c}\text { WG } \\
\mathbf{( k W )}\end{array}$ \\
\hline 1 & 2245.1 & 8 & 1813.73 & 15 & 1186.27 & 22 & 2235.29 & 29 & 2421.5 \\
\hline 2 & 2264.7 & 9 & 2411.76 & 16 & 343.14 & 23 & 1196.08 & 30 & 2117.6 \\
\hline 3 & 2137.25 & 10 & 2470.59 & 17 & 2450.98 & 24 & 617.65 & 31 & 323.53 \\
\hline 4 & 1892.16 & 11 & 2460.78 & 18 & 1931.37 & 25 & 2215.69 & 32 & 990.2 \\
\hline 5 & 2127.45 & 12 & 2303.92 & 19 & 1803.92 & 26 & 19.61 & 33 & 254.9 \\
\hline 6 & 284.31 & 13 & 235.29 & 20 & 313.73 & 27 & 2245.1 & 34 & 196.8 \\
\hline 7 & 1666.6 & 14 & 1529.41 & 21 & 156.86 & 28 & 1725.5 & & \\
\hline
\end{tabular}


iterations the THDS will come down under the IEEE limits. However over a range of 1000 generations the THD deviation is minimized by almost $90 \%$.

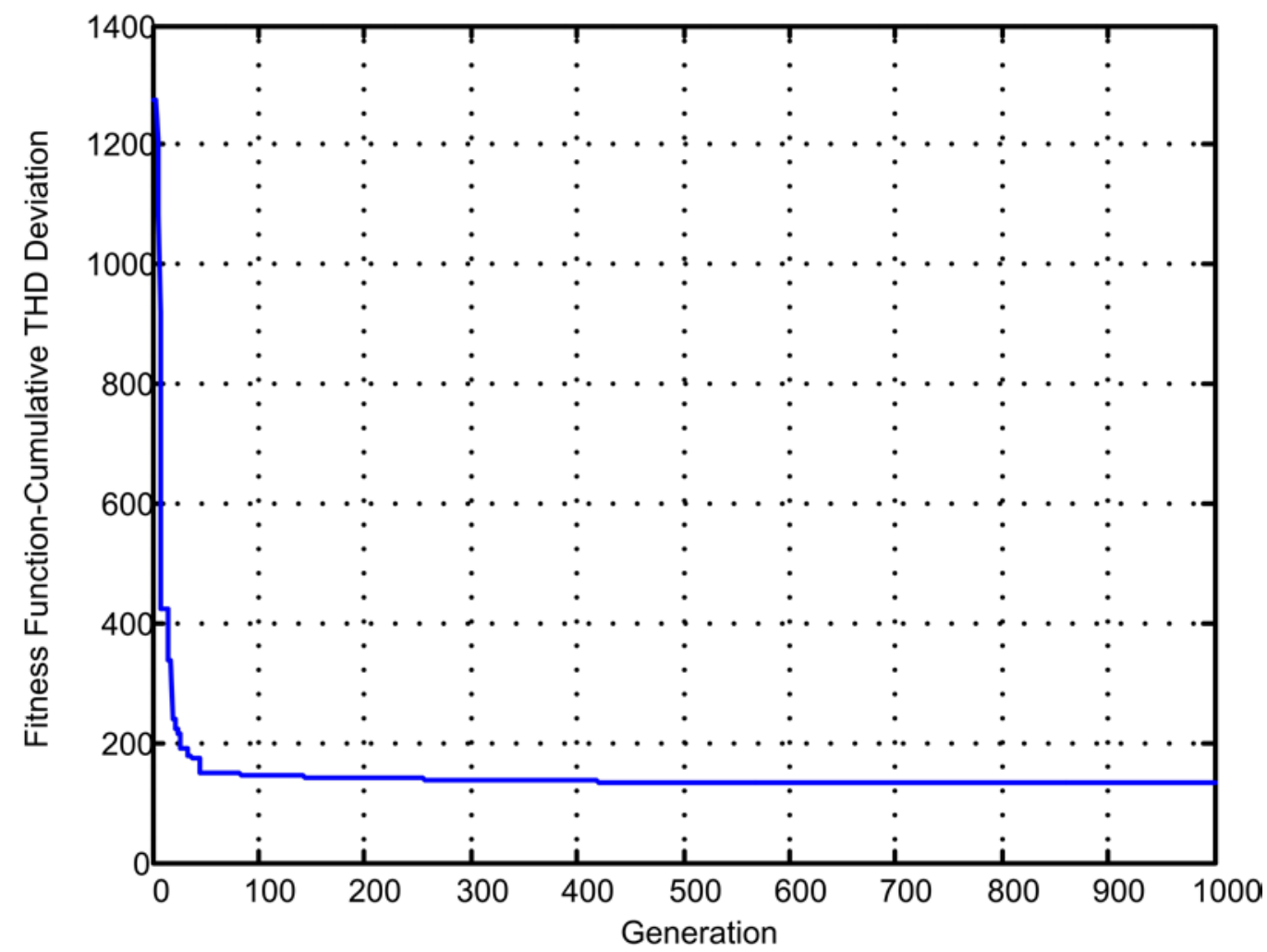

Figure 4.7: Minimization of Voltage THDs for High PEV Penetration using GA.

For the current THDs the performance of GA has been shown in Figure 4.8. The minimized THD values of currents in selected branches have been presented in Table 4.11. Also the optimal size of WGs is given in Table 4.12. It can be seen the THDs in all the monitored branches are less than 7\%. In Figure 4.8 the cumulative current THD deviation has been reduced by almost $83 \%$ over the range of 1000 iterations. 
Table 4.11: THD of Line Currents for High PEV Penetration.

\begin{tabular}{|c|c|c|c|}
\hline Branch & THD $I_{a}(\%)$ & THD $I_{b}(\%)$ & THD $I_{c}(\%)$ \\
\hline $844-846$ & 3.89 & 4.24 & 5.27 \\
\hline $828-830$ & 0.72 & 0.69 & 0.93 \\
\hline $808-806$ & 0.67 & 0.65 & 0.82 \\
\hline $834-860$ & 4.33 & 3.59 & 5.14 \\
\hline
\end{tabular}

Table 4.12: Optimal WG Size for Current THDs in High PEV Penetration.

\begin{tabular}{|c|c|c|c|c|c|c|c|c|c|}
\hline Node & $\begin{array}{c}\mathbf{W G} \\
\mathbf{( k W})\end{array}$ & Node & $\begin{array}{c}\mathbf{W G} \\
\mathbf{( k W})\end{array}$ & Node & $\begin{array}{c}\text { WG } \\
\mathbf{( k W )}\end{array}$ & Node & $\begin{array}{c}\text { WG } \\
\mathbf{( k W )}\end{array}$ & Node & $\begin{array}{c}\text { WG } \\
\mathbf{( k W )}\end{array}$ \\
\hline 1 & 756.08 & 8 & 473.73 & 15 & 784.31 & 22 & 800 & 29 & 72.16 \\
\hline 2 & 800 & 9 & 78.43 & 16 & 774.9 & 23 & 771.76 & 30 & 12.55 \\
\hline 3 & 128.63 & 10 & 279.22 & 17 & 498.82 & 24 & 683.92 & 31 & 624.31 \\
\hline 4 & 94.12 & 11 & 53.33 & 18 & 12.55 & 25 & 727.84 & 32 & 163.14 \\
\hline 5 & 329.41 & 12 & 539.61 & 19 & 134.9 & 26 & 6.27 & 33 & 320 \\
\hline 6 & 345.1 & 13 & 345.1 & 20 & 787.45 & 27 & 614.9 & 34 & 21.96 \\
\hline 7 & 263.53 & 14 & 800 & 21 & 699.61 & 28 & 498.82 & & \\
\hline
\end{tabular}




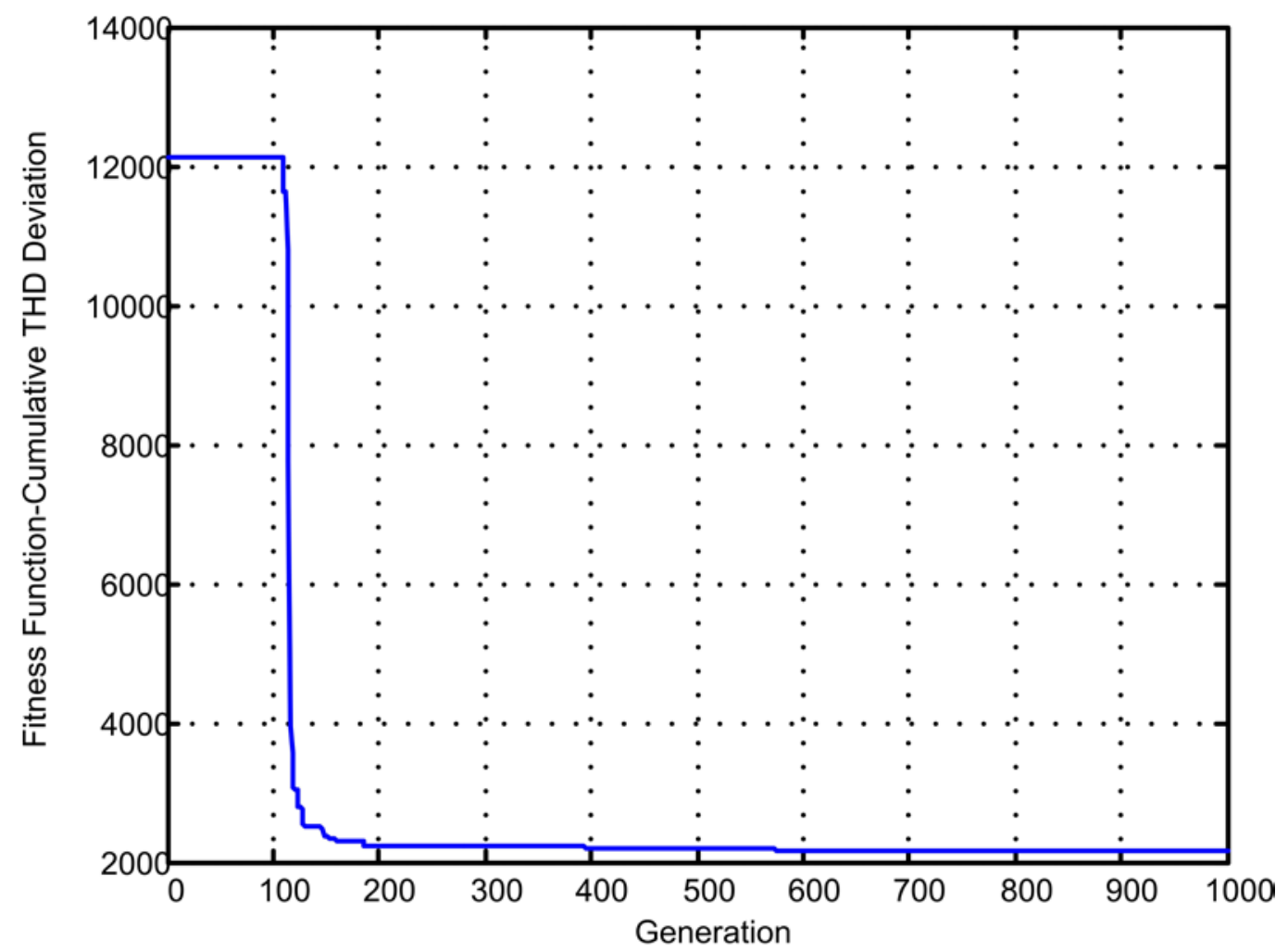

Figure 4.8: Minimization of Current THDs for High PEV Penetration using GA.

The case of high PEV penetration can be taken as the worst possible scenario as it will inject harmonics of highest magnitude. The grid network should be designed in such a way that it will able to handle the harmonics injected due to a $100 \%$ integration of PEVs into the grid. With this GA based technique, even in the presence of highest order of PEV loads, it can be seen from the Table 4.9 and Table 4.11 all the voltage and current harmonics are well below their respective limits prescribed by the IEEE [77].

A comparison can be drawn between Table 4.9 and Table 4.10, with Table 3.8 and Table 3.9 from Chapter 3 here to describe the usefulness of the GA based approach. In case of voltage THDs in Table 3.8, Case 15 after the introduction of WGs, the harmonics increased by approximately $10 \%$ and the values were still above the standard limit of voltage THDs i. e., 5\%. Similarly, in Table 3.9 in Chapter 3 Case 18, 
the current harmonics values were being changed abruptly and for certain phases the values were still above 7\% which is a violation of the IEEE standard of current THDs. However, with the proper implementation of GA based technique, in both Table 4.9 and Table 4.10 the voltage and current harmonics values are well below 5\% and 7\% respectively in all the phases and at all branches.

To represent the minimization of the voltage and current THDs over a certain number of iterations in the GA algorithm, change of the THDs over the iteration period has been plotted for the aforementioned branches. The change of voltage THDs has been shown in Figure 4.9, Figure 4.10, Figure 4.11, Figure 4.12 which respectively represent branch $844-846,828-830,808-806,834-860$. The current THD patterns for branch 844-846, 828-830, 808-806, 834-860 has been shown in Figure 4.13, Figure 4.14, Figure 4.15, Figure 4.16 respectively.

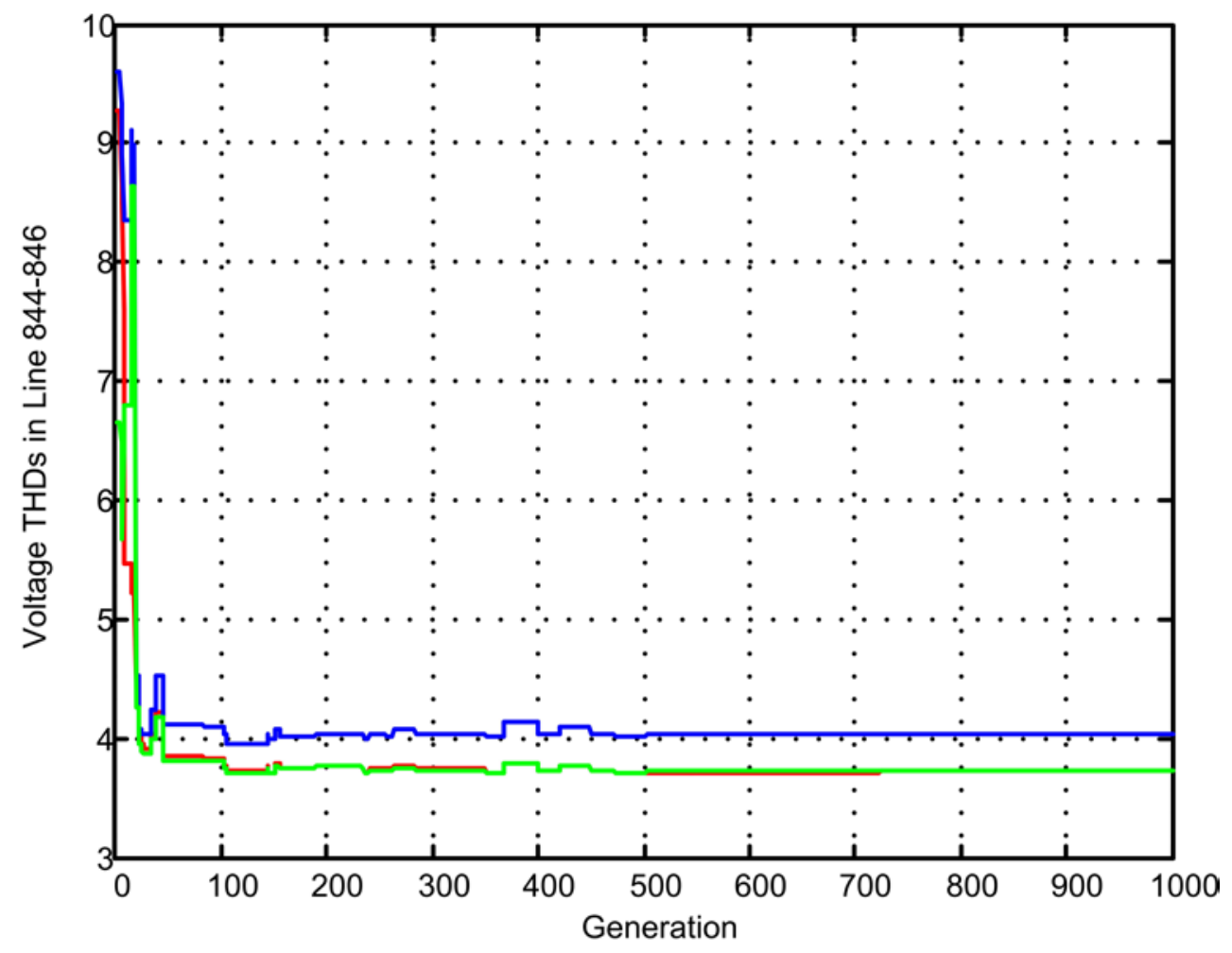

Figure 4.9: Change of Voltage THD in Line 844-846 for High PEV Penetration. 


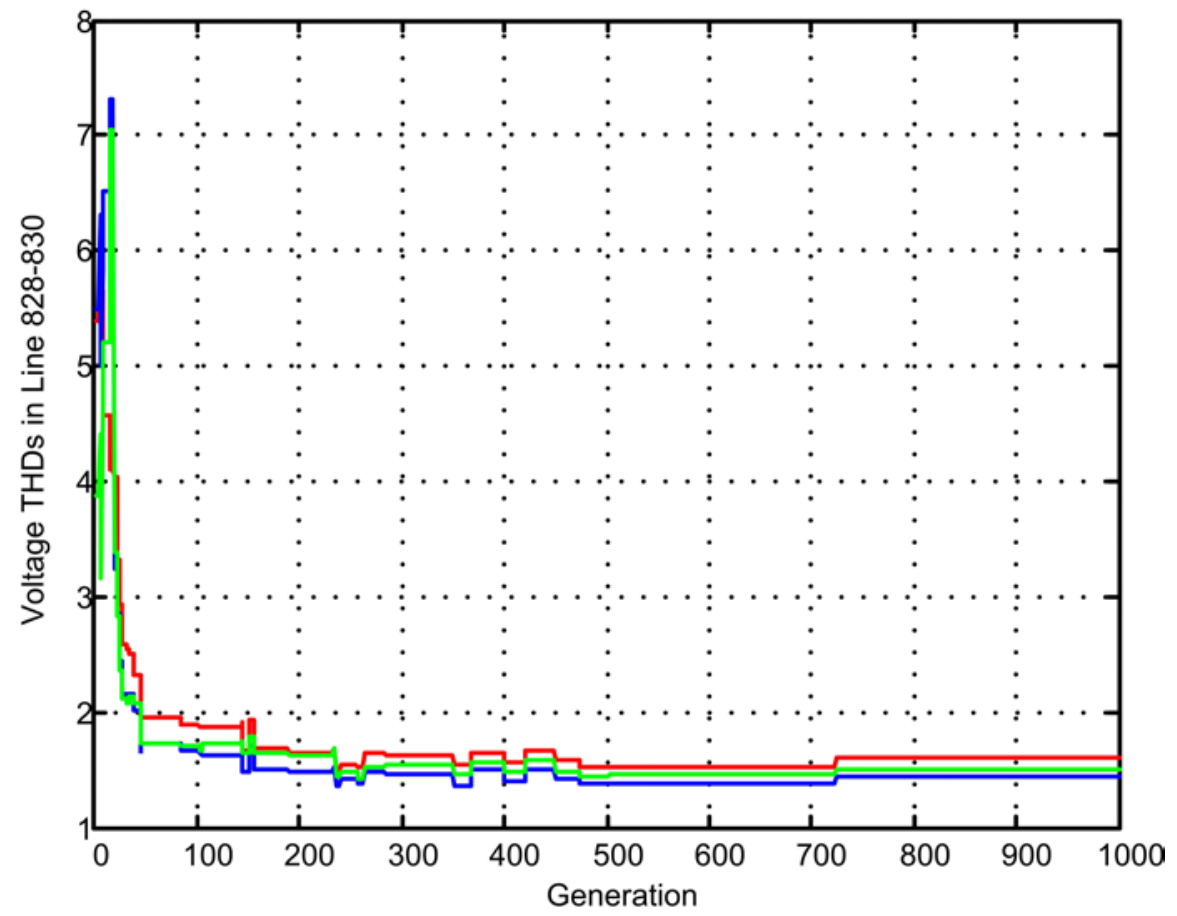

Figure 4.10: Change of Voltage THD in Line 828-830 for High PEV Penetration.

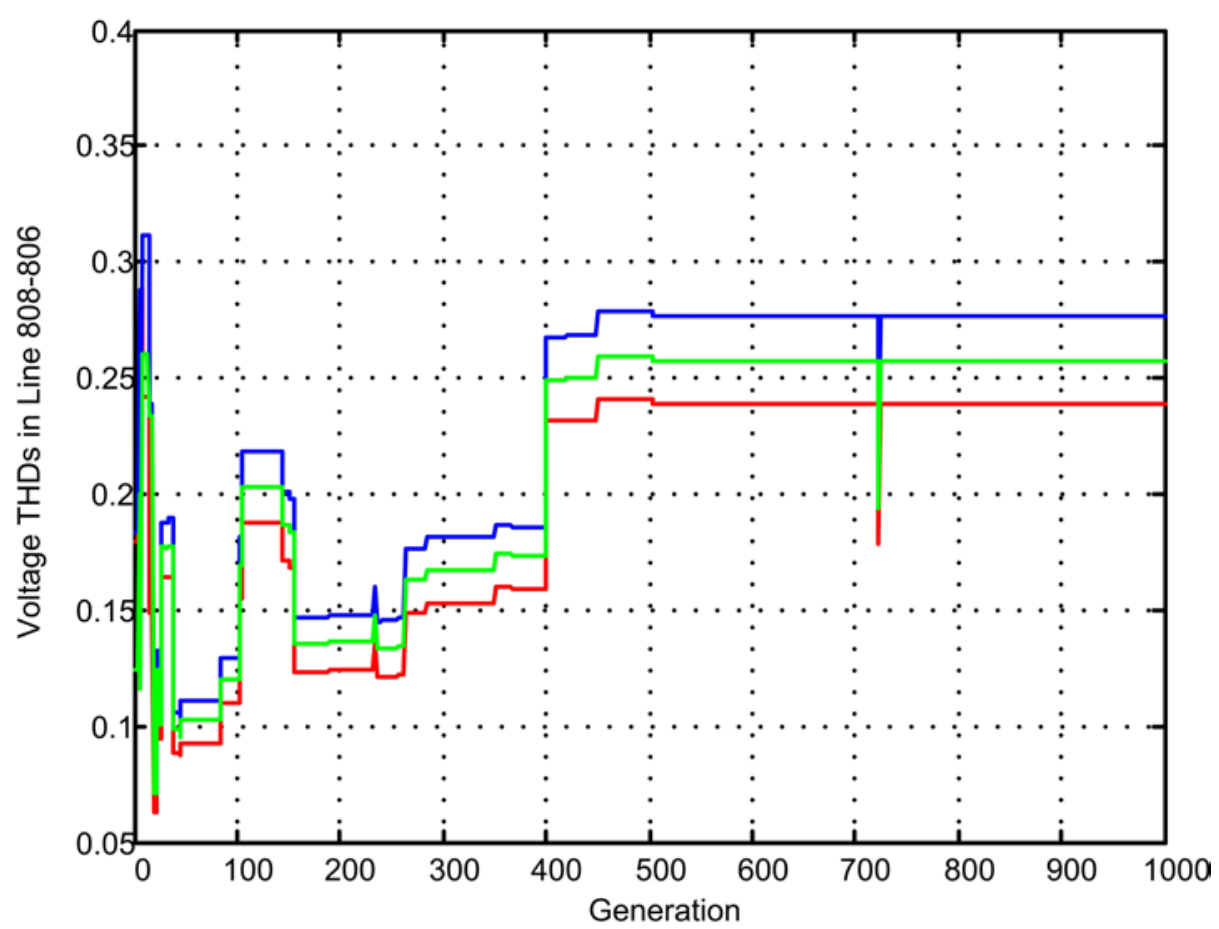

Figure 4.11: Change of Voltage THD in Line 808-806 for High PEV Penetration. 


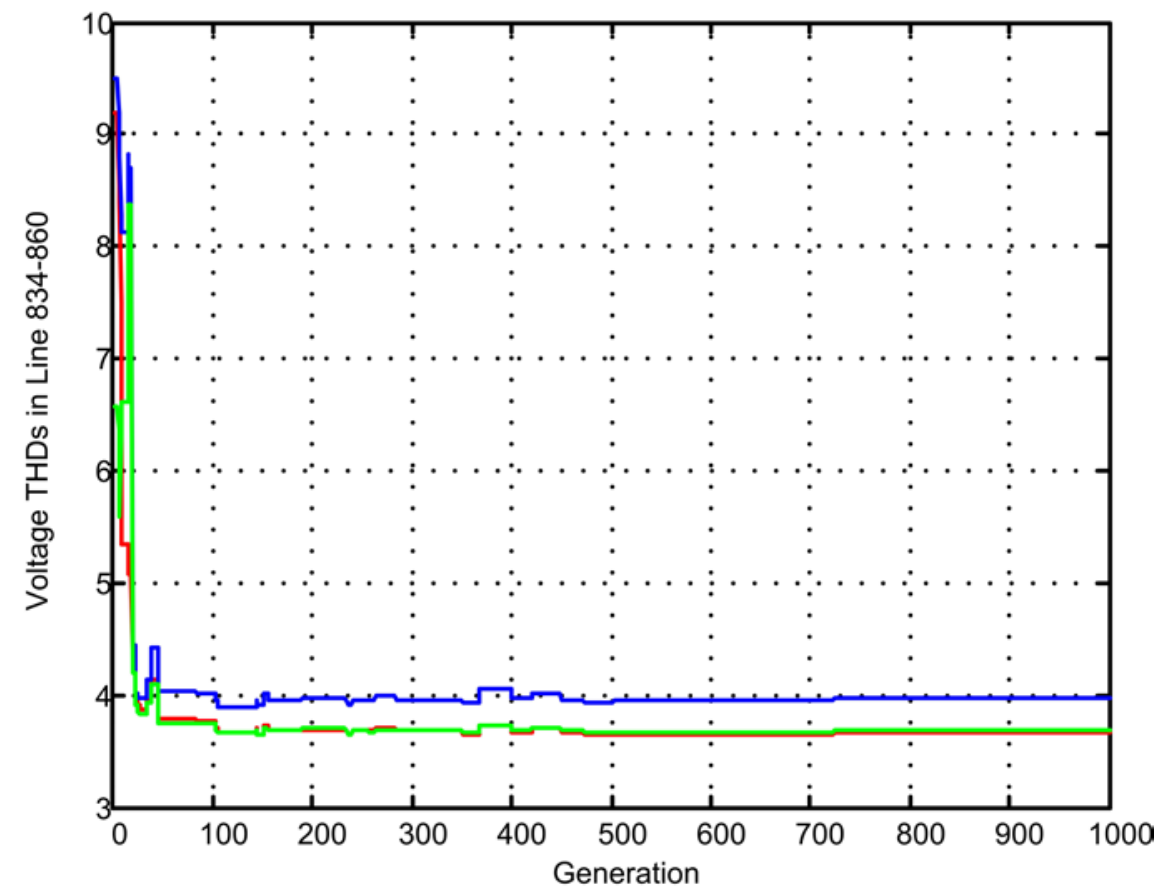

Figure 4.12: Change of Voltage THD in Line 834-860 for High PEV Penetration.

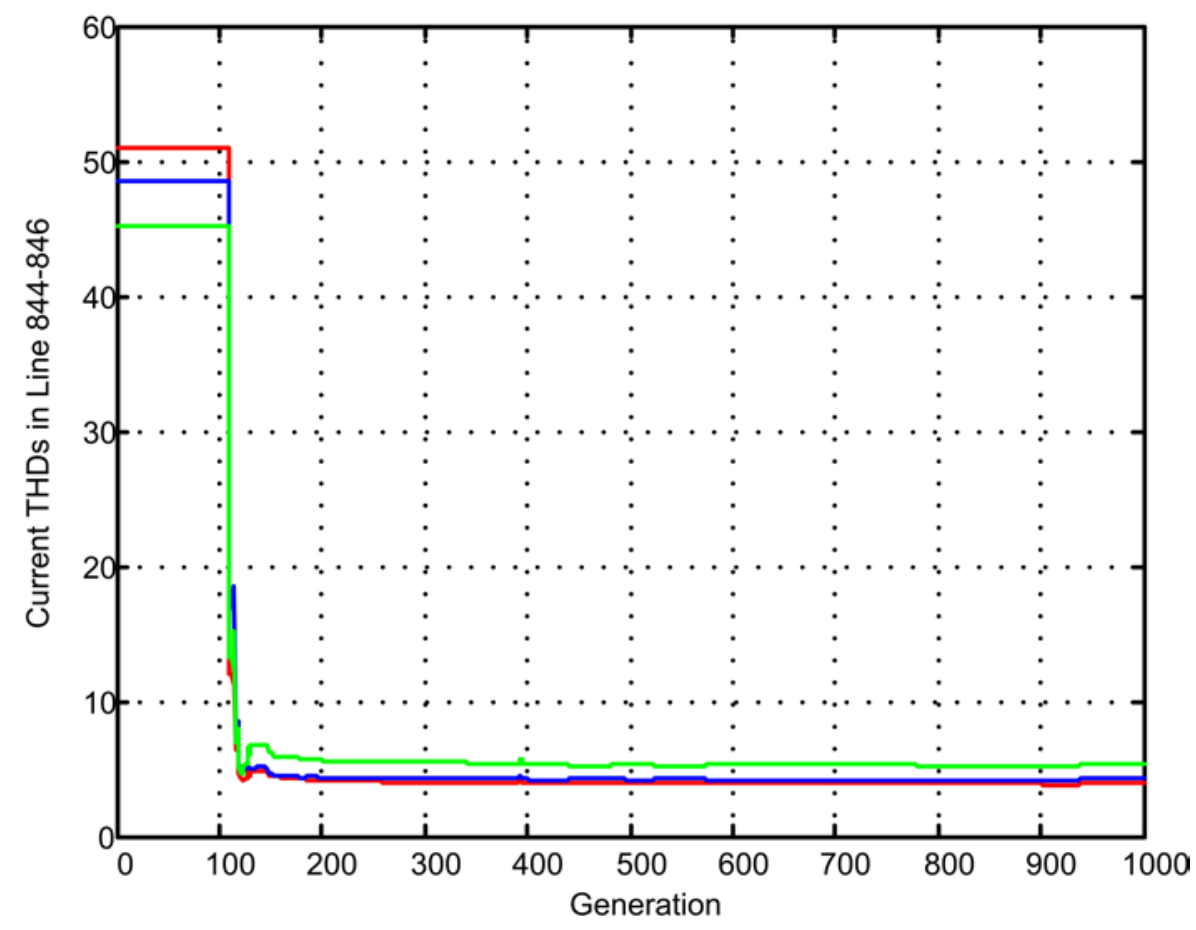

Figure 4.13: Change of Current THD in Line 844-846 for High PEV Penetration. 


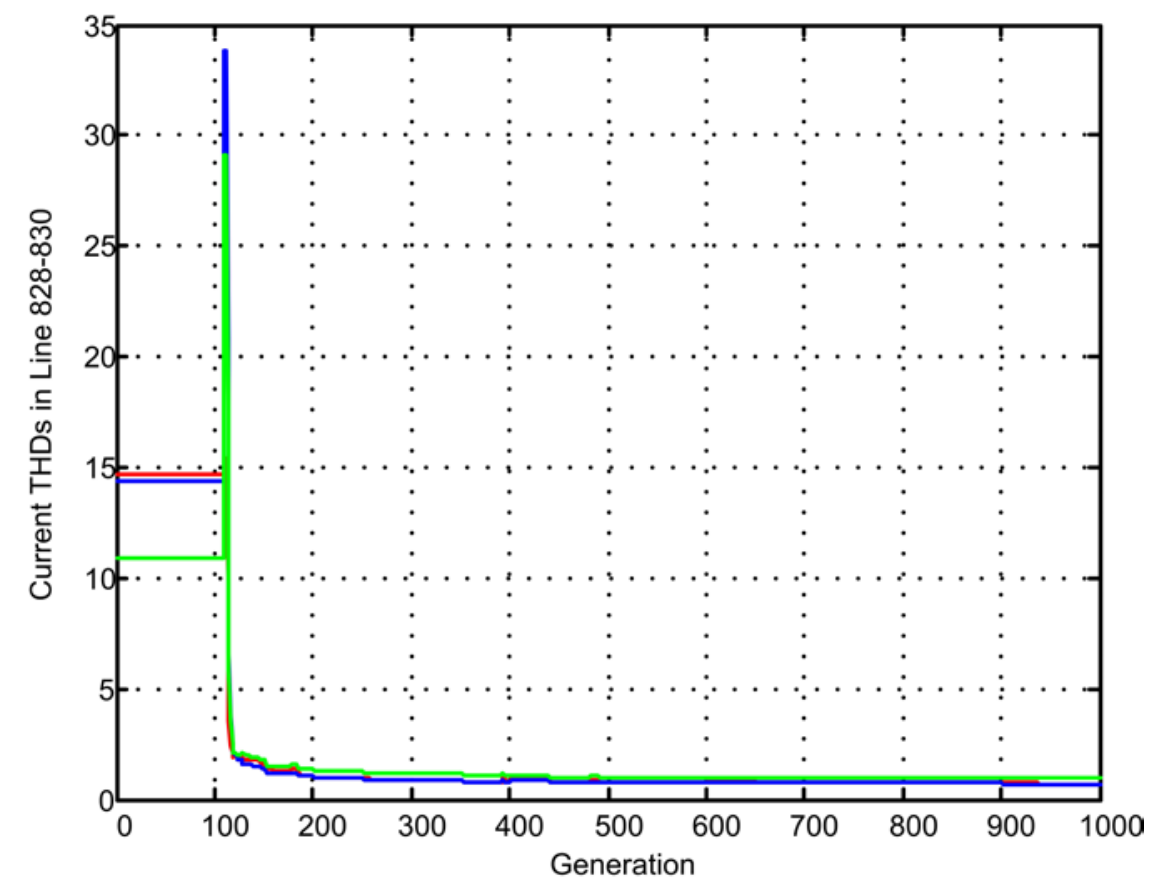

Figure 4.14: Change of Current THD in Line 828-830 for High PEV Penetration.

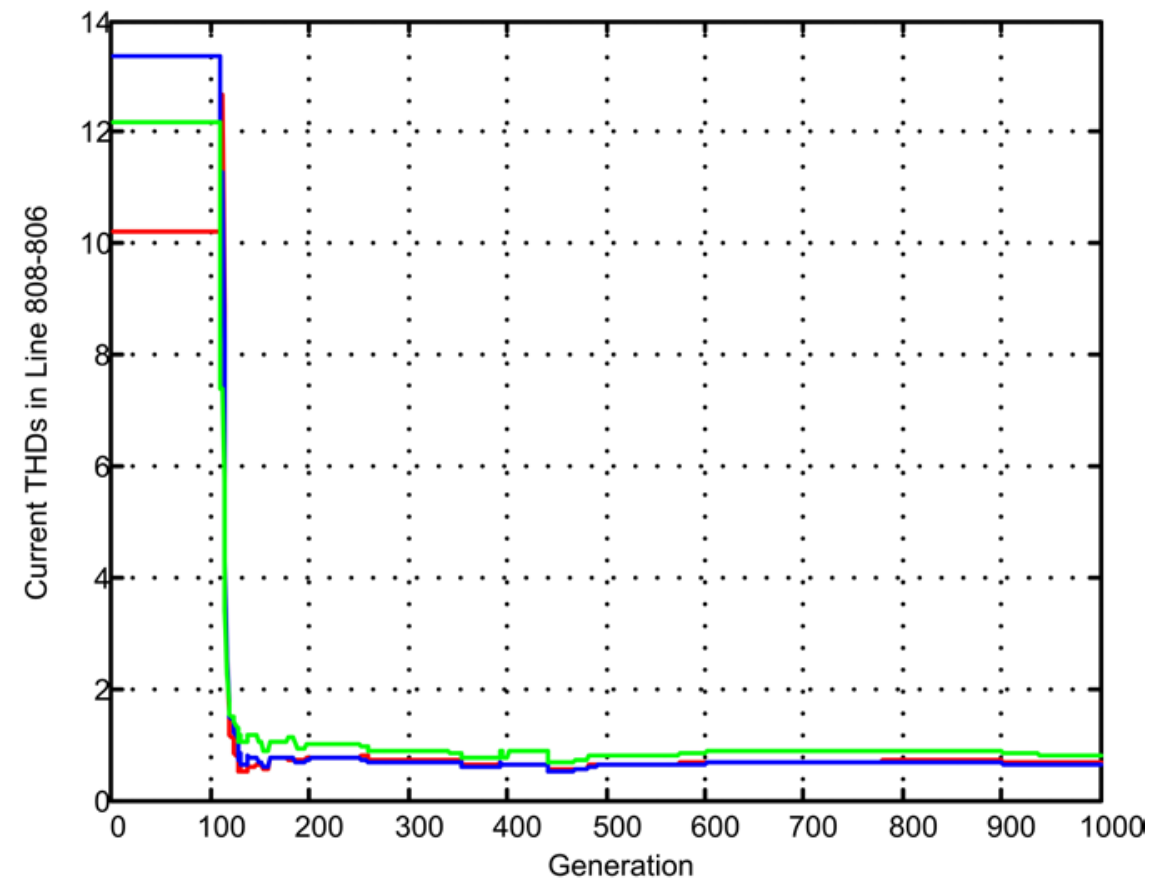

Figure 4.15: Change of Current THD in Line 808-806 for High PEV Penetration. 65 


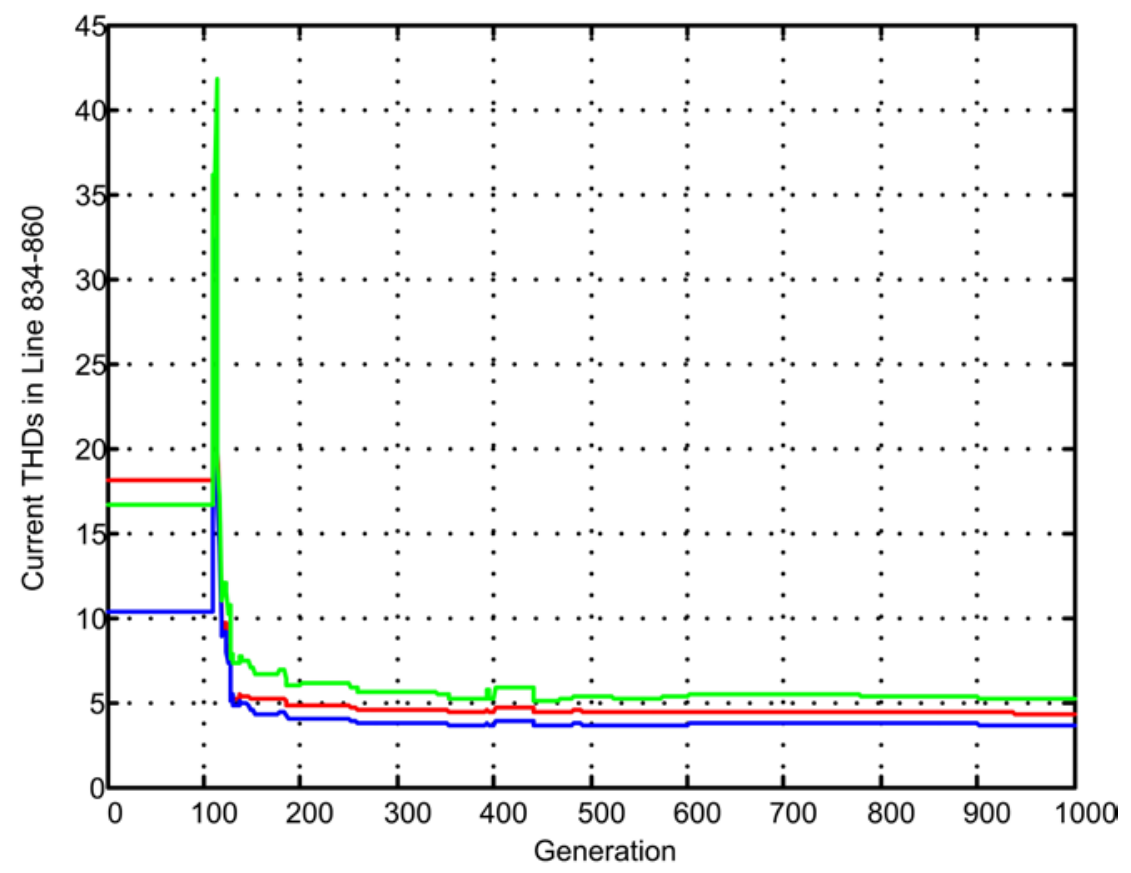

Figure 4.16: Change of Current THD in Line 834-860 for High PEV Penetration. In figure 4.17 and 4.18 the optimal WG values for voltage and current THD reduction is shown respectively, for high PEV penetration. The black dots are representing the nodes in the system. In the each box, the output of the connected WG with respective nodes are shown. 


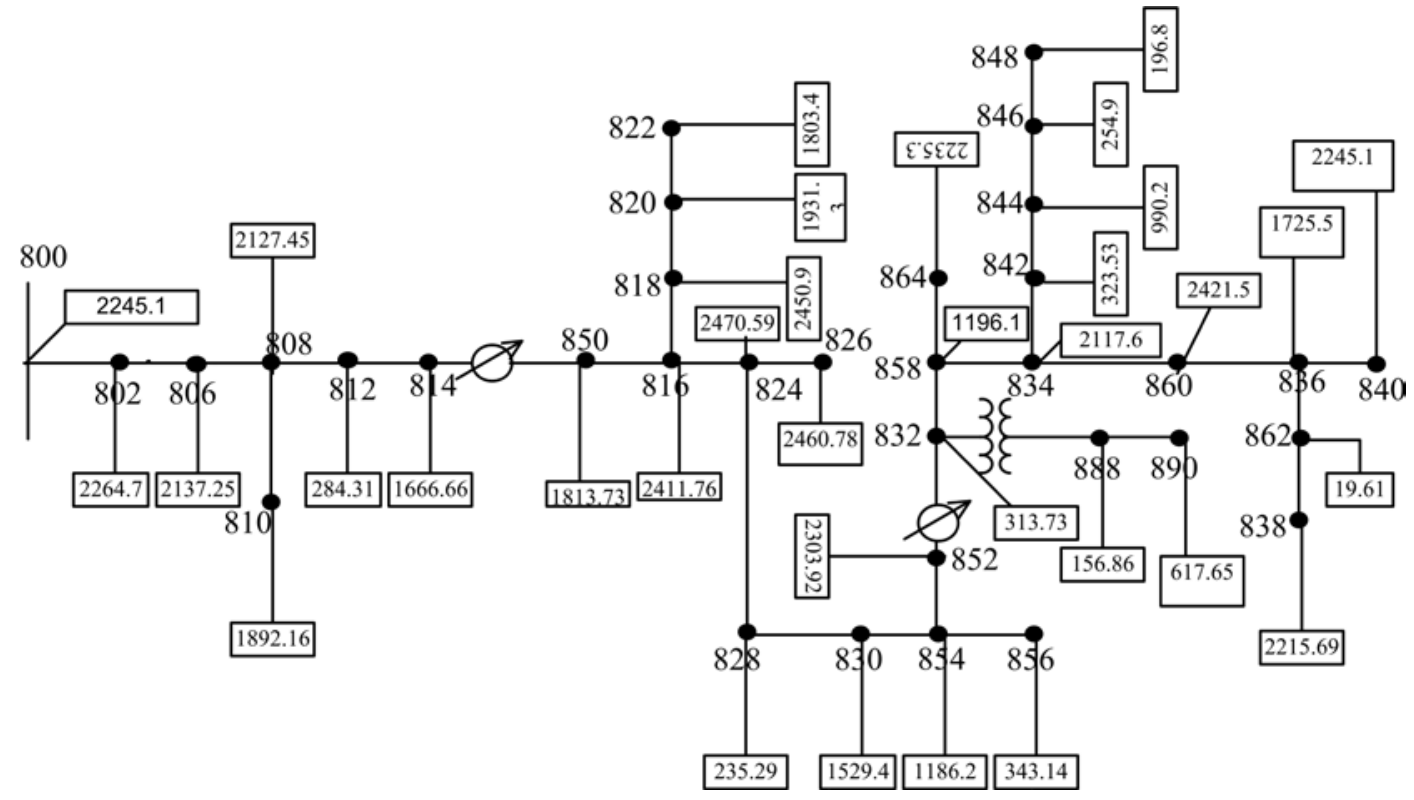

Figure 4.17: Optimal WG Values for Minimized Voltage THDs at High PEV

Penetration.

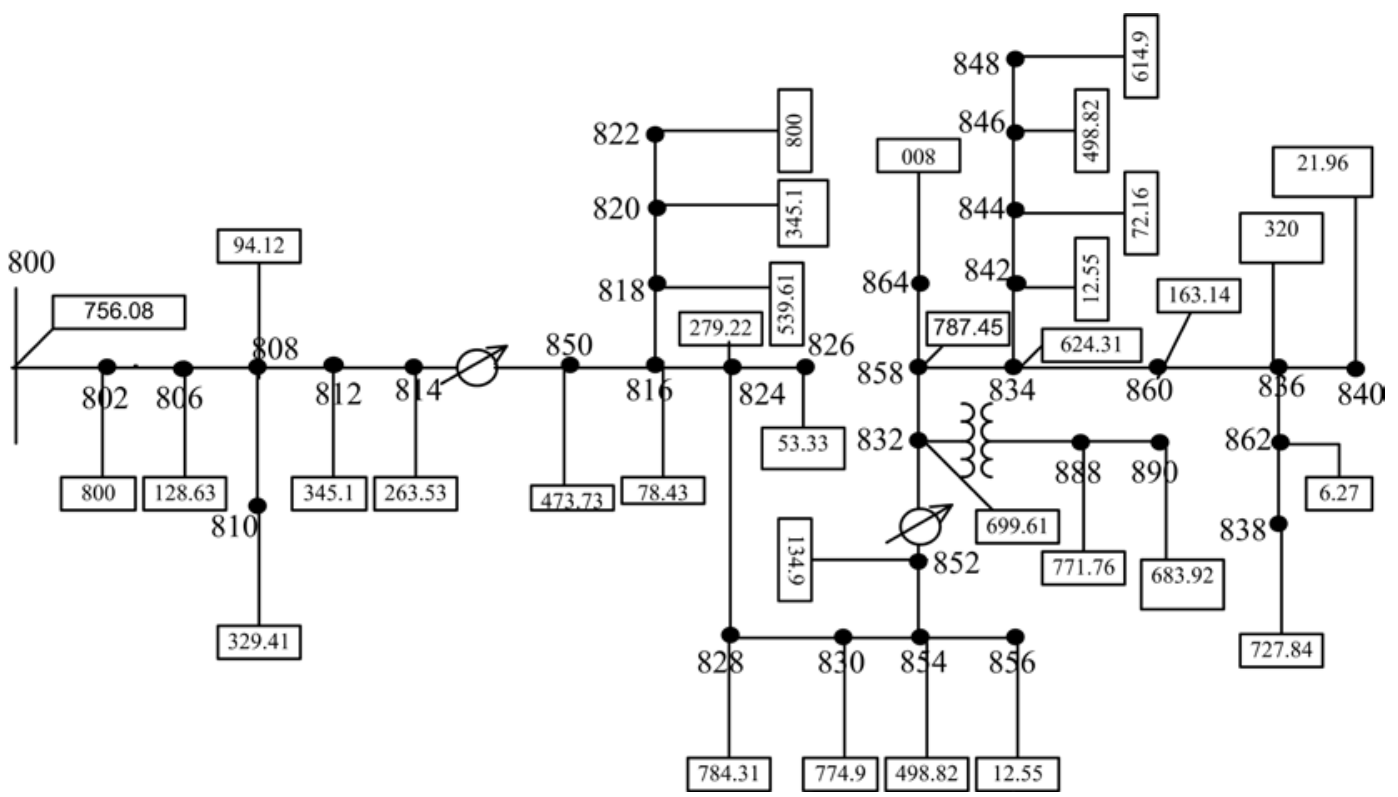

Figure 4.18: Optimal WG Values for Minimized Current THDs at High PEV Penetration. 


\subsection{Summary}

In this chapter a generic overview of the COM interface between the MATLAB and OpenDSS is provided. The implementation of GA and harmonic power flow on these tools has been discussed in detail. The framework of the GA and its implementation in distribution system consisting of PEVs and WGs has been discussed. It has been shown that the optimally sized WG is capable of reducing the current and voltage THDs, caused by the PEVs, for varying level of penetration. These results have also been compared with the previous results obtained in Chapter 3, by randomly selecting WG location, to demonstrate the significance of the used GA algorithm. 


\section{Chapter 5}

\section{Conclusions and Future Work}

\subsection{Chapter Summary}

The research presented in this thesis mainly focuses on decreasing the voltage and current THDs that are caused by PEV loads in the grid. The reduction in harmonics in the distribution system is achievable through the use of WGs and a GA based approach. The main summaries that can be drawn from the thesis are:

- Chapter 1 presented the motivations behind this work. It outlines the concerns such as environmental impacts, depletion of natural energy reserves, which is the driving force behind the integration of wind power and PEV into the grid. A literature review of some works pertaining to this research has been briefly discussed. The focus of the review was on optimal setting and sizing of DGs, impact of PEVs on harmonics, coordinated energy dispatch using WGs and PEVs etc. This chapter also provides an overview and contribution of this research.

- Chapter 2 discussed the basic background information related to this research. A basic overview of the basic distribution system components has been provided. This chapter also presented a general discussion on the optimization and different techniques that have been related to this research. In this chapter, a brief description on the OpenDSS software is also provided. The mathematical modeling of the harmonic power flow in OpenDSS was also presented.

- Chapter 3 discussed on the impacts of PEVs and WGs on current and voltage THDs of distribution systems. The parameters of the test system were also briefly discussed in this chapter. The modeling of the PEVs and WGs in the presence of harmonics was also explained. In Chapter 3 different case studies 
on impact on voltage/current THDs with varying level of PEV penetration was demonstrated. Also, a harmonic reduction technique by integrating WGs into the system was discussed with case studies considering different number of WGs.

- Chapter 4 presented the GA modelling and implementation of the GA based technique to reduce the THDs using the WGs. Through the proposed GA technique, the optimal size of the WGs was determined in varying levels of PEV penetration to mitigate the current/voltage THDs. Different case studies similar to Chapter 3 but with optimization was carried out. It was shown that the GA is able to minimize the cumulative THD of the system with proper sizing of WGs.

\subsection{Thesis Contributions}

The main contributions of this thesis are outlined as following:

- A three-phase unbalanced distribution system model required for harmonic power flow studies have been developed. In this model, the impact of PEVs on current/voltage harmonics has been studied with varying level of penetration. Carefully planned WGs have been used to demonstrate its impact on reducing the harmonic distortions.

- An optimization framework based on GA has been developed. It utilizes the previous model as constraint and WGs as decision variables. This model was able to successfully find the optimal size of WGs which reduced current/voltage THDs with varying PEV penetration level. 


\subsection{Limitation and Future Work}

The limitations of this work can be used as a scope to improve the proposed work. Some of the main shortcomings this work is:

- While minimizing the PEV induced harmonics in the system the optimal size of the WGs in all nodes have been calculated. It has been inferred from the Chapter 3, that the placements of the WG make a difference while reducing the system harmonics. However, there are many practical constraints which do not allow installation of wind at every node in the distribution circuits. It needs to be carefully considered in the optimization problem to obtain more meaningful results.

- In the modeling part of the test system PEV loads are taken as a fixed power. However, in real-time PEV loads certainly have a charging profiles and it changes over 24 hour period. So, it will be more accurate to take care of the charging profiles into the case studies while modeling the distribution system. 


\section{Appendix}

\section{IEEE 34 Node Test Feeder Data}

Table A1: Underground Cable Data.

\begin{tabular}{|c|c|c|c|c|}
\hline $\begin{array}{c}\text { Phase } \\
\text { Conductor }\end{array}$ & $\begin{array}{c}\text { Diameter over } \\
\text { Insulation } \\
\text { (inch) }\end{array}$ & $\begin{array}{c}\text { Diameter over } \\
\text { Screen (inch) }\end{array}$ & $\begin{array}{c}\text { Outside } \\
\text { Diameter (inch) }\end{array}$ & Ampacity \\
\hline $2(7 \mathrm{x})$ & 0.78 & 0.85 & 0.98 & 135 \\
\hline $1 / 0(19 \mathrm{x})$ & 0.85 & 0.93 & 1.06 & 175 \\
\hline $2 / 0(19 \mathrm{x})$ & 0.9 & 0.97 & 1.1 & 200 \\
\hline $250(37 \mathrm{x})$ & 1.06 & 1.16 & 1.29 & 260 \\
\hline $500(37 \mathrm{x})$ & 1.29 & 1.39 & 1.56 & 385 \\
\hline $1000(61 \mathrm{x})$ & 1.64 & 1.77 & 1.98 & 550 \\
\hline
\end{tabular}

Table A2: Conductor Data.

\begin{tabular}{|c|c|c|c|c|c|}
\hline Conductor & Type & $\begin{array}{c}\text { Resistance } \\
(\mathbf{O h m s} / \mathbf{m i})\end{array}$ & $\begin{array}{c}\text { Diameter } \\
\text { (Inch) }\end{array}$ & $\begin{array}{c}\text { GMR } \\
\text { (Ft.) }\end{array}$ & $\begin{array}{c}\text { Rating } \\
\text { (Amps) }\end{array}$ \\
\hline $\begin{array}{c}1,000,000 \\
\text { CM }\end{array}$ & AA & 0.105 & 1.15 & 0.0368 & 698 \\
\hline $556,500 \mathrm{CM}$ & ACSR & 0.186 & 0.927 & 0.0311 & 730 \\
\hline $500,000 \mathrm{CM}$ & AA & 0.206 & 0.813 & 0.026 & 483 \\
\hline $250,000 \mathrm{CM}$ & AA & 0.41 & 0.567 & 0.0171 & 329 \\
\hline $336,400 \mathrm{CM}$ & ACSR & 0.306 & 0.721 & 0.0244 & 530 \\
\hline $4 / 0$ & ACSR & 0.592 & 0.563 & 0.00814 & 340 \\
\hline $2 / 0$ & AA & 0.769 & 0.414 & 0.0125 & 230 \\
\hline $1 / 0$ & ACSR & 1.12 & 0.398 & 0.00446 & 230 \\
\hline $1 / 0$ & CU & 0.607 & 0.368 & 0.01113 & 310 \\
\hline 2 & AA & 1.54 & 0.292 & 0.00883 & 156 \\
\hline 2 & ACSR & 1.69 & 0.316 & 0.00418 & 180 \\
\hline 4 & ACSR & 2.55 & 0.257 & 0.00452 & 140 \\
\hline 10 & CU & 5.903 & 0.102 & 0.00331 & 80 \\
\hline 12 & CU & 9.375 & 0.081 & 0.00262 & 75 \\
\hline 14 & CU & 14.872 & 0.064 & 0.00208 & 20 \\
\hline
\end{tabular}


Table A3: Overhead Line Configuration.

\begin{tabular}{|c|c|c|c|c|}
\hline Configuration & Phasing & Phase (ACSR) & Neutral (ACSR) & $\begin{array}{c}\text { Spacing } \\
\text { ID }\end{array}$ \\
\hline 300 & B A C N & $1 / 0$ & $1 / 0$ & 500 \\
\hline 301 & B A C N & $6 / 1$ & $6 / 1$ & 500 \\
\hline 302 & A N & $6 / 1$ & $6 / 1$ & 510 \\
\hline 303 & B N & $6 / 1$ & $6 / 1$ & 510 \\
\hline 304 & B N & $6 / 1$ & $6 / 1$ & 510 \\
\hline
\end{tabular}

Table A4: Distributed Load Data.

\begin{tabular}{|c|c|c|c|c|c|c|c|c|}
\hline $\begin{array}{c}\text { Nod } \\
\text { e A }\end{array}$ & $\begin{array}{c}\text { Node } \\
\text { B }\end{array}$ & $\begin{array}{c}\text { Load } \\
\text { Model }\end{array}$ & $\begin{array}{c}\text { Ph-1 } \\
(\mathbf{k W})\end{array}$ & $\begin{array}{c}\text { Ph-1 } \\
\text { (kVAr) }\end{array}$ & $\begin{array}{c}\text { Ph-2 } \\
\text { (kW) }\end{array}$ & $\begin{array}{c}\text { Ph-2 } \\
(\mathbf{k V A r})\end{array}$ & $\begin{array}{c}\text { Ph-3 } \\
(\mathbf{k W})\end{array}$ & $\begin{array}{c}\text { Ph-3 } \\
\text { (kVAr) }\end{array}$ \\
\hline 802 & 806 & Y-PQ & 0 & 0 & 30 & 15 & 25 & 14 \\
\hline 808 & 810 & Y-I & 0 & 0 & 16 & 8 & 0 & 0 \\
\hline 818 & 820 & Y-Z & 34 & 17 & 0 & 0 & 0 & 0 \\
\hline 820 & 822 & Y-PQ & 135 & 70 & 0 & 0 & 0 & 0 \\
\hline 816 & 824 & D-I & 0 & 0 & 5 & 2 & 0 & 0 \\
\hline 824 & 826 & Y-I & 0 & 0 & 40 & 20 & 0 & 0 \\
\hline 824 & 828 & Y-PQ & 0 & 0 & 0 & 0 & 4 & 2 \\
\hline 828 & 830 & Y-PQ & 7 & 3 & 0 & 0 & 0 & 0 \\
\hline 854 & 856 & Y-PQ & 0 & 0 & 4 & 2 & 0 & 0 \\
\hline 832 & 858 & D-Z & 7 & 3 & 2 & 1 & 6 & 3 \\
\hline 858 & 864 & Y-PQ & 2 & 1 & 0 & 0 & 0 & 0 \\
\hline 858 & 834 & D-PQ & 4 & 2 & 15 & 8 & 13 & 7 \\
\hline 834 & 860 & D-Z & 16 & 8 & 20 & 10 & 110 & 55 \\
\hline 860 & 836 & D-PQ & 30 & 15 & 10 & 6 & 42 & 22 \\
\hline 836 & 840 & D-I & 18 & 9 & 22 & 11 & 0 & 0 \\
\hline 862 & 838 & Y-PQ & 0 & 0 & 28 & 14 & 0 & 0 \\
\hline 842 & 844 & Y-PQ & 9 & 5 & 0 & 0 & 0 & 0 \\
\hline 844 & 846 & Y-PQ & 0 & 0 & 25 & 12 & 20 & 11 \\
\hline 846 & 848 & Y-PQ & 0 & 0 & 23 & 11 & 0 & 0 \\
\hline
\end{tabular}


Table A5: Spot Load Data.

\begin{tabular}{|c|c|c|c|c|c|c|c|}
\hline Node & $\begin{array}{c}\text { Load } \\
\text { Model }\end{array}$ & $\begin{array}{c}\text { Ph-1 } \\
(\mathbf{k W})\end{array}$ & $\begin{array}{c}\text { Ph-1 } \\
\text { (kVAr) }\end{array}$ & $\begin{array}{c}\text { Ph-2 } \\
(\mathbf{k W})\end{array}$ & $\begin{array}{c}\text { Ph-2 } \\
(\mathbf{k V A r})\end{array}$ & $\begin{array}{c}\text { Ph-3 } \\
(\mathbf{k W})\end{array}$ & $\begin{array}{c}\text { Ph-3 } \\
(\mathbf{k V A r})\end{array}$ \\
\hline 860 & Y-PQ & 20 & 16 & 20 & 16 & 20 & 16 \\
\hline 840 & Y-I & 9 & 7 & 9 & 7 & 9 & 7 \\
\hline 844 & Y-Z & 135 & 105 & 135 & 105 & 135 & 105 \\
\hline 848 & D-PQ & 20 & 16 & 20 & 16 & 20 & 16 \\
\hline 890 & D-I & 150 & 75 & 150 & 75 & 150 & 75 \\
\hline 830 & D-Z & 10 & 5 & 10 & 5 & 25 & 10 \\
\hline
\end{tabular}

Table A6: All Aluminum Coil.

\begin{tabular}{|c|c|c|c|c|}
\hline $\begin{array}{c}\text { Phase } \\
\text { Conductor }\end{array}$ & $\begin{array}{c}\text { Diameter over } \\
\text { Insulation (inch) }\end{array}$ & $\begin{array}{c}\text { Diameter over } \\
\text { Shield (inch) }\end{array}$ & $\begin{array}{c}\text { Outside } \\
\text { Diameter (inch) }\end{array}$ & Ampacity \\
\hline $1 / 0 \mathrm{AL}$ & 0.82 & 0.88 & 1.06 & 165 \\
\hline
\end{tabular}




\section{References}

[1] L. Chiao-Ting, A. Changsun, P. Huei, J. Sun, "Synergistic control of plug-in vehicle charging and wind power scheduling," IEEE Transactions on Power Systems, vol. 28, no. 2, pp. 1113-1121, May 2013.

[2] A. Y. Saber, G. K. Venayagamoorthy, "Plug-in Vehicles and Renewable Energy Sources for Cost and Emission Reductions," IEEE Transactions on Industrial Electronics, vol. 58, no. 4, pp. 1229-1238, April 2011.

[3] J. Zhao, F. Wen, Z. Y. Dong, Y. Xue, K. Wong, "Optimal Dispatch of Electric Vehicles and Wind Power Using Enhanced Particle Swarm Optimization," IEEE Transactions on Industrial Informatics, vol. 8, no. 4, pp. 889-899, November 2012.

[4] L. Chiao-Ting, A. Changsun, P. Huei, J. Sun, "Integration of plug-in electric vehicle charging and wind energy scheduling on electricity grid," 2012 IEEE PES Innovative Smart Grid Technologies (ISGT), Jan. 2012.

[5] Committee on Assessment of Resource Needs for Fuel Cell and Hydrogen Technologies, National Research Council, Transitions to Alternative Transportation Technologies-Plug-in Hybrid Electric Vehicles. Washington DC, U.S.A., National Academies Press, 2010.

[6] "Supplemental tables to the annual energy outlook 2010 with projections to 2035," U.S. Department of Energy, U.S. Energy Information Administration (EIA). Washington, DC, USA, Dec. 2009.

[7] S. Powell, Southern California Edison private communication, Mar.2010. 
[8] S. J. Gunter, K. K. Afridi, D. J. Perreault, "Optimal Design of Grid-Connected PEV Charging Systems With Integrated Distributed Resources," IEEE Transactions on Smart Grid, vol. 4, no. 2, pp. 956-967, June 2013.

[9] A. M. Foley, I. J. Winning, B. P. O. Gallachoir, "State-of-the-art in electric vehicle charging infrastructure," 2010 IEEE Vehicle Power and Propulsion Conference (VPPC), pp. 1-6, Sept. 2010

[10] B. Moore, Japan Charges Ahead With Electric Cars [Online]. Available: http://www.autosavant.com/2008/08/27/japan-charges-aheadwith-electric-cars/.

[11] H. Weihao, C. Su, Z. Chen, B. Bak-Jensen, "Optimal Operation of Plug-In Electric Vehicles in Power Systems With High Wind Power Penetrations," IEEE Transactions on Sustainable Energy, vol. 4, no. 3, pp. 577-585, July 2013.

[12] Jidong Wang, Xuhao Du, Guodong Li, Guanqing Yang, " Harmonic Analysis of the Interconnection of Wind Farm," Electronics and Signal Processing, Springer Berlin Heidelberg, LNEE 97, pp. 1031-1038.

[13] A.S Masoum, S. Deilami, P. S. Moses, M. A. S. Masoum, A. Abu-Siada, "Smart load management of plug-in electric vehicles in distribution and residential networks with charging stations for peak shaving and loss minimization considering voltage regulation," , IET Generation, Transmission \& Distribution, vol. 5, no. 8, pp. 877888, August 2011.

[14] 33\% Renewables Portfolio Standard - Implementation Analysis Preliminary Results, June 2009, California Public Utilities Commission.

[15] S. V. Chakraborty, S. K. Shukla, J. Thorp, "System imbalance minimizing renewable generation portfolio selection in the presence of plug-in electric vehicles," 2012 IEEE Power and Energy Society General Meeting, pp. 1-8, 22-26 July 2012. 
[16] R. Doherty, M. O'Malley, "A New Approach to Quantify Reserve Demand in Systems with Significant Installed Wind Capacity," IEEE Transactions on Power Systems, vol. 20, pp. 587-595, 2005.

[17] R. Wiser and M. Bolinger, "2009 Wind Technologies Market Report," Department of Energy, Report \#DOE/GO-102010-3107, 2010.

[18] R. Singh, B. C. Pal, R. A. Jabr, 'Distribution system state estimation through Gaussian mixture model of the load as pseudo measurement', IET Proc. Gener. Transm Distrib., vol. 4, no. 1, pp. 50-59, 2010,

[19] R. Singh, B. C. Pal, R. A. Jabr, 'Statistical representation of distribution system loads using Gaussian mixture model', IEEE Transactions on Power Systems, vol. 25, no. 1, pp. 29-37, 2010.

[20] R. Singh, B. C. Pal, R. A. Jabr, 'Choice of estimator for distribution system state estimation', IET Proc., Gener. Transm.Distrib., vol. 3, no. 7, pp. 666-678, 2009.

[21] M. A. S. Masoum, P. S. Moses, S. Deilami, "Load management in smart grids considering harmonic distortion and transformer derating," Innovative Smart Grid Technologies (ISGT), pp.1-7, Jan. 2010.

[22] S. Massoud Amin and B. F. Wollenberg, "Toward a smart grid: power delivery for the 21st century," IEEE Power Energy Mag., vol.3, no.5, pp. 34-41, Sept.-Oct. 2005.

[23] S. Deilami, A. S. Masoum, P. S. Moses, M. A. S. Masoum, "Real-Time Coordination of Plug-In Electric Vehicle Charging in Smart Grids to Minimize Power Losses and Improve Voltage Profile," IEEE Transactions on Smart Grid, vol. 2, no. 3, pp. 456-467, Sept. 2011. 
[24] L. Zhipeng, W. Fushuan, G. Ledwich, "Optimal Siting and Sizing of Distributed Generators in Distribution Systems Considering Uncertainties," IEEE Transactions on Power Delivery, vol. 26, no. 4, pp. 2541-2551, Oct. 2011.

[25] C. S. Wang and M. H. Nehrir, "Analytical approaches for optimal placement of distributed generation sources in power systems," IEEE Transactions on Power Systems, vol. 19, no. 4, pp. 2068 -2076, 2004.

[26] K. H. Kim , K. B. Song, S. K. Joo , Y. J. Lee and J. O. Kim, "Multiobjective distributed generation placement using fuzzy goal programming with genetic algorithm", Eur. Trans. Elect. Power, vol. 18, no. 3, pp. 217 -230, 2008.

[27] S. Ghosh, S. P. Ghoshal and S. Ghosh, "Optimal sizing and placement of distributed generation in a network system", Elect. Power Energy Syst.,vol. 32, no. 8, pp. $849-856,2010$.

[28] M. M. Elnashar, R. E. Shatshat and M. A. Salama, "Optimum siting and sizing of a large distributed generator in a mesh connected system", Elect. Power Syst. Res., vol. 80, no. 6, pp.670 -697, 2010.

[29] T. Gozel and M. H. Hocaoglu, "An analytical method for the sizing and siting of distributed generators in radial systems", Elect. Power Syst. Res., vol. 79, no. 6, pp.912 -918, 2009.

[30] G. Carpinelli, G. Celli, S. Mocci, F. Pilo and A. Russo, "Optimisation of embedded generation sizing and siting by using a double trade-off method", Proc. Inst. Elect. Eng., Gen., Transm. Distrib., vol. 152, no. 4, pp.503 -513, 2005.

[31] O. Amanifar , "Optimal distributed generation placement and sizing for loss and thd reduction and voltage profile improvement in distribution systems using particle swarm optimization and sensitivity analysis [abstract only]," 2011 16th Conference on Electrical Power Distribution Networks (EPDC), pp.1, April 2011. 
[32] Alinejad-Beromi, Y.; Sedighizadeh, M.; Sadighi, M., "A particle swarm optimization for sitting and sizing of Distributed Generation in distribution network to improve voltage profile and reduce THD and losses," Universities Power Engineering Conference, 2008. UPEC 2008. 43rd International, vol., no., pp.1,5, 1-4 Sept. 2008.

[33] A. Keane , M. O' Malley, "Optimal allocation of embedded generation on distribution networks", IEEE Transactions on Power Systems, vol. 20, no. 3, pp. 1640 $-1646,2005$.

[34] R. K. Singh and S. K. Goswami, "Optimum siting and sizing of distributed generations in radial and networked systems", Elect. Power Compon. Syst., vol. 37, no. 2, pp. $127-145,2009$.

[35] D. Gautam and N. Mithulananthan, "Optimal DG placement in deregulated electricity market", Elect. Power Syst. Res., vol. 77, no. 12, pp. 1627 -1636, 2007.

[36] J. A. P. Lopes, F. J. Soares and P. M. R. Almeida, "Integration of electric vehicles in the electric power system", Proc. IEEE, vol. 99, no. 1, pp. 168 -183, 2011.

[37] W. Kempton and J. Tomic, "Vehicle-to-grid power implementation: From stabilizing the grid to supporting large-scale renewable energy", J. Power Sources, vol. 144, no. 1, pp. $280-294,2005$.

[38] S. L. Andersson, A. K. Elofsson, M. D. Galus, L. Goransson, S. Karlsson , F. Johnsson and G. Andersson, "Plug-in hybrid electric vehicles as regulating power providers: Case studies of Sweden and Germany", Energy Policy, vol. 38, no. 6, pp. $2751-2762,2010$.

[39] K. Clement-Nyns , E. Haesen and J. Driesen, "The impact of vehicle-to-grid on the distribution grid", Elect. Power Syst. Res., vol. 81, no. 1, pp. 185 -192, 2011. 
[40] K. M. Rogers, R. Klump, H. Khurana and T. J. Overbye, "Smart-grid enabled load and distributed generation as a reactive resource", 2010 IEEE Innovative Smart Grid Technologies, pp.1 -8, 2010.

[41] E. Larsen, D. K. Chandrashekhara and J. Ostegard, "Electric vehicles for improved operation of power systems with high wind power penetration", Proc. IEEE Energy 2030 Conf., pp. 1 -6, 2008.

[42] W. Hu , Z. Chen and B. Bak-Jensen, "Optimal operation of electric vehicles in competitive electricity markets and its impact on distribution power systems", 2011 IEEE Trondheim on PowerTech, pp.1 -7, 2011.

[43] K. Skytte, "The regulating power market on the Nordic power exchange Nord Pool: An econometric analysis", Energy Econom., vol. 21, no. 4, pp. 295 -308, 1999.

[44] D. Xu , L. Kang , L. Chang and B. Cao, "Optimal sizing of standalone hybrid wind/PV power systems using genetic algorithms", Proc. Can. Conf. Electr. Comput. Eng., pp. $1722-1725,2005$.

[45] B. S. Borowy and Z. M. Salameh, "Methodology for optimally sizing the combination of a battery bank and PV array in a wind/PV hybrid system," IEEE Trans. Energy Convers., vol. 11, no. 2, pp. 367 -375, 1996.

[46] A. Gupta, R. P. Saini and M. P. Sharma, "Hybrid energy system sizing incorporating battery storage: An analysis via simulation calculation", Proc. 2009 3rd Int. Conf. Power Syst., 2009.

[47] K. Clement-Nyns, E. Haesen and J. Driesen, "The impact of vehicle-to-grid on the distribution grid", J. Elect. Power Syst. Res., vol. 81, no. 1, pp. 185 -192, 2011.

[48] L. Goransson, S. Karlsson and F. Johnsson, "Integration of plug-in hybrid electric vehicles in a regional wind-thermal power system", J. Energy Policy, vol. 38, no. 10, pp. $5482-5492,2010$. 
[49] J. H. Wang, C. Liu and D. Ton, "Impact of plug-in hybrid electric vehicles on power systems with demand response and wind power", J. Energy Policy, vol. 39, no. 7, pp. $5482-5492,2011$.

[50] Z. S. Li , H. B. Sun, Q. L. Guo and X. Wang, "Study on wind-EV complementation on the transmission grid side considering carbon emission", J. Proc. CSEE, vol. 32, no. 10, pp. $41-48,2011$.

[51] W. Ting, Q. Yang, Z. Bao, W. Yan, "Coordinated Energy Dispatching in Microgrid With Wind Power Generation and Plug-in Electric Vehicles," IEEE Transactions on Smart Grid, vol. 4, no. 3, pp. 1453-1463, Sept. 2013.

[52] S. Deilami, A.S. Masoum, P. S. Moses, M. A. S. Masoum, "Voltage profile and THD distortion of residential network with high penetration of Plug-in Electrical Vehicles," 2010 IEEE PES Innovative Smart Grid Technologies Conference Europe (ISGT Europe), pp. 1-6, Oct. 2010.

[53] P. S. Moses, M. A. S. Masoum, K. M. Smedley, "Harmonic losses and stresses of nonlinear three-phase distribution transformers serving Plug-In Electric Vehicle charging stations," 2011 IEEE PES Innovative Smart Grid Technologies (ISGT), pp.16, 2011.

[54] M. A. S. Masoum, S. Deilami, S. Islam, "Mitigation of harmonics in smart grids with high penetration of plug-in electric vehicles," 2010 IEEE Power and Energy Society General Meeting, pp. 1-6, July 2010.

[55] M. Etezadi-Amoli, K. Choma, and J. Stefani, "Rapid-charge electric-vehicle stations," IEEE Transactions on Power Delivery, vol. 25, pp. 1883-1887, 2010.

[56] W. H. Kresting, Distribution System Modeling and Analysis, 2nd ed. Boca Raton: CRC Press 2006. 
[57] T. Gonen, Electric Power Distribution System Engineering, 2nd ed. Boca Raton: CRC Press 2006.

[58] S. Paudyal, C. A. Canizares, K. Bhattacharya, "Optimal Operation of Distribution Feeders in Smart Grids," IEEE Transactions on Industrial Electronics, vol. 58, no. 10, pp. 4495-4503, Oct. 2011.

[59] S. S. Rao, Engineering Optimization: Theory and Practice. New York: John Wiley \& Sons, Inc., 1996.

[60] T. Terlaky, Interior Point Methods of Mathematical Programming. Dordrecht, The Netherlands: Kluwer Academic Publishers, 1996.

[61] S. Paudyal, "Optimal Energy Management of Distribution Systems and Industrial Energy Hubs in Smart Grids," PhD Thesis, Department of Electrical and Computer Engineering, University of Waterloo, 2012.

[62] Back T. Selective pressure in evolutionary algorithms: A characteriziation of selectrion mechanisms. In: Proc. 1st IEEE Conf. on Evolutionary Computation. Piscataway, NJ, IEEE Press, 1994.57-62.

[63] Kwang Y.Lee, Mohamed A. El-Sharkwai, Modern Heuristic Optimization Techniques, IEEE Press Series on Power Engineering.

[64] OpenDSS. [Online]. Available:

http://sourceforge.netlapps/mediawiki/electricdsslindex.php

[65] C. K. Farhana, K. M. Nor, D. M. Said, F. Salim, "Impact study of practical harmonic data using time series simulation," 2012 IEEE 15th International Conference on Harmonics and Quality of Power (ICHQP), pp. 618-623, June 2012. 
[66] OpenDSS Program, [Online] Available through SourceForge.net, http://sourceforge.net/p/electricdss/code/889/tree/trunk/Doc/Harmonics\%20Load\%20 Modeling.docx.

[67] J.O Owuor, J. L. Munda, A. A. Jimoh, "The ieee 34 node radial test feeder as a simulation testbench for Distributed Generation," AFRICON, pp.1-6, 13-15 Sept. 2011.

[68] Mitsubishi, "iMiEV Mitsubishi innovative Electric Vehicle," 2010, [Online]. Available: http://www.mitsubishi-motors.com/special/ev/.

[69] "Tesla Motors - High performance electric vehicles," Tesla Motors, 2010, [Online]. Available: http://www.teslamotors.com/.

[70] Chevrolet, "2011 Volt Electric Car," 2010, [Online]. Available: http://www.chevrolet.com/electriccar/.

[71] Q. Chongming, K. M. Smedley, "Unified constant-frequency integration control of three-phase standard bridge boost rectifiers with power-factor correction," IEEE Transactions on Industrial Electronics, vol. 50, no.1, pp. 100-107, Feb. 2003.

[72] Web Source: http://www.seattle.gov/light/news/issues/irp/docs/dbg_538_a app_d_3.pdf

[73] C. Roe, A. P. Meliopoulos, J. Meisel, T. Overbye, "Power System Level Impacts of Plug-In Hybrid Electric Vehicles Using Simulation Data," 2008 IEEE Energy 2030 Conference, pp.1-6, Nov. 2008.

[74] P. T. Staats, W. M. Grady, A. Arapostathis, R. S. Thallam, "A statistical method for predicting the net harmonic currents generated by a concentration of electric vehicle battery chargers," IEEE Transactions on Power Delivery, vol. 12, no. 3, pp. 1258-1266, July 1997. 
[75] M. Khan, S. A. Saleh, M. A. Rahman, "Generation and harmonics in interior permanent magnet wind generator," IEEE International Electric Machines and Drives Conference, pp. 17-23, May 2009.

[76] F. Ghassemi, Kah-Leong Koo, "Equivalent Network for Wind Farm Harmonic Assessments," IEEE Transactions on Power Delivery, vol. 25, no. 3, pp. 1808-1815, July 2010 .

[77] T. M. Blooming, D. J. Carnovale, "Application of IEEE STD 519-1992 Harmonic Limits," Pulp and Paper Industry Technical Conference, pp. 1-9, June 2006. 